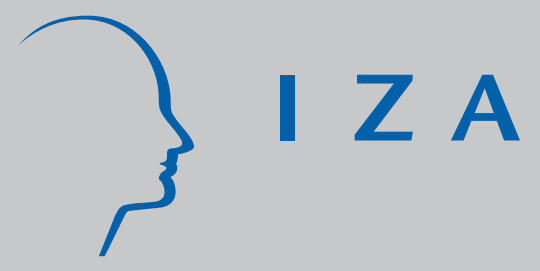

IZA DP No. 174

Does Money Illusion Matter?

An Experimental Approach

Ernst Fehr

J ean-Robert Tyran

J uly 2000 


\title{
Does Money Illusion Matter? An Experimental Approach
}

\author{
Ernst Fehr \\ Institute for Empirical Research in Economics, University of Zurich and IZA, Bonn \\ Jean-Robert Tyran \\ Department of Economics, University of St. Gallen
}

Discussion Paper No. 174

July 2000

\author{
IZA \\ P.O. Box 7240 \\ D-53072 Bonn \\ Germany \\ Tel.: +49-228-3894-0 \\ Fax: +49-228-3894-210 \\ Email: iza@iza.org
}

This Discussion Paper is issued within the framework of IZA's research area General Labor Economics. Any opinions expressed here are those of the author(s) and not those of the institute. Research disseminated by IZA may include views on policy, but the institute itself takes no institutional policy positions.

The Institute for the Study of Labor (IZA) in Bonn is a local and virtual international research center and a place of communication between science, politics and business. IZA is an independent, nonprofit limited liability company (Gesellschaft mit beschränkter Haftung) supported by the Deutsche Post AG. The center is associated with the University of Bonn and offers a stimulating research environment through its research networks, research support, and visitors and doctoral programs. IZA engages in (i) original and internationally competitive research in all fields of labor economics, (ii) development of policy concepts, and (iii) dissemination of research results and concepts to the interested public. The current research program deals with (1) mobility and flexibility of labor markets, (2) internationalization of labor markets and European integration, (3) the welfare state and labor markets, (4) labor markets in transition, (5) the future of work, (6) project evaluation and (7) general labor economics.

IZA Discussion Papers often represent preliminary work and are circulated to encourage discussion. Citation of such a paper should account for its provisional character. 
IZA Discussion Paper No. 174

July 2000

\title{
ABSTRACT \\ Does Money Illusion Matter? An Experimental Approach*
}

Money illusion means that people behave differently when the same objective situation is represented in nominal terms rather than in real terms. This paper shows that seemingly innocuous differences in payoff representation cause pronounced differences in nominal price inertia indicating the behavioral importance of money illusion. In particular, if the payoff information is presented to subjects in nominal terms, price expectations and actual price choices after a fully anticipated negative nominal shock are much stickier than when payoff information is presented in real terms. In addition we show that money illusion causes asymmetric effects of negative and positive nominal shocks. While nominal inertia is quite substantial and long-lasting after a negative shock, it is rather small after a positive shock.

JEL Classification: C92, E32, E52

Keywords: $\quad$ Money illusion, nominal inertia, sticky prices, non-neutrality of money

\author{
Ernst Fehr \\ University of Zurich \\ Institute for Empirical Research in Economics \\ Blümlisalpstrasse 10 \\ $\mathrm{CH}-8006$ Zürich \\ Tel.: +4116343709 \\ Fax: +4116344907 \\ Email: efehr@iew.unizh.ch
}

\footnotetext{
* We are grateful for financial support by the Swiss National Science Foundation under project no. 1214051000.97/1, and by the EU-TMR Research Network (project no. FMRX-CT98-0238).We are particularly grateful for two excellent referee reports and for comments by George Akerlof, Linda Babcock, Jim Cox, Urs Fischbacher, Simon Gächter, Ed Glaeser, Lorenz Goette, Charles Goodhart, Reinhard Selten, Richard Thaler and Michael Waldman. In addition, we acknowledge helpful comments by the participants of seminars at the universities of Berlin, Bonn, Harvard, Mannheim, the NBER conference on behavioral macroeconomics, the CEPR summer workshop on financial economics, the ESA-meeting in New Orleans and the Amsterdam workshop for experimental economics. Ernst Fehr also gratefully acknowledges the hospitality of the Center for Economic Studies (CESIFO) in Munich. Valuable research assistance has been provided by Martin Brown, Beatrice Zanella and Tobias Schneider.
} 


\section{Introduction}

Until recently, the notion of money illusion seemed to be thoroughly discredited in modern economics. Tobin (1972:3) described the negative attitude of most economic theorists towards money illusion as follows: "An economic theorist can, of course, commit no greater crime than to assume money illusion." As a consequence, for several decades money illusion was anathema to the profession. The index of the Handbook of Monetary Economics (Friedman and Hahn 1990), for example, does not even mention the term "money illusion". In principle, money illusion could provide an explanation for the inertia of nominal prices and wages and, thus, for the non-neutrality of money. The stickiness of nominal prices and wages seems to be an important phenomenon (see e.g. Akerlof, Dickens and Perry 1996, Bernanke and Carey 1996, Bewley 1998, Blinder 1990, Card and Hyslop 1998, Kahn 1997). It has puzzled economists for decades because it is quite difficult to explain in an equilibrium model with maximizing individuals. Instead of money illusion other factors like informational frictions (Lucas 1972), staggering of contracts (e.g., Fischer 1977, Taylor 1979), costs of price adjustment (Mankiw 1985) and near-rationality (Akerlof and Yellen 1985) have been invoked to explain nominal inertia.

In this paper we do not contest the potential relevance of these explanations. We do, however, argue that money illusion has prematurely been dismissed as a potential candidate for the explanation of sluggish nominal price adjustment. Our argument is based on rigorous experimental evidence from a price setting game that isolates money illusion from other potential determinants of nominal inertia. In particular, we show that after a fully anticipated negative nominal shock, long-lasting nominal inertia prevails, even if informational frictions, costs of price adjustment and staggering are absent. Our results indicate that the direct and indirect effects of money illusion are the major determinant of this long-lasting nominal inertia. We show, in addition, that money illusion causes much less nominal inertia after a fully anticipated positive nominal shock. Our results suggest that this asymmetric effect is caused by a particular form of money illusion that arises when some people take nominal payoffs as a proxy for real payoffs. After a negative money shock nominal payoffs decline because prices tend to decline while after a positive shock nominal payoffs increase because prices tend to rise. If these changes in nominal payoffs are taken as a proxy for changes in real payoffs there will be more reluctance to adjust prices to the new equilibrium after a negative shock.

Our experiments also allow us to judge the relative importance of the direct and indirect effects of money illusion on nominal inertia. The direct effects of money illusion are defined as 
those effects that are the direct result of individual optimization mistakes. The indirect effects of money illusion are defined as those effects that arise because some agents expect that others are prone to money illusion and, as a consequence, they behave differently. The distinction between the direct and the indirect effects of money illusion is important because many economists seem to believe that money illusion is not a widespread phenomenon at the individual level, i.e., that the direct effects of money illusion are small. The textbook example where all nominal prices and nominal incomes are doubled nicely illustrates this view. It is hard to believe that many people make an individual optimization mistake by choosing a different bundle of goods when prices and incomes are doubled. Our results clearly show, however, that it would be misleading to conclude that money illusion is largely irrelevant because the direct effects of money illusion are small. In our experiments the direct effects of money illusion on nominal inertia after the negative shock are also rather small but the total effects nevertheless are very large. The reason for this finding is that money illusion renders price expectations very sticky after the negative shock, which in turn induces agents to choose sticky prices. This result lends support to theories that stress that small amounts of individual-level irrationality can have large aggregate effects (Akerlof and Yellen 1985, Haltiwanger and Waldman 1985 and 1989, Russell and Thaler 1985). Taken together, the results of our experiments suggest that money illusion matters, i.e., money illusion should be considered as a serious candidate in the explanation of nominal inertia.

The rest of the paper is organized as follows: In section 2 we discuss the notion of money illusion and its potential aggregate implications in more detail. In section 3 we argue that experimental methods are appropriate for studying whether money illusion matters and we present our experimental design. In section 4 the experimental results of the design with the negative nominal shock are presented. Section 5 argues that the nature of money illusion in our experiment suggests that after a positive nominal shock there should be less nominal inertia. This conjecture is tested in a design with a positive nominal shock. In the final section we summarize and interpret our main results.

\section{Money illusion at the individual and the aggregate level}

\subsection{Money illusion at the individual level}

Leontief (1936) defined money illusion as a violation of the "homogeneity postulate". This postulate stipulates that demand and supply functions are homogeneous of degree zero in all nominal prices, i. e., they depend only on relative and not on absolute prices. Although other 
authors have used slightly different definitions, the intuition behind their definitions seems to be rather similar. ${ }^{3}$ This intuition says that if the real incentive structure, i.e. the objective situation an individual faces, remains unchanged, the real decisions of an illusion-free individual do not change either. Two crucial assumptions underly this intuition: First, the objective function of the individual does not depend on nominal but only on real magnitudes. Second, people perceive that purely nominal changes do not affect their opportunity set. For example, people have to understand that an equi-proportionate change in all nominal magnitudes leaves the real constraints unaffected. Whether people are, in fact, able to pierce the veil of money, i.e., whether they understand that purely nominal changes leave their objective circumstances unchanged, is an empirical question. Irving Fisher (1928), for example, was convinced that ordinary people are, in general, prone to money illusion.

More recently Shafir, Tversky and Diamond (1997) provided interesting questionnaire evidence indicating that frequently one or both preconditions for the absence of money illusion are violated. Their results suggest that the preferences of many people as well as their perceptions of the constraints are affected by nominal values. Moreover, the answers of many people do not only indicate that they themselves suffer from money illusion but that they also expect other people's behavior to be affected by money illusion.

Since the absence of money illusion means that an individual's preferences, perceptions and, hence, choices of real magnitudes are not affected by purely nominal changes, it is natural to view money illusion as a framing or representation effect. From this viewpoint an individual exhibits money illusion, if his or her decisions depend on whether the same environment is represented in nominal or real terms. There is a large body of experimental research that shows that alternative representations of the same situation may well lead to systematically different responses (Selten and Berg 1970, Tversky and Kahneman 1981). Representation effects seem to arise because people tend to adopt the particular frame that is presented and evaluate the options within this frame. Because some options loom larger in one representation than in another, alternative framings of the same options may provoke different choices.

It is important to note that the nominal representation of an economic situation is probably the natural representation for most people. This is so because most economic transactions in people's lives involve the use of money and, hence, are framed in nominal terms. Therefore, it is likely that people often perceive and think about economic problems in nominal terms which may induce money illusion. A rather basic form of money illusion occurs, e. g., when people take

\footnotetext{
${ }^{3}$ For the different definitions of money illusion see Howitt (1989). Patinkin (1949), e. g., used a definition that also takes into account the potential effect of people's real wealth on their supply and demand behavior.
} 
nominal values or changes in nominal values as a proxy for real values or changes in real values, respectively. Note that this rule of thumb makes perfect sense in an environment with a given aggregate price level. However, this rule is inappropriate in situations where the aggregate price level is changing. Therefore, the application of this rule in an environment with changing aggregate prices constitutes a form of money illusion.

\subsection{Money illusion at the aggregate level}

In the past, economists frequently invoked the assumption of money illusion to account for the short-run non-neutrality of money. ${ }^{4}$ However, since the success of the rational expectations revolution economists have been extremely reluctant to invoke money illusion to explain the short-run non-neutrality of money. While New Classical macroeconomists focus on informational frictions to account for short-run non-neutrality (Lucas 1972), New Keynesjans mainly focus on costs of price adjustment or staggering (see e. g. Mankiw and Romer 1991). ${ }^{5}$ In the absence of menu costs, staggering, and informational frictions, the models of New Keynesian and New Classical economists rule out that purely monetary changes have real effects. A common feature of these models is that they exclusively focus on the equilibrium states of their economies. In general, they remain silent on how economic agents move from one equilibrium to the other. In models that exclusively focus on equilibrium the assumption of the absence of money illusion is very intuitive because it is difficult to imagine that an illusion could persist in equilibrium. However, there is a strong a priori argument that money illusion is likely to affect the adjustment process of an economy after a fully anticipated monetary shock. This argument is based on the simple fact that in an interactive situation the failure of some agents to fully adjust to the nominal shock will, in general, provide incentives for other agents to not fully adjust to the shock, either. Thus, there may be a snowball effect that causes less than full adjustment for a prolonged period of time.

This can be illustrated in the context of a monopolistically competitive economy as analyzed in, for example, Akerlof and Yellen (1985) or Blanchard and Kiyotaki (1987). To keep the argument simple we focus solely on the firms' behavior. The reduced form real profit function for firms in these models can be written as

\footnotetext{
${ }^{4}$ Irving Fisher's explanation of business cycles, for example, is based on lenders' money illusion during an upswing. Fisher believed that lenders are willing to supply more in the face of a rise in nominal interest rates although real interest rates decline or remain unchanged due to inflation.

${ }^{5}$ The near-rationality approach of Akerlof and Yellen (1985) can, in principle, be subsumed under the menu-cost approach by stipulating "cognitive" menu costs of maximizing behavior.
} 


$$
\pi_{i}=\pi_{i}\left(P_{i} / \bar{P}, M / \bar{P}\right)
$$

where $\pi_{i}$ is firm $i$ 's real profit, $P_{i}$ is the nominal price set by firm $i, \bar{P}$ is the aggregate price level and $M$ denotes the supply of money. ${ }^{\circ}$ In these models $M / \bar{P}$ is proportional to real aggregate demand. For simplicity, we assume identical firms, the absence of menu costs and informational frictions, and a unique and symmetric equilibrium $P_{i}^{*}=P_{j}^{*}$, for all $i, j$. In this equilibrium each firm maximizes real profits by setting $P_{i}^{*}=\bar{P}^{*}$. Since (1) is homogeneous of degree zero in $P_{i}$, $\bar{P}$ and $M$, a change in $M$ to $\lambda M(\lambda \neq 1)$ leads to post-shock equilibrium values of $\lambda P_{i}^{*}$ and $\lambda \bar{P}^{*}$.

Suppose now that there is one group of agents who suffers from money illusion and does, therefore, not fully adjust their nominal prices to $\lambda P_{i}^{*}$. Suppose further that there is a second group of agents that anticipates the behavior of the first group. The second group, therefore, anticipates a change in real aggregate demand $M / \bar{P}$ such that their members, in general, have an incentive to choose a price that differs from $\lambda P_{i}^{*}$, too. Whether the interaction between these groups causes aggregate nominal inertia depends in an important way on the strategic environment, i. e., whether agents' actions are strategic complements or strategic substitutes. Haltiwanger and Waldman (1989) have shown that in the presence of strategic complementarity between agents' decisions the existence of a small group of non-rational subjects can have large effects on the process of adjustment to equilibrium. In the above mentioned model of monopolistic competition strategic complementarity means that firm $i$ 's profit maximizing nominal price $P_{i}^{\prime}$ is positively related to the aggregate price level $\bar{P}$. This means that firms which believe that, because of money illusion, the prices of other agents are kept close to the preshock equilibrium have a rational reason to choose a nominal price that is also close to the preshock equilibrium.

Thus, under strategic complementarity rational firms have an incentive to partly imitate the behavior of the non-rational firms which gives the latter a disproportionately large impact on the aggregate price level. In contrast, in the presence of strategic substitutability, i. e., if $P_{i}^{\prime}$ is negatively related to $\bar{P}$, rational firms have an incentive to partly compensate the behavior of the non-rational ones so that the latter have a disproportionately small impact on the aggregate outcome. The results of Haltiwanger and Waldman (1989) thus suggest that, given strategic complementarity, the existence of a small group of subjects that suffer from money illusion may generate substantial nominal inertia. However, while this is a plausible theoretical argument,

${ }^{6}$ Equation (1) already incorporates (i) the maximizing behavior of all households, (ii) the cost minimizing behavior of all firms for given output and wages levels, (iii) the equilibrium real wage, and (iv) the equilibrium relation between real aggregate demand and real money balances. In Akerlof and Yellen (1985) the real wage is given by the Solow condition because firms are efficiency wage setters. In Blanchard and Kiyotaki (1987) households are wage setters so that firms take real wages as given when choosing nominal prices and output. 
there is, to our knowledge, no empirical evidence for the claim that a small amount of money illusion may generate substantial nominal inertia.

\section{An experimental approach to money illusion}

One way to rigorously examine whether money illusion matters, is to look for a natural experiment in which an exogenous and fully anticipated monetary shock occurs. The shock has to be exogenous because if the central bank responds to real events in the economy there can be a co-movement between money and output that has nothing to do with the real effects of money. The shock has to be fully anticipated because nobody doubts that nominal inertia and real effects occur in the presence of non-anticipated shocks. These effects should not be confounded with money illusion.

Of course, in order to unambiguously identify whether the shock is fully anticipated the researcher needs to know individual information sets before the shock. Moreover, to judge whether the anticipated shock causes a disequilibrium and nominal inertia the researcher has to know the equilibrium values of nominal prices before and after the shock. By comparing the preand post shock equilibrium values of nominal prices with actual prices the researcher can identify (i) to what extent actual prices are anchored at the pre-shock equilibrium and (ii) how long it takes for actual prices to adjust to the new equilibrium. Furthermore, to examine whether money illusion causes nominal inertia the researcher should identify two similar natural experiments. In one experiment the "world" should be framed in nominal terms while in the other experiment it should be framed in real terms.

In our view, it seems extremely difficult, if not impossible, to meet the above requirements with field data. In fact, the exogeneity of monetary policy and the causality between money and output is a matter of considerable debate (e.g., Romer and Romer 1989, 1994; Hoover and Perez 1994; Coleman 1996). Whether monetary shocks are anticipated or not is usually controversial, too. Belongia (1996) for example, shows that the measurement of unanticipated money shocks may be quite sensitive to the choice of monetary aggregates. Moreover, full

\footnotetext{
${ }^{7}$ Since strategic complementarity is important for our argument in favor of the aggregate relevance of (beliefs about) money illusion one would like to know to what extent it does prevail in naturally occurring economies. In fact, several papers suggest that strategic complementarity may well be an important feature of real economies. It arises frequently in imperfectly competitive labor and product markets. Strategic complementarity is an inherent feature of models of monopolistic price competition (Ball and Romer 1987), it can arise from the nature of preferences and technologies (Bryant 1983) or in environments in which heterogeneous agents search for transaction partners (Diamond 1982). Oh and Waldman (1990, 1994), Cooper and Haltiwanger (1993) and Blinder, Canetti, Lebow and Rudd (1998) provide evidence in favor of the relevance of strategic complementarity in real economies.
} 
knowledge of the pre- and post-shock equilibrium values of nominal prices is clearly beyond the information content of presently available field data. Finally, as already mentioned in the introduction, almost all business transactions are shrouded in nominal money, i. e., it is very difficult to find real world examples of a real frame.

In an appropriate laboratory setting, however, the above mentioned data requirements can be met. The techniques of experimental economics allow the implementation of exogenous and fully anticipated nominal shocks and the experimenter can exert full control over pre- and postshock equilibrium values of nominal prices. In addition, the experimenter controls the framing of the situation, e.g., whether subjects receive the payoff information in nominal or in real terms. Finally, experimental methods also provide the opportunity to observe subjects' behavior in interactive and non-interactive settings that are otherwise structurally identical. These enhanced control opportunities suggest that laboratory experiments provide valuable information regarding the impact of money illusion on nominal inertia, which may complement and help to interpret the results of studies based on field data.

The use of experimental methods also distinguishes our examination from the study of Shafir et al. (1997). While these authors asked subjects hypothetical questions we directly observe subjects' behavior in our experiments. In our view the study of Shafir et al. neatly shows that questionnaires can be a very useful instrument to examine the nature of money illusion at the individual level. It is, however, also clear that it is impossible to examine aggregate effects of individual interactions and adjustment processes with this method. For our purposes the most important advantage of experimental methods, relative to questionnaires, is that we can directly observe the evolution of individual and aggregate behavior after a nominal shock. This means, e. g., that we can directly study the impact of the nominal frame, i. e., of money illusion, on the evolution of price sluggishness after the shock.

\subsection{General description of the experimental design}

To study the impact of money illusion we designed an $n$-player pricing game with strategic complementarity. The pricing game was divided into a pre-shock and a post-shock phase. All $n$ players had to determine their nominal prices in each period of the game. They were

\footnotetext{
${ }^{8}$ For field evidence related to the question of money illusion see e.g. Abbott and Ashenfelter (1976) and Niemi and Lloyd (1981). Abbott and Ashenfelter estimate a system of commodity demand and labor supply functions and find evidence that the system does not satisfy the homogeneity restriction. Niemi and Lloyd report the result that the inflation rate has an independent impact on female labor supply.
} 
free to change their nominal prices in each period at no cost. The players interacted anonymously via computer terminals. Each treatment condition had $2 T$ periods. During the first $T$ periods of a session the money supply was given by $M_{0}$. Then we implemented a fully anticipated monetary shock by reducing the money supply to $M_{1}$. This shock and the fact that the post-shock phase again lasted $T$ periods was common knowledge.

Our major interest concerns subjects' pricing behavior in the post-shock phase. The preshock phase serves the purpose to make subjects acquainted with the computer terminal and the decision environment. In addition, and more importantly, the pre-shock phase allows us to see whether subjects reach equilibrium in the pre-shock phase. After all, one can only argue that money illusion is a disequilibrating force if equilibrium has in fact been reached before the shock.

The real payoff of subject $i, \pi_{i}$, is given by

$$
\pi_{i}=\pi_{i}\left(P_{i}, \bar{P}_{-i}, M\right) \quad i=1, \ldots, n
$$

where $P_{i}$ denotes $i$ 's nominal price, $\bar{P}_{-i}$ represents the average price of the other $n$ - 1 group members while $M$ denotes a nominal shock variable (money supply). The nominal payoff of subject $i$ is given by $\bar{P}_{-i} \pi_{i}$. In total, we have four treatment conditions and the payoff functions (2) are the same in all conditions. The four conditions differ along two dimensions (see Table 1). The first dimension concerns the framing of the situation, i. e., whether payoffs are represented in real or in nominal terms. In the real treatments, denoted by $\mathrm{RC}$ and $\mathrm{RH}$, subjects received the payoff information in real terms while in the nominal treatments, denoted by NC and NH, payoffs were represented in nominal terms. Thus, to compute their real payoffs in the nominal treatments subjects had to divide their nominal payoffs $\bar{P}_{-i} \pi_{i}$ by $\bar{P}_{-i}$.

\section{Insert Table 1 here}

The second dimension concerns the fact whether our experimental subjects face $n$ - 1 preprogrammed computerized players or whether they face $n-1$ other human subjects. The crucial point here is that in the computerized condition, i. e., if one human subject faces $n-1$ preprogrammed computers, the subject is informed about the aggregate response rule of the computers in advance. The response rule of the computers is given by the best replies of the computers (based on the computers' payoff functions (2)). Therefore, there is no strategic uncertainty and, hence, no need to form expectations about the behavior of the other players in this condition. Moreover, since the computers play best replies their behavior rules out any money illusion or any other form of irrationality. In contrast, in the condition with human opponents each subject faces the task of forming expectations about the other players' price choices. This 
necessarily also involves a guess about the extent to which other players are affected by money illusion.

The condition with computerized players essentially boils down to an individual decisionmaking experiment in which human subjects can maximize their money earnings by playing optimally against the known aggregate best reply of the $n-1$ computerized players. Note that in the computerized condition the indirect effects of money illusion, which operate via the expectations that other players are affected by money illusion, can play no role because the computers play best reply. This condition, therefore, allows us to examine to what extent money illusion has direct effects on nominal inertia, i.e., to what extent it simply causes individual optimization mistakes. In the condition with human opponents the indirect effects of money illusion can, in addition, also play a role.

An important aspect of our design is that exactly the same payoff functions were implemented in all treatment conditions. Moreover, we also ensured that there is a unique equilibrium in each condition, and that the equilibrium price choices of all $n$ players (human and computerized) are identical across all conditions. Therefore, the only difference between the real treatments $\mathrm{RC}$ and $\mathrm{RH}$ on the one hand and the nominal treatments $\mathrm{NC}$ and $\mathrm{NH}$ on the other hand is, that in the real treatments subjects received the payoff information in real terms while in the nominal treatments they received this information in nominal terms. The experimental design in Table 1 allows to isolate various potentially important determinants of nominal inertia. The treatments with a real payoff frame allow us, in particular, to isolate those determinants of nominal inertia that have nothing to do with money illusion.

In the RC money illusion is ruled out at the individual and, hence, also the aggregate level. Therefore, if we observe in the $\mathrm{RC}$ a slow adjustment of the nominal price chosen by the human subject after the shock, money illusion cannot be the source of this nominal inertia. Instead, other sources of individual irrationality must be responsible. Since the computers are programmed to play a best reply to the choice of the human subject, any deviation from equilibrium must be due to an optimization mistake of the subject.

In the $\mathrm{NC}$, in contrast, money illusion can affect the behavior of individuals because as a part of the individual optimization problem human subjects have to correctly deflate nominal payoffs at the various $\left(P_{i}, \bar{P}_{-i}\right)$-combinations. Hence, by comparing the post-shock prices of human subjects in the RC and the NC we can observe whether there exists money illusion at the individual level. If, e.g., nominal inertia is more pronounced in the $\mathrm{NC}$ than in the RC we would have evidence in favor of individual-level money illusion. 
In the $\mathrm{RH}$, as in the RC, individual-level irrationality other than money illusion can play a role. However, in the RH the adjustment to the new post-shock equilibrium is not just an individual optimization problem of the human subjects. In the $\mathrm{RH}$ adjustment to the new equilibrium also involves the coordination of the expectations of all human subjects. Although there exists a unique equilibrium it cannot be taken for granted that subjects instantaneously succeed to act according to the new post-shock equilibrium. For example, if subjects play the equilibrium before the shock for several periods, it may well be the case that after the shock some subjects are anchored or believe that others are somehow anchored at the old equilibrium. As a consequence, adjustment to the post-shock equilibrium may not occur instantaneously. Since in the RC subjects face no coordination problem, we can isolate the amount of nominal inertia that is due to the coordination problem by comparing the adjustment process in the RC and the RH. In case that we find no individual irrationality in the RC the nominal inertia observed in the RH can be fully attributed to the coordination problem present in the RH.

In the NH subjects face the same coordination problem as in the RH. We are, however, particularly interested in the impact of adding the nominal frame to this coordination problem, $\mathrm{i}$. e., in a comparison of the $\mathrm{NH}$ and the $\mathrm{RH}$. This comparison allows us to isolate the total effects of money illusion in an environment where subjects face a coordination problem. The total effects of money illusion in this environment consist of the direct effects of individual-level money illusion as exhibited in the NC plus the indirect "multiplier" effects of individual-level illusion. These "multiplier" effects may arise because in our setting with human opponents subjects with money illusion can also affect the expectations and thus the behavior of the subjects without money illusion.

\subsection{General properties of the payoff functions}

Before we proceed to the specific numerical parameters of our experiment, it is useful to provide a general description of the payoff functions (2). They have the following properties:

(i) They are homogeneous of degree zero in $P_{i}, \bar{P}_{-i}$, -and $M$.

(ii) The best reply is (weakly) increasing in $\bar{P}_{-i}$.

In addition, our functional specification ${ }^{9}$ of (2) implies that the equilibrium

(iii) is unique for every $M$,

(iv) is the only Pareto efficient point in payoff space, and

\footnotetext{
${ }^{9}$ The functional form is presented in Appendix A.
} 
can be found by iterated elimination of weakly dominated strategies.

Note that the real payoff $\pi_{i}$ does not depend on the average price $\bar{P}$ of all group members but on $\bar{P}_{-i}$. This feature makes it particularly easy to play a best reply for a given expectation about the other players' average price. If we made $\pi_{i}$ dependent on $\bar{P}$, so that $P_{i}$ affects $\bar{P}$, it would have been much more difficult for $i$ to compute the best reply (see also below). It is also worthwhile to point out that the nominal payoff for each subject $i$ is given by $\bar{P}_{-i} \pi_{i}$ and not by $\bar{P} \pi_{i}$. This makes the computation of the real payoffs from a given nominal payoff much easier because the deflator is independent of one's own price choice.

Properties (i) and (iii) above were implemented because our analysis focuses on the impact of money illusion on the adjustment process of an economy with a unique money-neutral equilibrium $P_{i}^{*}, i=1, \ldots, n$. To see that properties $(i)$ and (iv) imply neutrality, note that a change in $M$ from $M_{0}$ to $\lambda M_{0}$ leaves real payoffs unaffected if prices change to $\lambda P_{i}$ and $\lambda \bar{P}_{-i}$. Moreover, if $P_{i}^{\prime}, i=1, \ldots, n$, is a best reply to $\bar{P}_{-i}$ at $M_{0}, \lambda P_{i}^{\prime}$ also is a best reply to $\lambda \bar{P}_{-i}$, at $\lambda M_{0}$. Thus, $\lambda P_{i}^{*}$ for all $i$ is the post-shock equilibrium.

Property (ii) captures strategic complementarity and was implemented for the reasons given in section 2.2. In our pilot experiments we initially implemented a price-setting game with monopolistic competition. However, it turned out that subjects quickly realized that under monopolistic competition cooperative gains can be achieved by out-of-equilibrium behavior. Therefore, both in the nominal as well as in the real frame, subjects systematically tried to achieve real payoff gains through out-of-equilibrium behavior. Only towards the end of each phase these attempts vanished. Thus, in the pre- as well as in the post-shock phase of our pilot experiments adjustment towards equilibrium was strongly retarded by attempts to cooperate. To remove this confound with the other sources of nominal inertia we chose payoff functions that ensured that the equilibrium was the unique Pareto-efficient point in the whole payoff space (property $(i v))$.

Finally, property $(v)$ means that there is a method for finding the equilibrium that works exactly in the same way in the real as well as in the nominal frame. Note that the framing of payoffs has no impact at all on whether a particular strategy is (weakly) dominated. In the real frame a (weakly) dominated strategy $P_{i}$ has (weakly) smaller real payoff numbers at any level of $\bar{P}_{-i}$. In the nominal frame a (weakly) dominated strategy $P_{i}$ has (weakly) smaller nominal payoff numbers at any level of $\bar{P}_{-i}$. Thus, to eliminate (weakly) dominated strategies in either frame, subjects only need to eliminate those strategies that have (weakly) smaller (real or nominal) payoff numbers at any given level of $\bar{P}_{-i}$. Since in the condition with human opponents the best 
reply function and, hence, the number of (weakly) dominated strategies is exactly the same under the real and the nominal frame, there is, in the absence of money illusion, no reason why adjustment should differ across the RH and the NH.

\subsection{Experimental procedures and parameters}

All major experimental parameters are summarized in Table 2. The experiment was conducted in a computerized laboratory with a group size of $n=4$. The group composition did not change throughout the whole experiment, i.e., for $2 T$ periods. In each group there were two types of subjects: Subjects of type $x$ and subjects of type $y$. Payoff functions differed among the types. This difference implied that $x$-types had to choose a relatively low price in equilibrium while $y$-types had to choose a relatively high price (see Table 2 for details). There is no particular reason for our choice of the group size because there are no strong conjectures about the net effects of a different group size. On the one hand, a larger group size, e. g., enhances the chances that there are individuals with money illusion in a group. On the other hand, the relative impact of an individual on average prices becomes smaller. With regard to the heterogeneity of the players' payoff functions, the case of four different payoff functions would be the most realistic but also the most complicated case. Therefore, we went for an intermediate solution with only two types of players, i. e. two different payoff functions.

\section{Insert Table 2 here}

In the pre-shock phase of each treatment the money supply was given by $M_{0}=42$ while in the post-shock phase it was given by $M_{1}=M_{0} / 3=14$. In the pre-shock equilibrium the average price over all $n$ group members is given by $\bar{P}_{0}^{*}=18$ while in the post-shock equilibrium it is $\bar{P}_{l}^{*}$ $=6$. In the treatments with human opponents both the pre- and the post-shock phase consists of $T$ $=20$ periods while in the treatments with computerized opponents $T=10$. The reason for this difference was that we expected that adjustment would take longer in the presence of a coordination problem. For the purpose of comparing post-shock nominal inertia across treatments it is crucial that the required adjustment, i. e. the difference between actual nominal prices in the final pre-shock period and the new post-shock equilibrium price is roughly the same. To ensure comparable adjustment requirements across treatments we gave players more time to reach the equilibrium in the treatments with a coordination problem.

\footnotetext{
${ }^{10}$ The payoff functions of the two types were the same up to a parallel shift. Except for $P_{k}^{*}$ and $P_{k}^{*}$ all parameters of the payoff function specified in Appendix A are the same for both types.
} 
In each decision period subjects had to choose an integer $P_{i} \in\{1,2, \ldots, 30\}$. In addition, they had to provide an expectation about $\bar{P}_{-i}$ which we denote by $\bar{P}_{-i}^{e}$. Finally, subjects indicated their confidence about their expectation $\bar{P}_{-i}^{e}$ by choosing an integer from 1 to 6 where 1 indicated that the subject is "not at all confident" while 6 indicated that he or she is "absolutely confident". This measure of confidence can be interpreted as an indicator of subjects' perceived uncertainty about the other players' choices. Note that this uncertainty is an inevitable component of the coordination problem that subjects face in the condition with human opponents. At the end of each period each subject was informed about the actual realization of $\bar{P}_{-i}$ and the actual real payoff $\pi_{i}$ on a so-called "outcome screen" (see Figure B2 in Appendix B). In addition, the outcome screen provided information about the subject's past choices of $P_{i}$, past realizations of $\bar{P}_{-i}$ and past real payoffs $\pi_{i}$.

Subjects received the payoff information in matrix form. Appendix C contains the payoff matrices of $x$ - and $y$-types for all treatment conditions. The payoff matrix shows the real and the nominal payoff, respectively, for each feasible integer combination of $\left(P_{i}, \bar{P}_{-i}\right)$. To inform subjects about the payoffs of the other type, each subject also received the payoff matrix of the other type. This information condition was common knowledge. The presentation of payoffs in the form of a matrix made it particularly easy to find the best reply for any given $\bar{P}_{-i}$ : The subject just had to look for the highest real or nominal payoff in the column associated with $\bar{P}_{-i}{ }^{12}$ In fact, one of the first things most subjects did, after we distributed the instructions, was to mark the best replies in the payoff tables.

In the treatments with computerized opponents, subjects received the same instructions and payoff tables as in the treatments with human opponents. In addition, subjects were informed that the decisions of the other 3 players in the group would be made by pre-programmed computers. Subjects received an information sheet that informed them about the $\bar{P}_{-i}$-response of the three computers to each price choice $P_{i} \in\{1,2, \ldots, 30\} .50$ percent of the human subjects in these conditions were endowed with the payoff function of an $x$-player, the other 50 percent had the payoff function of a $y$-player.

At the end of the final pre-shock period the nominal shock was implemented in the following way: Subjects were publicly informed that $x$ - and $y$-types received new payoff tables.

\footnotetext{
11 The detailed meaning attached to the numbers is: $1=$ not at all confident; $2=$ not much confidence; $3=$ not quite confident; 4 = quite confident; 5 = very confident; $6=$ absolutely confident.

12 If a subject is uncertain about the true value of $\bar{P}_{-i}$ the calculation of the best reply requires, of course, to take into account the subjective distribution of $\bar{P}_{-i}$ and not only the expectation of $\bar{P}_{-i}$. However, for simplicity, in the following we will use the term "best reply" in the sense of a best reply to the expectation of $\bar{P}_{-i}$.
} 
These tables are based on $M_{1}=M_{0} / 3$. Again each type received the payoff table for his own and the other type. Subjects kept the pre-shock tables and were encouraged to compare the pre- and post-shock tables. They were told that, except for payoff tables, everything else would remain unchanged. They were given enough time to study the new payoff tables and to choose $P_{i}$ for the first post-shock period. ${ }^{T 3}$ This procedure ensured that in the first post-shock period subjects faced an exogenous and fully anticipated negative nominal shock. At the beginning of this period it was also common knowledge that the experiment would last for another $T$ periods.

Before we proceed to the experimental results, it needs to be emphasized that in a given phase the number of dominated price choices is identical across all treatments. It is, however, not identical between the pre- and the post-shock phase. Since the money supply is lower in the postshock phase the number of dominated strategies is also lower in this phase. Note that the smaller number of dominated strategies in the post-shock phase is an inevitable result of the fact that the money supply is reduced while the nominal strategy space and the nominal accounting unit is kept constant. ${ }^{14}$ Due to the differences in the number of dominated strategies a comparison of the adjustment speed across phases must take this difference into account. The higher number of dominated strategies in the pre-shock phase means, in particular, that the indirect effects of money illusion are likely to be smaller in this phase. This is so because, if a strategy is dominated, it is optimal to not play this strategy irrespective of the expectations about other players' behavior. Thus, expectations about other players' money illusion necessarily have less impact and, as a consequence, one would expect a quicker adjustment towards equilibrium in the preshock phase. Note also that the different number of dominated strategies across phases is not a problem for the main purpose of our research. We are not interested in comparing adjustment speed across phases but across treatments in the post-shock phase. For our purposes the crucial point is that in the post-shock phase the number of dominated strategies is identical across treatments because the only difference in the payoff tables concerns the framing of the payoffs.

\footnotetext{
13 Subjects were told that they had 10 minutes to study the new payoff tables and, in addition, 3 minutes to make a decision for the first post-shock period. Yet, almost all subjects made their decision well before the 13 minutes had elapsed. In the second post-shock period subjects were told that they should make a decision approximately within $2^{1 / 2}$ minutes, in the third post-shock period within 2 minutes, and so on, until the time limit reached 1 minute. However, most subjects were far from exhausting these time limits. If, occasionally, a subject used up the whole decision time the computer told her that she should now make a decision. Subjects could, however, violate the time limits without any sanction. The decreasing sequence of decision times was introduced because in the pilot experiments we noticed that subjects needed much less time after the first few periods.

${ }^{14}$ A change in the nominal price in the post-shock phase (i. e. at $M_{0} / 3$ ) by one unit has the same real effects as a change in the nominal price by three units in the pre-shock phase (i. e. at $M_{0}$ ). This means that if a nominal price is strictly dominated in the post-shock phase there will, in general, be three nominal prices that are strictly dominated in the pre-shock phase.
} 
While the framing of the payoffs is irrelevant from a purely game-theoretic viewpoint, it may well be relevant for subjects' expectations and behavior. If, for example, some subjects apply the rule of thumb to take (variations in) the nominal payoff as a proxy for (variations in) the real payoff, adjustment to equilibrium in the NH may be slower than in the RH. The reason is that after a negative shock adjustment requires a decrease in nominal prices. By definition, a decrease in nominal prices is associated with a decrease in nominal payoff numbers in the NH (see, e. g., payoff table $\mathrm{C} 3 \mathrm{~b}$ in appendix $\mathrm{C}$ ). Therefore, subjects who apply the above rule of thumb mistakenly believe that real payoffs decrease with lower nominal prices. Thus, they prefer to stay at higher nominal prices, which may have a direct adjustment reducing effect. Moreover, if some subjects believe that others apply this rule of thumb, they have an incentive to slow down adjustment, too. In the RH, however, this rule of thumb cannot become effective because payoffs are represented in real terms. In the $\mathrm{RH}$, it is, therefore, completely transparent that general price reductions are not associated with lower real payoffs (see, e.g., payoff table $\mathrm{C} 4 \mathrm{~b}$ in appendix $\mathrm{C}$ ).

\section{Results}

In total, 130 subjects participated in the experiments described in Table $1 .{ }^{3} 22$ subjects participated in the real treatment with computerized opponents (RC) and 24 subjects in the nominal treatment with computerized opponents (NC). 11 groups of four human subjects participated in the nominal treatment with human opponents $(\mathrm{NH})$ and 10 groups in the real treatment with human opponents $(\mathrm{RH})$. Subjects were undergraduate students from different disciplines at the University of Zürich, Switzerland. They were paid a show-up fee of CHF 15 (\$12) and their total earnings from the experiment were on average CHF 35 (\$28) (including the show-up fee). On average, an experimental session lasted 90 minutes.

\subsection{Nominal price adjustment as an individual optimization problem}

In this section we address the question whether individual-level money illusion and other individual-level irrationality contribute to nominal inertia. Therefore, our discussion is constrained to the RC and the NC where adjustment to the post-shock equilibrium is a purely individual optimization problem. Our first main result is that in the RC all subjects instantaneously adjust to the new post-shock equilibrium, i. e., nominal inertia is completely

15 In follow-up experiments with a positive money shock, described in detail in section five, another 96 subjects participated. 
absent. Support for this claim is provided by column 1 of Table 3 and by Figure 1 . Both the table and the figure show the pre- and post-shock path of the average price of all human subjects in the $\mathrm{RC}$. What is remarkable here is that, except for a few periods, the average price is exactly equal to the equilibrium price of $\bar{P}_{0}^{*}=18$ in the pre- and $\bar{P}_{1}^{*}=6$ in the post-shock period. Moreover, it is not just the average that coincides with equilibrium. In most periods literally all subjects play the equilibrium. This result contrasts with what we observe in the nominal frame. In the NC there is a small amount of nominal inertia since some subjects do not fully adjust prices to the new postshock equilibrium. This claim is supported by Table 3 (column 2) and Figure 1. Both the table and the figure show that the evolution of average prices is, in general, more volatile relative to the RC. This suggests that at least some subjects in the NC have problems in finding the optimal solution to their maximization problem. Moreover, while in the RC all subjects instantaneously adjust their prices fully to the post-shock equilibrium, in the NC only 80 percent of the subjects do so. The rest of the subjects choose prices above the equilibrium so that in the first post-shock period the average price is by 2.0 units too high. Throughout the whole post-shock phase the NC most of the time is close but never exactly in equilibrium which contrasts again with the RC where after the second post-shock period all subjects are exactly in equilibrium most of the time.

\section{Insert Figure 1 here}

\section{Insert Table 3 here}

These differences in post-shock adjustment also give rise to differences in the real income losses across RC and NC. Nominal inertia in the NC causes small but non-negligible real income losses in the post-shock phase. In contrast, in the RC there are no or only extremely small real incomes losses in the post-shock phase. To verify this claim we calculate by how much actual real income of player $i, \pi_{i}$, falls short of real income in equilibrium $\pi^{*}$. For this purpose we have computed $\varepsilon_{i t} \equiv\left(\pi^{*}-\pi_{i t}\right) / \pi^{*}$ for all players in each period $t$. $\varepsilon_{i t}$ is a measure of the income loss relative to the equilibrium payoff as a percentage of the equilibrium payoff. Since the equilibrium is efficient it is also a measure of the efficiency loss. Columns 5 and 6 of Table 3 present the evolution of the average value of $\varepsilon_{i t}$ over all players in the RC and in the NC. The two columns indicate that after the shock the average efficiency loss is most of the time zero in the RC and always lower than in the NC.

Taken together the results of the treatments with computerized opponents indicate that there is a small amount of money illusion at the individual level but beyond that there is no individual irrationality. The small amount of individual-level money illusion is suggested by the small price differences between the NC and the RC after the shock. The absence of other forms of 
individual irrationality is suggested by the perfect adjustment to the shock and the generally high incidence of equilibrium play in the RC.

\subsection{Nominal price adjustment as a coordination problem}

The fact that in the RC the adjustment to the post-shock equilibrium is perfect makes the interpretation of the deviation of prices from the post-shock equilibrium in the $\mathrm{RH}$ particularly easy. It means that the whole deviation is due to the fact that subjects in the $\mathrm{RH}$ face a coordination problem. The major facts about price adjustment in the RH are displayed in Table 3 and Figure 1. Column 3 of Table 3 shows that in the first post-shock period average prices in the $\mathrm{RH}$ are 3.1 units above the average equilibrium price of $\bar{P}_{1}^{*}=6$. This deviation quickly decreases to 1.4 units in period three and after period four the deviation is never larger than one unit. This pattern of average behavior is not an artifact of aggregation but is also revealed at the level of individual choices. In the final pre-shock period 93 percent of the subjects in the RH play exactly their equilibrium strategies. In the first post-shock period only 35 percent of the subjects play the new equilibrium and 23 percent of the subjects are only one or two price units above the equilibrium. The other 42 percent are more than two units above the equilibrium. Yet, after only three periods the distribution of individual price choices has moved much closer to the equilibrium. In period four 45 percent of all subjects play exactly the equilibrium, 48 percent are one or two units above and only 7 percent are more than two units above the equilibrium. This post-shock evolution of prices indicates that the coordination problem initially causes considerable nominal inertia but that after a few periods this effect is rather small because prices are again close to the equilibrium.

Our description of the pattern of nominal inertia in the RH is also supported by formal statistical tests. To check how long average group prices in the RH and the NH deviate significantly from the equilibrium we ran the following regression for the post-shock phase:

$$
\bar{P}_{i t}-\bar{P}_{1}^{*}={ }_{t=1}^{19} \alpha_{t} d_{t}+{ }_{t=1}^{20} \beta_{t}\left(1-d_{t}\right)
$$

where $\bar{P}_{i t}$ denotes the average price of group $\mathrm{i}$ in period t. $d_{t}=1$ if the price observation in period $t$ comes from the RH. The coefficients $\alpha_{t}$ measure the deviation from equilibrium in the $\mathrm{RH}$ while 
the coefficients $\beta_{t}$ measure the deviation in the $\mathrm{NH}^{\square}$ The results of regression (3) are summarized in Table 4. The table shows that, at the five percent level, average prices in the RH deviate significantly from the equilibrium for two periods. Yet, from period three onwards, the hypothesis that average prices are in equilibrium can no longer be rejected.

\section{Insert Table 4 here}

To what extent is nominal inertia in the RH associated with real income losses? Column 7 of Table 3 indicates that in the first post-shock period the real income loss resulting from disequilibrium is quite considerable (52 percent). Yet, due to the relatively quick adjustment of nominal prices after this period the real income loss declines substantially and after the fifth postshock period it is - except for period ten - always below ten percent. In the final periods the real income loss is always rather small which reflects the high incidence of equilibrium play.

The key difference between the RC and the RH is the presence of a coordination problem in the RH. If subjects perceive coordination as a difficult problem this should be reflected in subjects' confidence in $\bar{P}_{-i}^{e}$. In the first few pre-shock periods subjects' average confidence is at a level of 4 which means that they are, on average "quite confident". The high frequency of equilibrium play before the shock then causes a general increase in the confidence level. In the last five pre-shock periods subjects exhibit, on average, a confidence level between 5 and 5.5 . This means that most subjects are "very confident" (= level 5) or even "absolutely confident" (= level 6) that they have correct expectations. The anticipated negative money shock causes, however, a considerable decrease in subjects' confidence. In the first post-shock period subjects on average confidence are "not quite confident" (level 3) and "quite confident" (level 4) that their expectations will be correct. It takes about eight periods until pre-shock confidence levels are again established. This indicates that the money shock indeed causes a coordination problem for the subjects.

Taken together, the evidence suggests that the introduction of a coordination problem in the real treatment causes initially a non-negligible amount of nominal inertia that is associated with considerable real effects. Yet, nominal inertia vanishes relatively quickly so that already after a few periods prices are quite close to the equilibrium.

\footnotetext{
${ }^{16}$ To prevent linear dependence among the set of regressors we included no dummy variable for period 20 of the RH. We also ran a regression where we added a constant to (3) so that all deviations are measured relative to the small deviation in period 20 of the RH. The results of this regression are very similar.
} 


\subsection{Coordination in the presence of money illusion}

Nominal inertia in the RH has nothing to do with money illusion but is caused by the problem to coordinate expectations and actions on the new equilibrium. From the comparison between the RC and the NC we already know that individual-level money illusion has a small positive effect on nominal inertia. In the $\mathrm{NH}$ a small amount of individual-level money illusion may, however, cause important indirect effects. These indirect effects can arise because the presence of individual-level money illusion is likely to affect subjects' expectations, which in turn affect their behavior. If money illusion indeed causes such indirect effects we should observe that the introduction of the nominal frame has a larger effect in the setting with human players than in the setting with computerized players. We should, in addition, also observe that in the setting with human players the nominal frame gives rise to an increase in the stickiness of subjects' price expectations.

Figure 1 and Table 3 (columns 3 and 4) provide the relevant information regarding the impact of the nominal frame. They show that nominal prices are indeed much stickier in the NH compared to the RH. In the final pre-shock period the overwhelming majority of the subjects play exactly the equilibrium both in the RH (93 percent) and the NH (80 percent). Therefore, average prices are very close to the pre-shock equilibrium $\bar{P}_{0}^{*}=18$. In the first post-shock period, however, only 11.5 percent of all subjects in the NH play exactly the equilibrium and 73 percent of the subjects are three or more price units above the equilibrium. In contrast, in the RH 35 percent play exactly the equilibrium and, in addition, 23 percent are only two or less price units above the new equilibrium. These treatment differences in individual adjustment behavior also give rise to large differences in the average price level. In the first post-shock period the average price in the $\mathrm{NH}$ is 7.1 units above the equilibrium while in the $\mathrm{RH}$ the deviation is only 3.1 units (see Table 3). It takes eight periods in the $\mathrm{NH}$ until the deviation of average prices from equilibrium decreases to 3.1 units. These large differences in price adjustment speed are also confirmed by formal statistical tests. Table 4 reveals that in the NH the hypothesis of equilibrium play can be rejected at the five percent level for the first twelve post-shock periods while in the $\mathrm{RH}$ it can only be rejected for two periods.

To what extent is nominal inertia in the $\mathrm{NH}$ associated with real income losses? Column 8 of Table 3 indicates that shortly before the shock subjects in the $\mathrm{NH}$ achieve almost full efficiency. The monetary shock leads, however, to a substantial real income loss. In the first period after the shock the average income loss is 65 percent and during the first ten post-shock periods the loss is never below 9.5 percent. Note also that throughout the whole post-shock period 
the income loss is in general much higher in the $\mathrm{NH}$ than in the $\mathrm{RH}$ which is a consequence of the much stickier prices in the NH. For example, in the first ten post-shock periods of the NH the aggregate real income loss is roughly twice as large as the loss in the $\mathrm{RH}^{47}$ Thus, the evidence clearly indicates two results: (i) In the setting with human players the introduction of a nominal frame has large and long-lasting effects on price stickiness. (ii) This increase in price stickiness is associated with a considerable increase in the real income loss caused by the anticipated money shock.

From Figure 1 and Table 3 we can also infer that the nominal frame causes much stickier prices when money illusion can have indirect effects, i. e., in the setting with human players. Throughout the first ten post-shock periods the adjustment difference in average prices between the $\mathrm{NH}$ and the RH is between 2 and 13 times larger than the adjustment difference between the $\mathrm{NC}$ and the RC. In the second post-shock period, e. g., the adjustment difference between the NH and the $\mathrm{RH}$ is $12.9-7.7=5.2$ price units while the difference between the NC and the RC is only $7.4-7.0=0.4$ units. Hence, in this period the impact of the nominal frame is 13 times larger in the setting with human players compared to the setting with computerized players. In the tenth post-shock period the adjustment difference is still 1.8 units in the setting with human players and only 0.5 units in the setting with computerized players. Thus, the implementation of the nominal frame has a much larger impact in the setting where money illusion can also have indirect effects.

If money illusion has indirect effects we should also observe that expectations are stickier in the NH compared to the RH. Figure 2 shows the evolution of the average price expectations over time in both treatments. The figure shows that in the last few pre-shock periods expectations are in equilibrium in both treatments. In the post-shock phase there are, however, striking differences. While expectations are very sticky in the NH they are far less sticky in the RH. Thus, there can be little doubt that the nominal frame causes a large increase in the stickiness of price expectations. The next question then is, to what extent this difference in expectations causes differences in subjects' price choices. Or put differently, to what extent did subjects play a best reply to their expectations. The vast majority of subjects in both treatments indeed played best replies to $\bar{P}_{-i}^{e}$. During the first ten post-shock periods, e.g., 84 percent of the subjects in the RH choose exactly the payoff-maximizing price in response to $\bar{P}_{-i}^{e}$ and the rest of the subjects chooses prices that were very close to the best reply. In the NH there are slightly fewer subjects (80 percent ) who chose exact best replies during the first ten post-shock periods. Yet, as in the $\mathrm{RH}$ the deviations from the exact best reply where in general very small. The fact that most

${ }^{17}$ To be precise: In total, groups in the NH lose $26 \%$ of the potential payoff in the first ten post-shock periods. In the $\mathrm{RH}$, the respective losses are slightly less than 14 percent. 
subjects responded to $\bar{P}_{-i}^{e}$ with a payoff-maximizing price choice suggests that the greater stickiness of the expectations in the $\mathrm{NH}$ also caused a greater stickiness of actual prices in the NH.

\section{Nominal Inertia after a positive money shock}

\subsection{The relevance of a positive money shock}

Our results so far indicate that the direct effects of individual-level money illusion are relatively small. The introduction of the nominal frame in the setting with computerized players leads only to a small increase in nominal inertia. Nominal inertia is much more pronounced, however, when money illusion can also affect players' expectations and can, thus, also have indirect effects. In the NH subjects' expectations are much stickier and, as a consequence, prices are much stickier. This raises the question of why expectations are so sticky in the NH compared to the RH. We believe that the answer to this question can be found in the existence of subjects who take nominal payoffs as a proxy for real payoffs. Subjects who apply this rule of thumb mistakenly believe that if all players choose relatively high prices, all will reap high real payoffs because they all reap high nominal payoffs. They mistakenly believe that there are real gains from jointly setting high prices. Such subjects will, therefore, be reluctant to cut their nominal prices after the negative money shock in the NH. Moreover, if the presence of subjects who are reluctant to cut prices is anticipated by other subjects, others will be induced to cut their price insufficiently, also.

It is important to note that the above rule of thumb cannot become effective in the RH. In the RH the numbers in the payoff tables represent real payoffs which makes it completely transparent that at high nominal prices real payoffs are not generally higher. This means that the presence of subjects who take nominal payoffs as a proxy for real payoffs causes no reluctance to cut nominal prices after the negative shock in the RH. These differences between the NH and the $\mathrm{RH}$ in the reluctance to cut nominal prices also provide a rationale for the much stickier price expectations in the $\mathrm{NH}$.

Yet, if the above explanation for the stickier expectations in the NH is correct, we should also observe that after a positive money shock prices and expectations adjust more quickly to the equilibrium than after a negative shock. This is so because after a positive shock adjustment towards equilibrium means adjustment towards higher prices and, hence, higher nominal payoffs. Note, however, that while we should observe a quicker adjustment to equilibrium after a positive 
shock in the $\mathrm{NH}$, the adjustment speed in the $\mathrm{RH}$ should not differ across positive and negative shocks. The reason is again that the rule of thumb cannot become operative in the RH.

To test these implications of our explanation for the much stickier expectations in the NH we conducted additional experiments with a positive money shock. 48 subjects (12 groups) participated in the $\mathrm{RH}$ and another 48 subjects (12 groups) participated in the NH with the positive money shock. The easiest way to implement a positive shock would be a reversal in the sequence of the money supply in our previous design. Unfortunately, this approach is not reasonable because the number of strictly dominated strategies is much larger in the pre-shock phase than in the post-shock phase. Therefore, the indirect effects of money illusion can play a much smaller role in the pre-shock phase. The fact that prices in the NH adjust much more quickly to the equilibrium in the pre-shock phase than in the post-shock phase (see Figure 1) is consistent with this argument. Therefore, if we just reversed the sequence of the money supply, we would probably observe that adjustment is indeed quicker after the positive shock. Yet, this increase in the adjustment speed would not count as evidence for our explanation of the stickier expectations in the $\mathrm{NH}$.

What is, therefore, needed, is an experimental design in which the number of dominated strategies is roughly the same after the negative and after the positive shock. Our parameterization of the design with the positive shock serves this purpose. Except for three aspects, all experimental details in the positive-shock design are identical to the negative-shock design. In particular, all six features of the payoff functions, as described in section 3.2., are also present in the positive-shock design. The differences are the following: (i) We did not implement computerized players in the positive-shock design because the main purpose of this design was to observe whether the expectations of human players and, hence, also prices adjust more quickly to the equilibrium after a positive shock compared to the negative shock. (ii) In the positive-shock design the pre- and the post-shock phase consisted of 15 instead of 20 periods. This shortening of the phases was implemented because in the negative-shock design reliable equilibration was already achieved after 10-15 periods. (iii) To achieve roughly the same number of dominated strategies in the post-shock phase, equilibrium prices for $x$ - and $y$-types in the positive-shock design were as follows: The pre-shock equilibrium price for $x$-types $\left(y\right.$-types) is $P_{x}^{*}=11$ ( $P_{y}^{*}=$ 14) and the post-shock equilibrium price is $P_{x}^{*}=22\left(P_{y}^{*}=28\right)$. As a consequence, the average pre-shock equilibrium price in a group is $\bar{P}_{0}^{*}=12.5$ while in the post-shock equilibrium it is $\bar{P}_{1}^{*}$ $=25$. Thus, the difference in average prices between pre- and post-shock equilibrium is 12.5 in the positive-shock design while it is 12 in the negative shock design. This slightly bigger adjustment requirement in the positive shock design is, however, not a problem. If adjustment to 
equilibrium in the $\mathrm{NH}$ is faster after the positive shock, this is even more remarkable because it occurs despite the slightly bigger adjustment requirement in the positive shock design.

\subsection{Prices and expectations after the positive nominal shock}

Table 5 shows the evolution of pre- and post-shock average prices in the RH and the NH. In the NH pre-shock prices converge from above to the equilibrium $\bar{P}_{0}^{*}=12.5$ and as in the negative shock design the vast majority of individuals plays exactly the equilibrium in the final pre-shock period. Then, in the first post-shock period prices make a big jump upwards to 20.5 and already in period four after the shock average prices are almost exactly at the new equilibrium of $\bar{P}_{1}^{*}=25$. From that period onwards prices remain very close to the equilibrium. This contrasts sharply with the adjustment process after the negative shock where, throughout the whole postshock period, average prices never came so close to the equilibrium. This difference in NHadjustment paths after the negative and the positive shock is depicted in Figure 3. The heavy line in Figure 3 shows the difference in the post-shock deyiations of average prices from the equilibrium between the positive and the negative shock. ${ }^{18}$ The graph reveals to what extent in the NH the adjustment gap, i.e., the deviation of average prices from the equilibrium, is larger after the negative shock than after the positive shock. It shows that the deviation from equilibrium is substantially larger after the negative shock. Between period two and seven, e. g., the adjustment gap is four or more units bigger after the negative shock. Even in period ten the adjustment gap is still almost 3 units bigger.

\section{Insert Table 5 here}

\section{Insert Figure 3 here}

The impression conveyed by Figure 3 is confirmed by a more formal statistical analysis. If we perform regression (3) with the data after the positive shock, it turns out that in the $\mathrm{NH}$ the hypothesis of equilibrium play can only be rejected for the first three periods (at the five percent level). Remember that after the negative shock group prices were significantly above the equilibrium for twelve periods. Thus, the evidence unambiguously indicates that adjustment in the $\mathrm{NH}$ is much quicker after the positive shock, which is consistent with our hypothesis that there is less reluctance against adjustment after the positive shock.

\footnotetext{
${ }^{18}$ Let $\left(\bar{P}_{I+}^{*}-\bar{P}_{+}\right)$be the deviation of average prices from equilibrium in the positive-shock design and $\left(\bar{P}_{-}-\bar{P}_{1-}^{*}\right)$ the deviation in the negative-shock design. Then the heavy line in Figure 3 measures $\left(\bar{P}_{-}-\bar{P}_{l_{-}}^{*}\right)-\left(\bar{P}_{l_{+}}^{*}-\bar{P}_{+}\right)$for the first 15 periods of the post-shock phase in the NH.
} 
If there is indeed less reluctance against adjustment after the positive shock, at least some subjects should anticipate this. Therefore we should also observe that expectations are less sticky after the positive shock. The dashed heavy line in Figure 3 shows the differences in the average expectations about $\bar{P}_{-i}$ across shocks in the NH. Since this graph is constructed analogously to the previous graph it shows to what extent the adjustment gap in the expectations, i.e., the deviation of average expectations from equilibrium, is larger after the negative shock than after the positive one. The graph indicates that the adjustment gap in the expectations is much larger after the negative shock for many time periods. Interestingly, the graph is hump-shaped, i.e., the relative stickiness of expectations after the negative shock increases in the first few periods. This is due to the fact that between period two and five after the positive shock expectations rapidly converge to equilibrium while they are very sticky after the negative shock.

Finally, since the rule of thumb of taking nominal payoffs as a proxy for real payoffs cannot be operative in the $\mathrm{RH}$, we should observe no differences in price adjustment in the $\mathrm{RH}$ across negative and positive shocks. Table 5 shows the evolution of average prices in the RH after the positive shock and Figure 3 illustrates the differences in average prices and average expectations across shocks. Table 5 indicates that in the pre-shock phase of the RH the average price is very close to the equilibrium $\bar{P}_{0}^{*}=12.5$ already after three periods. Immediately after the positive shock there is a big upward jump in prices to 22.5 , only 2.5 units below the new equilibrium. Already in the third post-shock period the average price is again very close to the equilibrium. This indicates that price adjustment after the positive shock is rather quick in the RH - similar to the pattern after the negative shock. This similarity is also displayed in Figure 3 and by formal statistical analysis. The thin line in Figure 3 shows that price adjustment in the $\mathrm{RH}$ is only slightly faster after the positive shock. If we perform regression (3) with the post-shock data from the positive-shock design we get the following results: The hypothesis that average prices in the $\mathrm{RH}$ are in equilibrium can only be rejected for the first two periods (at the five percent level). Note that this is exactly the same number of out-of-equilibrium periods as after the negative shock. This suggests that the differences in the price adjustment across shocks in the RH are indeed negligible. The dashed thin line in Figure 3 indicates that we can basically make a similar conclusion with regard to the differences in the adjustment of expectations across shocks. While in the NH there are large differences in the stickiness of expectations across shocks, in the RH the differences in expectations are rather small.

Thus all major regularities are consistent with our hypothesis that there are beliefs that some subjects take nominal payoffs as a proxy for real payoffs. Nonetheless, it would be reassuring if subjects themselves expressed such a belief. To check to what extent subjects indeed 
believed this they could indicate their degree of agreement with the following statement after the experiment: "I believed that the other subjects would interpret high nominal payoffs as an indicator for high real payoffs". Participants could indicate whether they weakly (dis)agreed, whether they strongly (dis)agreed or whether they totally (dis)agreed with this statement. 30 percent of the subjects in the NH agreed either "strongly" or "totally" and further 25 percent indicated a weak agreement. In our view, this can be taken as direct evidence for the presence of a belief that other subjects are affected by money illusion. In any case, these answers nicely fit with our explanation for the large amount of nominal inertia observed in the $\mathrm{NH}$ after the negative shock.

\section{Summary and concluding remarks}

Most economic transactions are represented in nominal terms. Therefore, it seems likely that people often perceive and think about economic problems in nominal terms which may induce money illusion. However, for several decades money illusion has been considered as largely irrelevant for the nominal inertia of aggregate price levels. Instead, most economists have focused on informational frictions, costs of price adjustment and staggered contracts. This paper shows, however, that even in the absence of these factors a fully anticipated negative nominal shock can cause long-lasting nominal inertia that is associated with large real income losses during the adjustment phase. Our results indicate that a large part of this nominal inertia can be attributed to the direct and indirect effects of money illusion. The experiments in the setting with computerized opponents show that the direct effects of money illusion in the form of individual optimization mistakes are not very frequent: The introduction of the nominal frame in the setting with computerized opponents causes only a small amount of nominal inertia. However, the combined direct and indirect effects of money illusion generate a very large increase in nominal inertia. This is indicated by the fact that the introduction of the nominal frame in the setting with human opponents causes a huge increase in the sluggishness of prices. Instead of two it takes twelve periods until average prices reach the post-shock equilibrium in this setting.

The major cause for nominal inertia after the negative shock is that subjects' expectations are very sticky. In our view this stickiness of price expectations is related to the nature of money illusion in our experiment, i.e., to the belief that there are subjects who take nominal payoffs as a proxy for real payoffs. This conjecture is supported by direct questionnaire evidence and by the results of further experiments with a fully anticipated positive nominal shock. It turns out that price sluggishness is much smaller after a positive nominal shock than after the negative shock. 
This result is also interesting insofar as there is field evidence indicating that positive and negative money shocks have asymmetric effects. While negative shocks have an output reducing effect, positive shocks do not seem to affect output (Cover 1992, De Long and Summers 1988). The asymmetric effects of money illusion on price sluggishness can be considered as a potential micro-foundation for this result.

Finally, another interesting result of our experiments is that we isolate - in addition to money illusion - a further source of nominal inertia that has been largely neglected by economists. This source of nominal inertia is related to the fact that in a strategic situation subjects do not merely face an individual optimization problem but that they also have to predict other agents' behavior. After any shock, the new equilibrium can only be achieved if subjects have equilibrium expectations, i.e., if they have coordinated expectations. The comparison of adjustment paths in the real treatments with computerized and with human opponents shows that after a fully anticipated nominal shock, it cannot be taken for granted that subjects instantaneously succeed in solving this coordination problem. They will, in general, go through a period of disequilibrium that is associated with nominal inertia. Note, however, that the coordination problem alone causes substantially less nominal inertia than money illusion. It also does not cause asymmetric effects: In the real treatment with human opponents the extent of nominal inertia is very similar after the positive and the negative nominal shock.

In our view the results of our experiments suggest that money illusion should be considered as a serious candidate in the explanation of nominal inertia and the real effects of nominal shocks. Paraphrasing Abraham Lincoln , one can say that, to render money illusion behaviorally relevant, it is not necessary to fool all the people some of the time, not to speak of fooling all the people all the time. All that is needed is the presence of a small amount of money illusion at the individual-level - a presupposition that seems quite plausible.

${ }^{19}$ In his speech on 8 Sept. 1858 A. Lincoln said: "You can fool all the people some of the time, and some of the people all the time, but you cannot fool all the people all the time." 


\section{References}

Abbott, M. and Ashenfelter, O. (1976): Labor Supply, Commodity Demand and the Allocation of Time. Review of Economic Studies, 43(3): 389-411.

Akerlof, G.A. and Yellen, J.L. (1985): A Near Rational Model of the Business Cycle, with Wage and Price Inertia. Quarterly Journal of Economics, 100: 823-38.

Akerlof, G.A.; Dickens, W.T. and Perry, G.L. (1996): The Macroeconomics of Low Inflation. Brookings Papers on Economic Activity, (1): 1-76.

Ball, L. and Romer, D. (1987): Sticky Prices as a Coordination Failure. New York University. Mimeo.

Belongia, M.T. (1996): Measurement Matters: Recent Results from Monetary Economics Reexamined. Journal of Political Economy, 104(5): 1065-83.

Bernanke, B.S. and Carey, K. (1996): Nominal Wage Stickiness and Aggregate Supply in the Great Depression. Quarterly Journal of Economics, 111: 853-84.

Bewley T. F. (1998): Why Not Cut Pay?. European Economic Review; 42(3-5), 459-490.

Blanchard, O.J. (1990): Why does Money affect Output? A Survey. In: B.M. Friedman and F.M. Hahn (eds.): Handbook of Monetary Economics, Vol. 2, North-Holland: Amsterdam: 779835.

Blanchard, O.J. and Kiyotaki, N. (1987): Monopolistic Competition and the Effects of Aggregate Demand. American Economic Review, 77(4): 647-66.

Blinder, A. S. and Choi, D. H. (1990): A Shred of Evidence on Theories of Wage Stickiness. Quarterly Journal of Economics, 105: 1003-1016.

Blinder, A. S., E. D. Canetti, D. E. Lebow, and J. B. Rudd (1998): Asking about Prices - A New Approach to Understanding Price Stickiness, Russel Sage Foundation, New York.

Bryant, J. (1983): A Simple Rational Expectations Keynes-Type Model. Quarterly Journal of Economics, 98(Aug.): 525-8.

Card, D. and Hyslop D. (1998): Does Inflation 'Grease the Wheels of the Labor Market'? in: C.D. Romer and D.H. Romer (eds.): Reducing Inflation. Motivation and Strategy. University of Chicago Press.

Coleman, W.J. (1996): Money and Output: A Test of Reverse Causation. American Economic Review, 86(1): 90-111.

Cooper, R.W. and Haltiwanger, J. (1993): Evidence on Macroeconomic Complementarities. NBER Working Paper no. 4577.

Cover, J. P. (1992): Asymmetric Effects of Positive and Negative Money-Supply Shocks. Quarterly Journal of Economics, 107, 1261-1282.

De Long, J. B. and Lawrence Summers (1988): How does Macroeconomic Policy affect Output? Brookings Papers on Economic Activity, 2, 433-480.

Diamond, P.A. (1982): Aggregate Demand Management in Search Equilibrium. Journal of Political Economy, 90(Oct.): 881-94.

Fischer, S. (1977): Long-Term Contracts, Rational Expectations, and the Optimal Money Supply Rule. Journal of Political Economy, 85 (1): 191-205.

Fisher, I. (1928): The Money Illusion. Longmans: Toronto.

Friedman, B.M. and Hahn, F.M. (1990): Handbook of Monetary Economics. Vol. 2, NorthHolland: Amsterdam.

Haltiwanger, J. and Waldman, M. (1985): Rational Expectations and the Limits of Rationality: An Analysis of Heterogeneity. American Economic Review, 75(3): 326-40.

Haltiwanger, J. and Waldman, M. (1989): Rational Expectations and Strategic Complements: The Implications for Macroeconomics. Quarterly Journal of Economics, 104 (August): 463-84. 
Hoover, K.D. and Perez, S.J. (1994): Post hoc ergo propter hoc once more: An evaluation of 'Does Money Matter?' in the spirit of James Tobin. Journal of Monetary Economics, 34: 7588.

Howitt, P. (1989): Money Illusion. In: J Eatwell, M. Milgate and P. Newman (eds.): Money. W. W. Norton: New York, London: 244-247.

Kahn, S. (1997): Evidence of Nominal Wage Stickiness. American Economic Review, 88(5): 9931008 .

Leontief, W. (1936): The Fundamental Assumptions of Mr. Keynes' Monetary Theory of Unemployment. Quarterly Journal of Economics, 5(Nov.): 192-197.

Lucas, R.E. Jr. (1972): Expectations and the Neutrality of Money. Journal of Economic Theory, 4(April): 103-24.

Mankiw, N.G. (1985): Small Menu Costs and Large Business Cycles: A Macroeconomic Model of Monopoly. Quarterly Journal of Economics, 100(May): 529-537.

Mankiw, N.G. and Romer, D.H. (eds.) (1991): New Keynesian Economics. Vol. 1 \& Vol. 2, MIT Press: Cambridge, MA.

Niemi B. and Lloyd B. (1981): Female Labor Supply in the Context of Inflation. American Economic Review, 71(2): 70-75.

Oh, S. and Waldman, M. (1990): The Macroeconomic Effects of False Announcements. Quarterly Journal of Economics, 105(5): 1018-33.

Oh, S. and Waldman, M. (1994): Strategic Complementarity Slows Macroeconomic Adjustment to Temporary Shocks. Economic Inquiry, 32(April): 318-29.

Patinkin, D. (1949): The Indeterminacy of Absolute Prices in Classical Economic Theory. Econometrica 17(1): 1-27.

Romer, C.D. and Romer, D.H. (1989): Does monetary policy matter? A new test in the Spirit of Friedman and Schwartz. NBER Macroeconomics Annual 4 : 121.

Romer, C.D. and Romer, D.H. (1994): Monetary Policy Matters. Journal of Monetary Economics, 34: 75-88.

Russell, T. and Thaler, R.H. (1985) The Relevance of Quasi-Rationality in Competitive Markets. American Economic Review, 75(5): 1071-82.

Selten, R. and Berg, C.C. (1970): Drei experimentelle Oligopolserien mit kontinuierlichem Zeitablauf, in: H. Sauermann (ed.): Beiträge zur experimentellen Wirtschaftsforschung, Vol. II, Tübingen: 162-221.

Shafir, E.; Diamond, P.A. and Tversky, A. (1997): On Money Illusion. Quarterly Journal of Economics, 112(May): 341-74.

Taylor, J.B. (1979): Staggered Wage Setting in a Macro Model. American Economic Review, 69(2): 108-113.

Tobin, J. (1972): Inflation and Unemployment. American Economic Review, 62: 1-18.

Tversky, A. and Kahneman, D. (1981): The Framing of Decisions and the Psychology of Choice. Science 211: 453-8. 


\section{Appendices}

Appendix A Functional specification of payoffs

Appendix B Instructions for experimental subjects

Appendix C Payoff Tables for negative shock

Appendix D Payoff Tables for positive shock

Appendix E Response Rule for computerized agents

Appendix F Tables and Figures 


\section{Appendix A - Functional specification of payoffs}

As explained in detail in section 3.2 our specification of subjects' payoff functions served several purposes. A particularly important purpose was to rule out that the adjustment to the equilibrium is confounded by subjects' attempts to achieve real payoff gains by nonequilibrium behavior. Note that this purpose rules out payoff functions that are derived from oligopolistic or monopolistic competition among firms. We achieved our aim by the payoff functions below because they imply that the equilibrium is the only efficient point in payoff space.

Note also that the equilibrium price for each individual $i$ is a best reply not only to the equilibrium expectation for $\bar{P}_{-i}$ but also to out-of-equilibrium expectations that are close to the equilibrium expectation (see also payoff tables in Appendix C and D below). This feature of the payoff functions speeds up adjustment to equilibrium because it ensures that the equilibrium price choice is also a best reply for expectations that are not exactly in equilibrium. The arctan-function in the denominator reflects this property of the payoff functions.

The real payoff for agent $i$ of type $k=x, y$ is given by: 


\section{Appendix B Instructions}

The original instructions were in German. This section reprints a translation of the instructions used in the Nominal treatment with human opponents for agents of type $y$.

\section{General instructions for participants}

You are participating in a scientific experiment which is funded by the Swiss National Science Foundation. The purpose of this experiment is to analyze decision making in experimental markets. If you read instructions carefully and take appropriate decisions, you may earn a considerable amount of money. At the end of the experiment all the money you earned will be immediately paid out in cash.

Each participant is paid SFr.15.- for showing up. During the experiment your income will not be calculated in Swiss Francs but in points. The total amount of points you collected during the experiment will be converted into Swiss Francs, by applying the following exchange rate:

\section{Points $=15$ centimes.}

Here is a brief description of the experiment. A more detailed description is given below. All participants are in the role of firms, selling some product. In this experiment, there are two types of firms: firms of type $x$ and firms of type $y$. Each firm has to choose a selling price in every period. The income you earn depends on the price you choose and on the prices all other firms choose.

During the experiment you are not allowed to communicate with any other participant. If you have any questions, the experimenters will be glad to answer them. If you do not follow these instructions you will be excluded from the experiment and deprived of all payments.

The following pages describe the procedures of the experiment in detail.

\section{Detailed information for firms of type $y$}

This experiment lasts 20 periods plus one trial period. You are not paid for the trial period. You should nevertheless take the trial period seriously since you may gain experience in this period. This experience helps you to take decisions in the other periods which are paid out. You are in the role of a firm, just as all other participants in this experiment. All participants are in groups of 4 , i.e. every participant is in a group with three other firms. There are two firms of type $x$ and two firms of type $y$ in every group.

\section{You are a firm of type $y$}

Consequently, there are two other firms of type $x$ and one more firm of type $y$ in your group. No participant knows which persons are in his or her group. Yet, everybody knows that the group composition remains constant throughout the experiment. The decisions taken by other groups are irrelevant for your group. 
In every period all firms simultaneously decide which selling price they set for the current period. Every firm has to choose an integer price from the interval $1 \leq$ selling price $\leq 30$.

How much you earn depends on the price you choose and on the average price of all other firms in your group. Independent of the type, the average price for every firm is calculated by the following formula:

$$
\text { Average price }=(\text { Sum of selling prices of other } 3 \text { firms }) / 3
$$

Consequently, the average price will be in the interval $1 \leq$ selling price $\leq 30$.

The average price is rounded to the next integer number.

\section{How to read the income table for a firm of type $y$}

The green income table shows your nominal income in points if you choose a specific price and a specific average price results in this period (see separate table). Your income at the end of the experiment is not based on nominal point income, but on real point income. The following relation between the two holds:

\section{Real income $=$ Nominal income $/$ Average price of other firms}

This formula holds for all firms. The real point income that will be paid out is rounded in every period to the next integer number.

\section{Example:}

Suppose, you choose a price of 2 and the actual average price is 4 . In this case your nominal point income is 29 points. Your (rounded) real income is 7 points $(=29 / 4)$.

When you decide which price to choose, you do not yet know which average price will actually result in this period. The green income table can consequently help you to calculate your real point income given your expectation on the average price of other firms.

Example:

Given an expectation on the average price you can read off the green table the payoff you get when choosing different selling prices. For example, if you expect an average price of 30 and choose a price of 17, your expected nominal income is 141 points, your expected real income is 5 points $(=141 / 30)$. If you choose a price of 10 at this expected price, your expected nominal income is 86 points, your expected real income 3 points $(=86 / 30)$.

Please note that you are in a group with one firm of type $y$ and two firms of type $x$. To determine the income of the other firm of type $y$, you have to use the green table. To determine the income of the other two firms of type $x$, you have to use the blue income table. This table also shows nominal income in points. The same formula above is used to calculate real payoffs for firms of type $x$.

\section{What the screens show}

On both screens described below the current period is indicated in the upper left corner, and the upper right corner displays remaining time in seconds to decide or to view the screen.

The upper half of the input screen (see figure on next page) has three cells, where you can enter data into the computer. 
Price decision: Enter an integer number between 1 and 30 into the first cell. You can activate this cell (as well as the other cells) by clicking into the cell with your mouse. If you want to revise your decision, you can erase the number by hitting the backspace key.

Expected average price: Enter an integer number between 1 and 30 into the second cell. This input does not affect your income and will not be known to other firms. Your payoff will be determined by the actual average price of this period. Please try to indicate an expectation that is as exact as possible since this is going to help you to take your own price decision.

Confidence: Enter an integer number from 1 to 6 to indicate how confident you are that the average price you expect (= number in the second cell) will actually result.

The numbers stand for:

$1=\mathrm{I}$ am not at all confident that my expectation will be correct

$2=\mathrm{I}$ have not much confidence that my expectation will be correct

$3=\mathrm{I}$ am not quite confident that my expectation will be correct

$4=\mathrm{I}$ am quite confident that my expectation will be correct

$5=\mathrm{I}$ am very confident that my expectation will be correct

$6=\mathrm{I}$ am absolutely confident that my expectation will be correct

When you finished entering the numbers into the respective cells, press the OK-button. Once you have pressed the button, you cannot revise your decision any more for this period.

Figure B1: Input screen

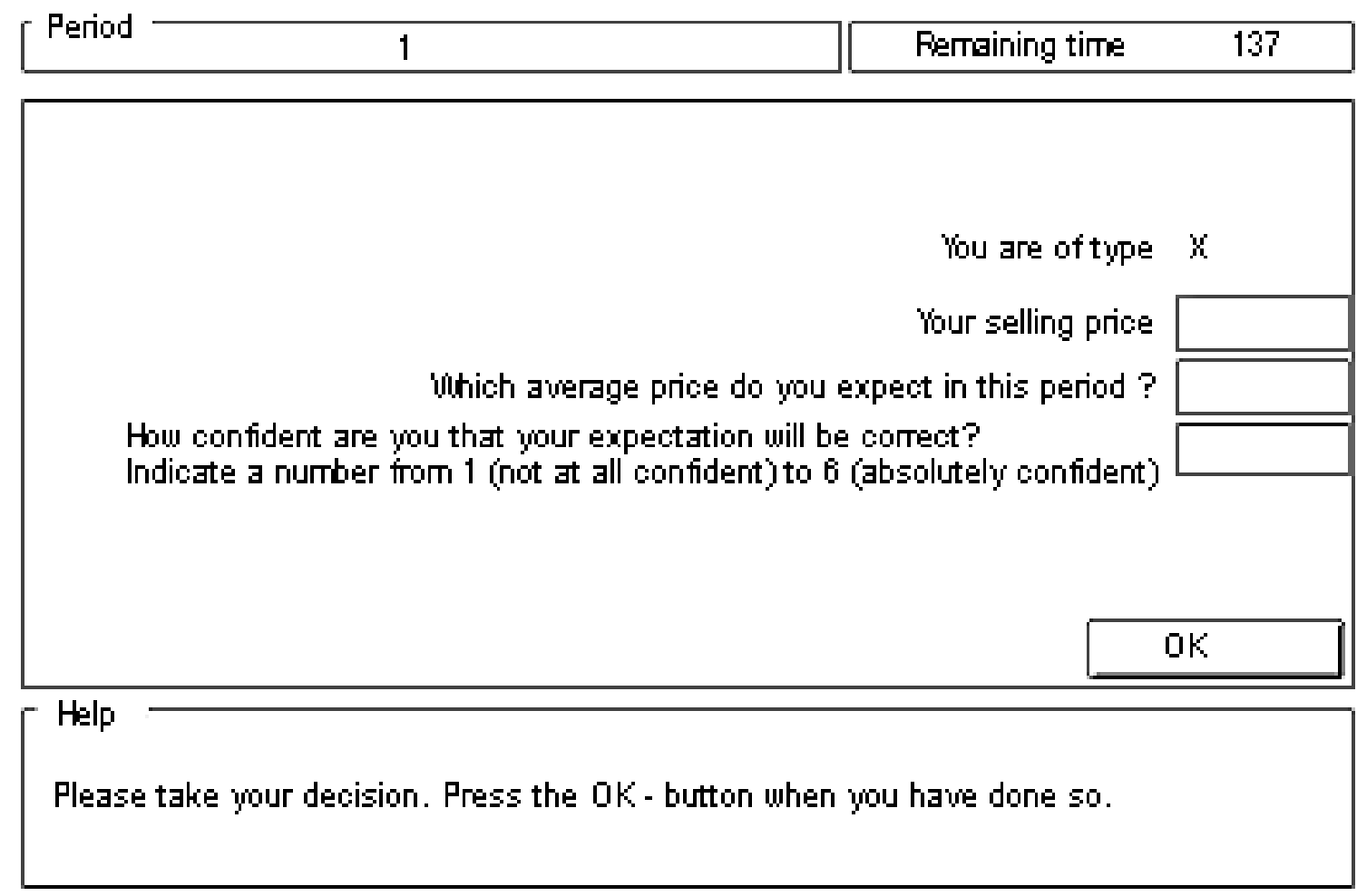

As soon as all firms have decided on their prices, the outcomes of this period will be shown in the outcome-screen. 
The upper part of this screen shows the outcomes of the current period. This screen shows your decision of the current period, the average price, your real income of this period, and your total real payoff.

The lower part of this screen displays the outcomes of past periods.

Figure B2: Outcome screen

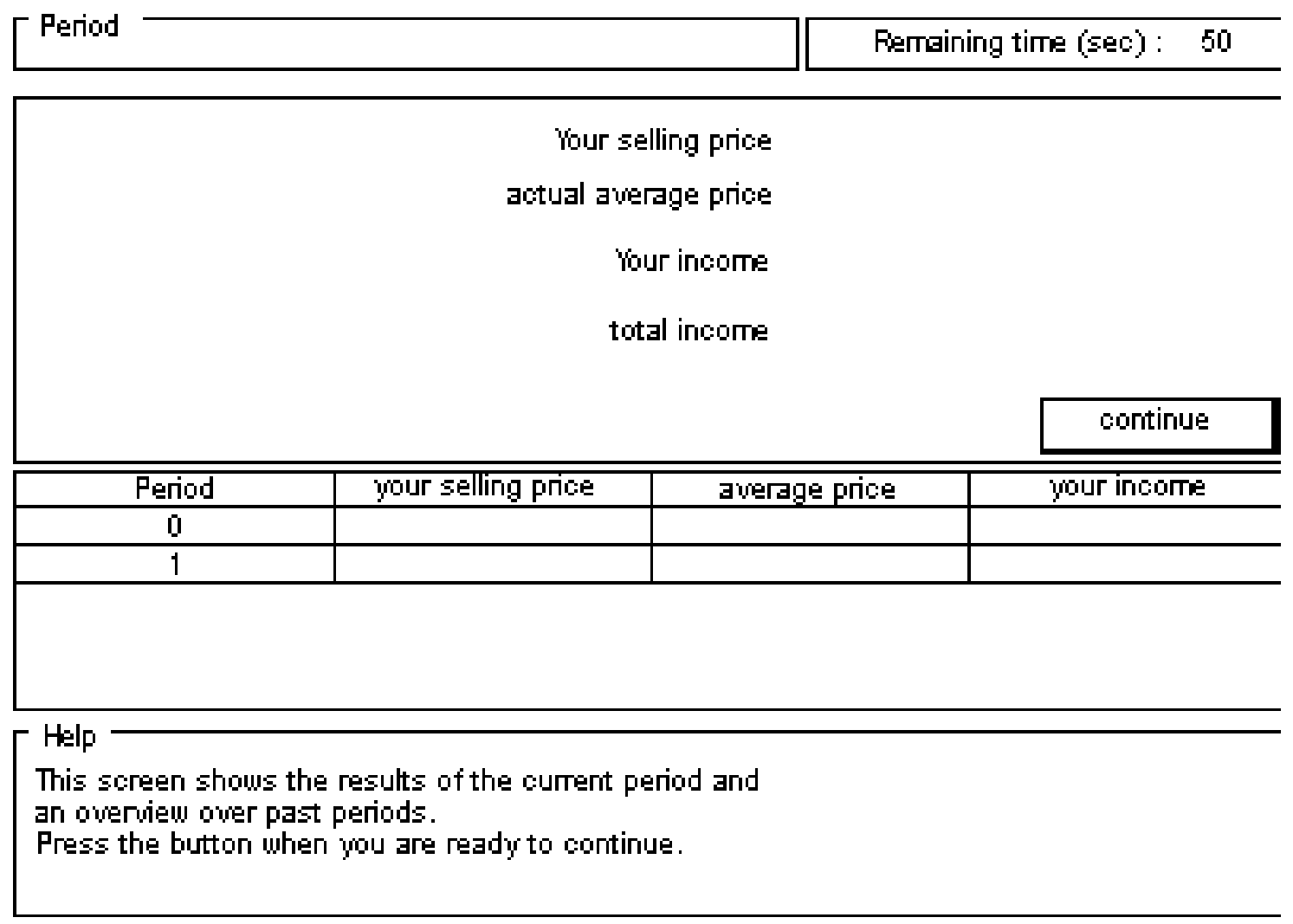

\section{Overview: What you have to do in every period.}

In every period every firm has to choose a price. Every integer price from 1 to 30 can be chosen $(1 \leq$ selling price $\leq 30)$

- Enter your price decision into the first cell of the input screen.

- Enter into the second cell the average you expect for this period

$(1 \leq$ selling price $\leq 30)$

- Enter your confidence in your price expectation into the third cell (numbers 1 to 6).

When you have completed the three cells, press the OK-Button. The remaining time to take your decisions is shown in the upper right corner of the screen.

When all participants have taken their decisions, or when the time has elapsed, all participants are shown the outcome screen. This screen shows your decisions, actual average prices and your real payoff in points for the current and the past periods. 
To take your decisions the following aids are at your disposition:

Green income table: Helps you to estimate your expected nominal point income (You are a firm of type $y$ ). Your payoff is determined by your real income in points.

You can calculate your real income from the nominal income (= numbers shown in the income table) by applying the following formula:

\section{Real income $=$ Nominal income $/$ Average price of other firms}

Blue income table: Helps to estimate the nominal point income of the firms of type $x$ in your group. The payoff of these firms are also determined by their real point income. To calculate the real income of firms of type $x$, you also apply the formula above.

Outcome screen: Displays your selling price, the actual average price and your real income for the present and the past periods.

Do you have any questions?

\section{Control questions}

You have to answer all of the following questions. If you do not answer a question, you will be excluded from the experiment and all payments. Wrong answers do not have any consequences. If you have any questions, please ask us.

1. Please indicate an expectation for the average price of other firms from 1 to 30. Expected average price

2. Please indicate a selling price from 1 to 30 .

Selling price

3) What is your expected nominal income in points at the prices you indicated in 1) and 2)?

Your nominal income

4. What is your expected real income in points at the prices you indicated in 1) and 2)? Your real income

5. Suppose you choose a price of 1 . The other firm of type $y$ chooses a price of 30 . The first firm of type $x$ chooses a price of 7 and the second firm of type $x$ chooses a price of 23.

a) What is your average price at the (fictitious) prices?

What is your nominal income?

What is your real income?

b) What is the average price of the other firm of type $y$ ?

What is the nominal income of this firm?

What is the real income of this firm?

c) What is the average price of the first firm of type $x$ ? 
What is the nominal income of this firm?

What is the real income of this firm?

d) What is the average price of the second firm of type $x$ ?

What is the nominal income of this firm?

What is the real income of this firm? 


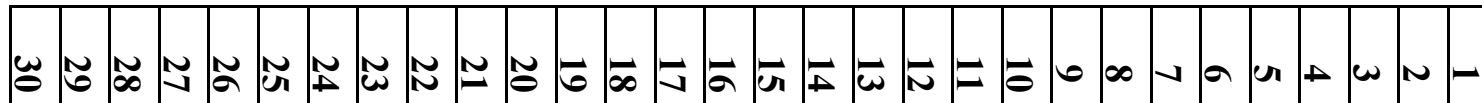

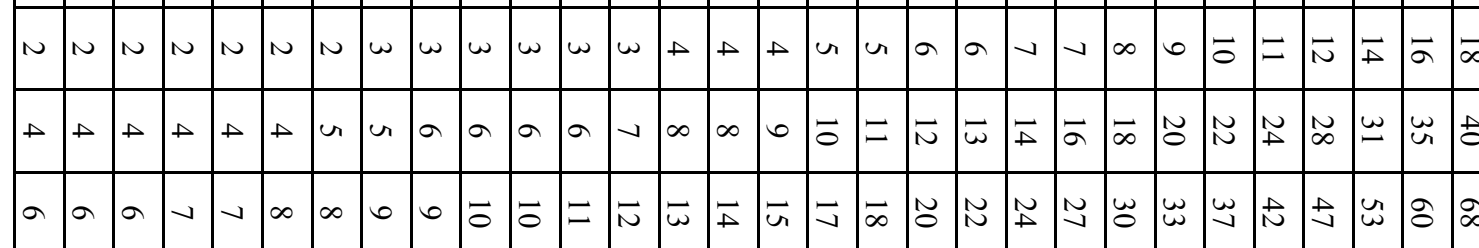

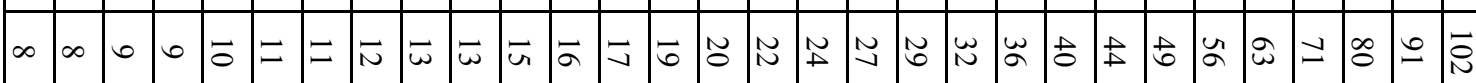

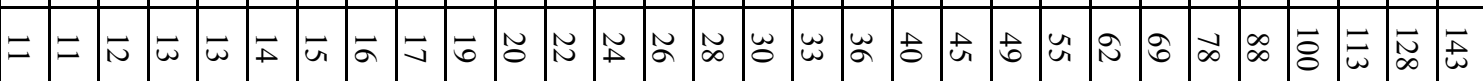

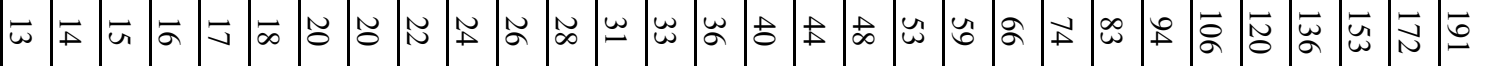

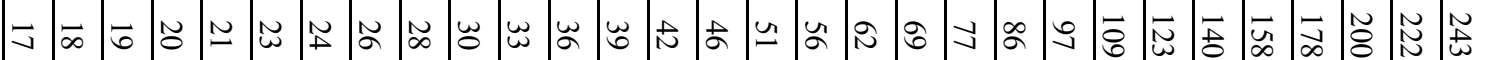

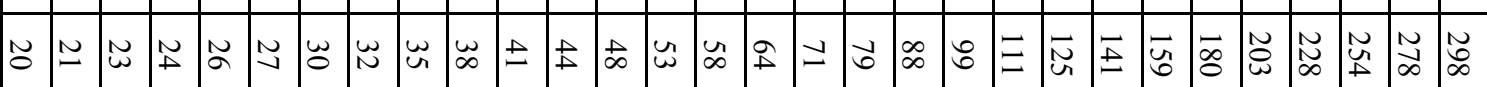

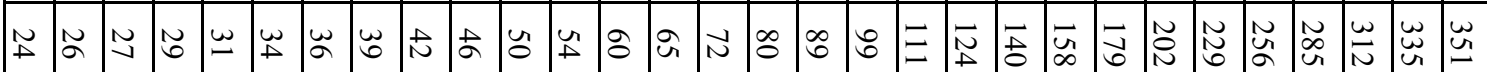

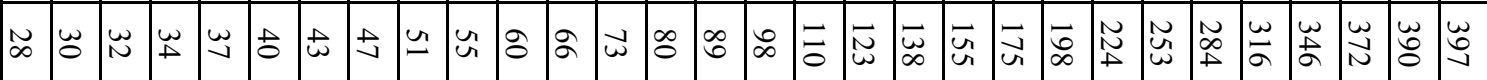

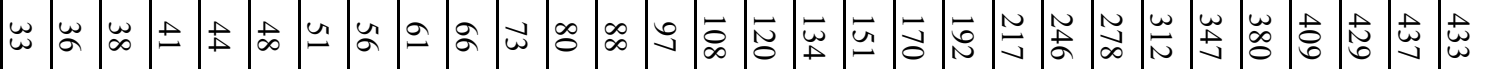

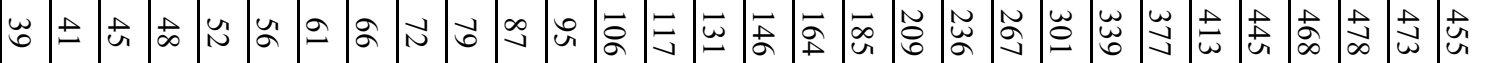

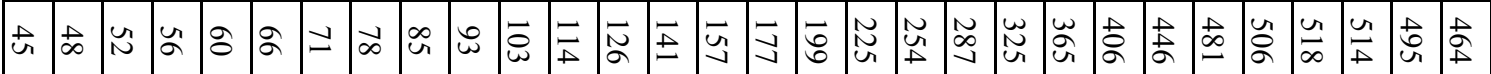
心 ư

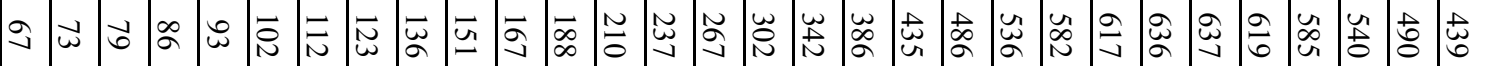

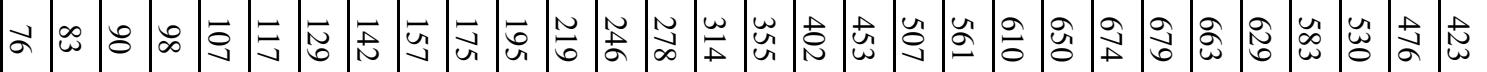

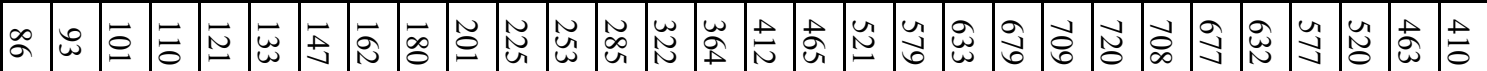

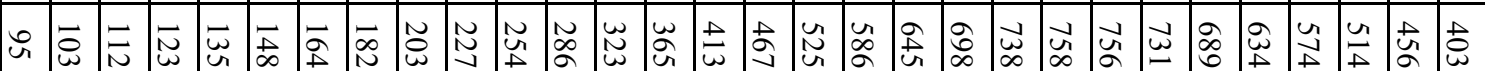

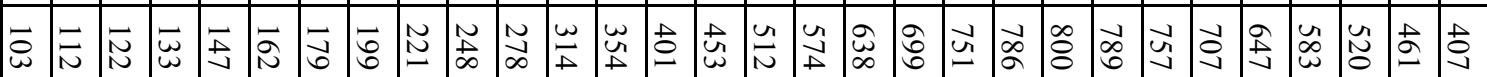

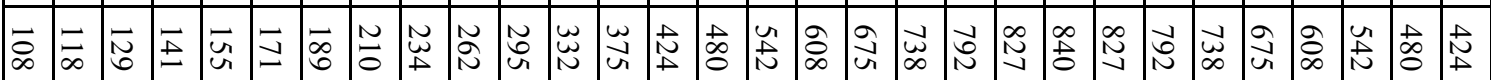

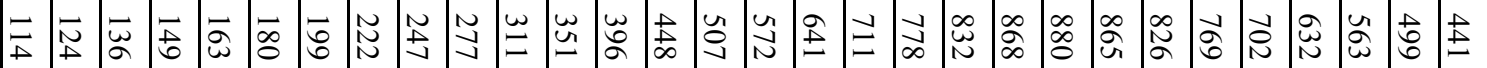

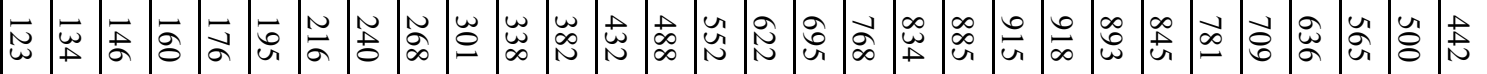

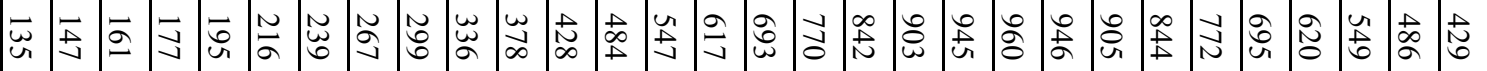

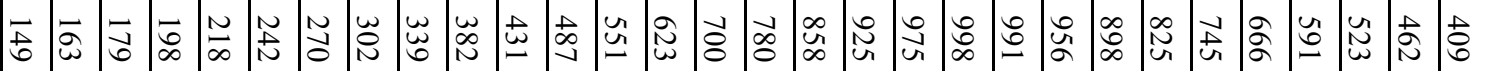

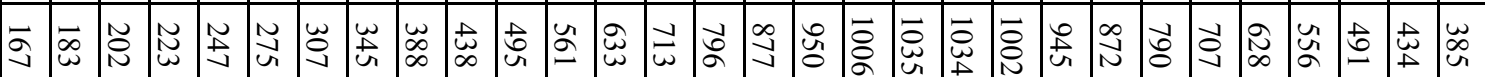

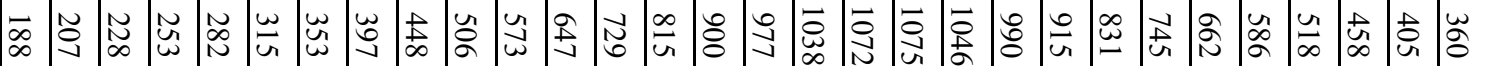

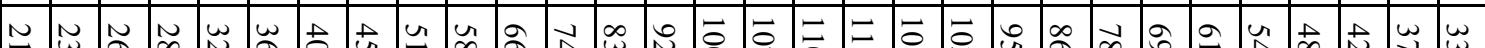

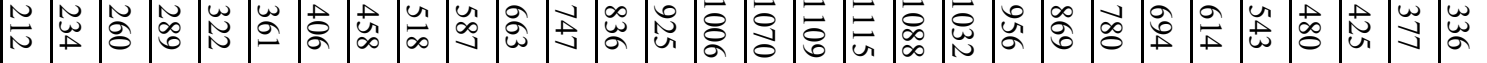

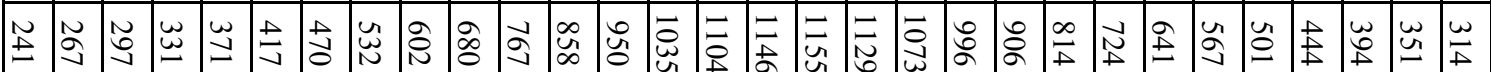

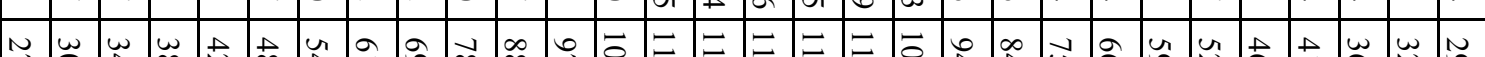

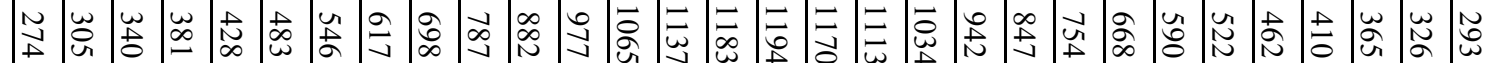




\section{岗}

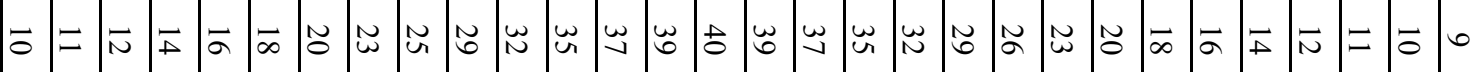

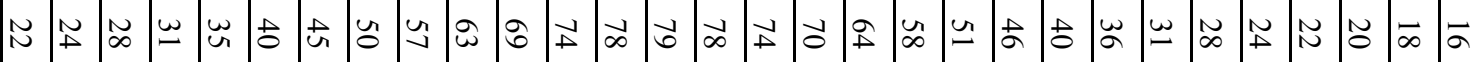

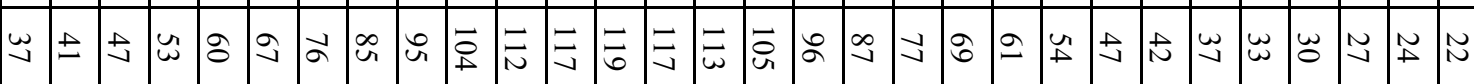
ư

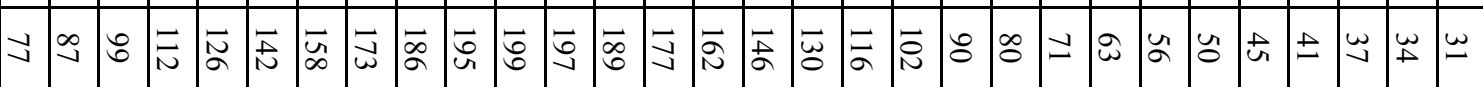

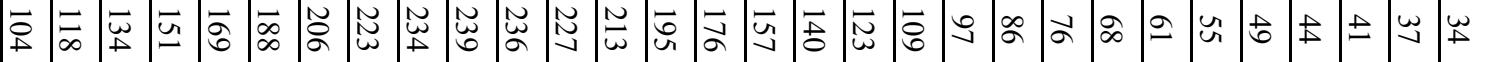

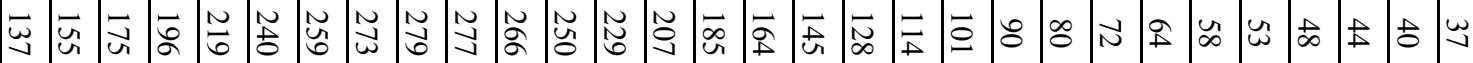

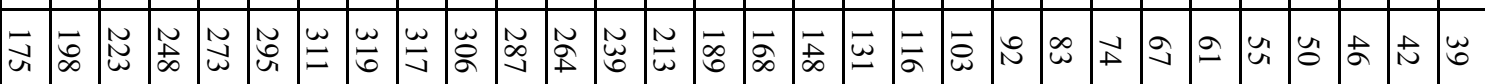

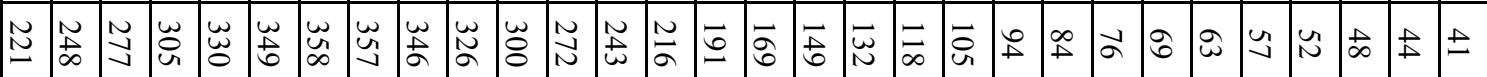

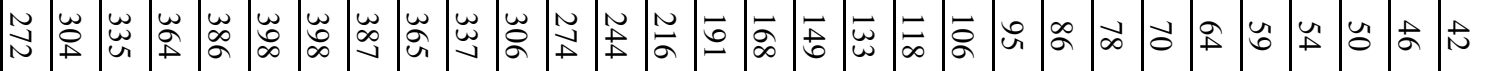

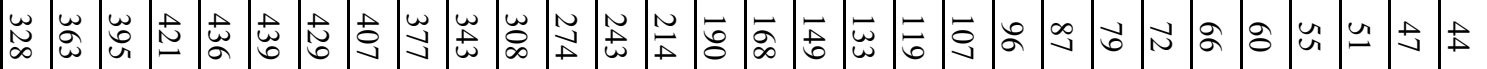

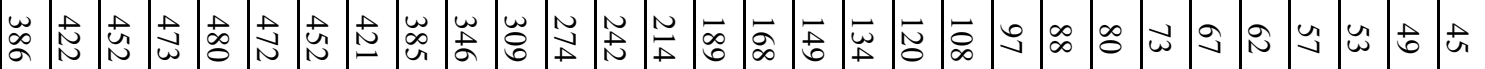

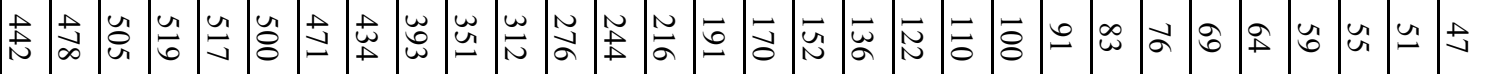

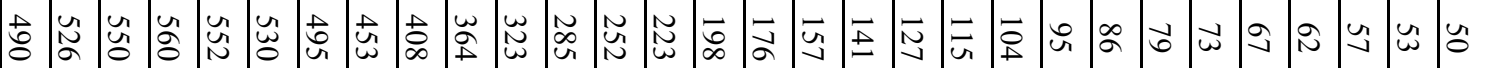
岕

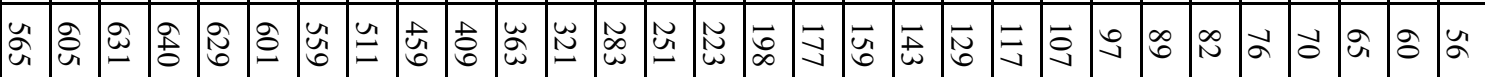

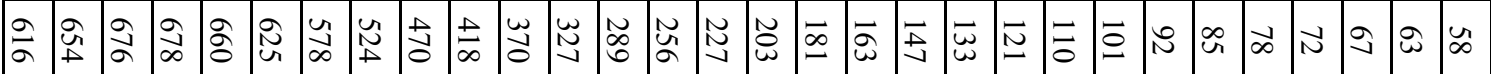

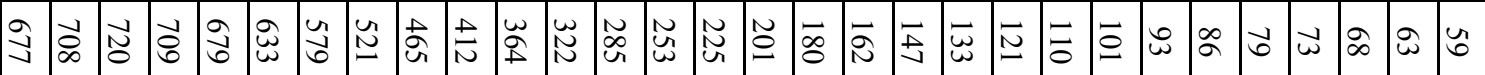

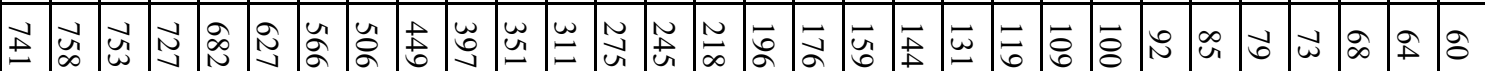

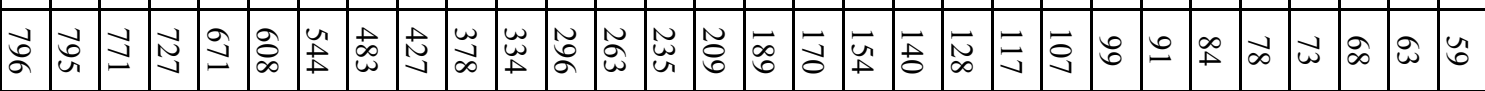

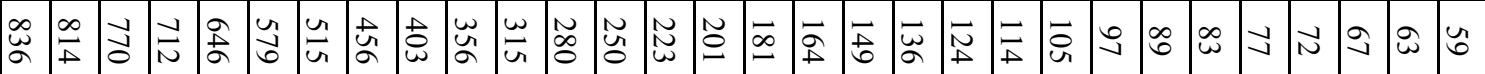

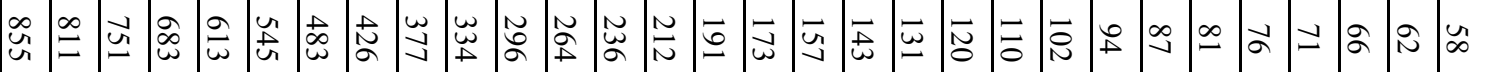

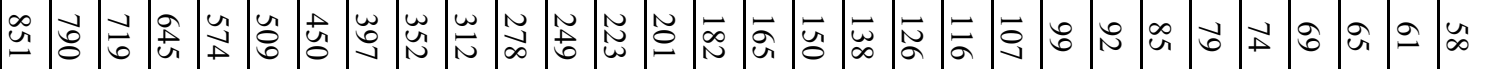

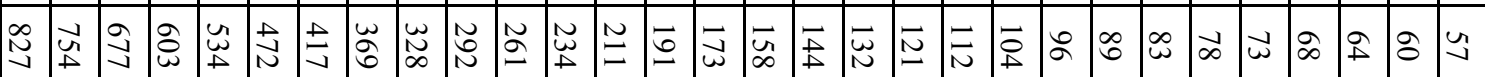

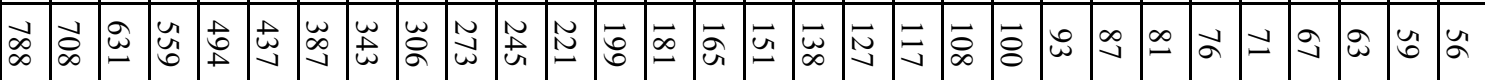
岕

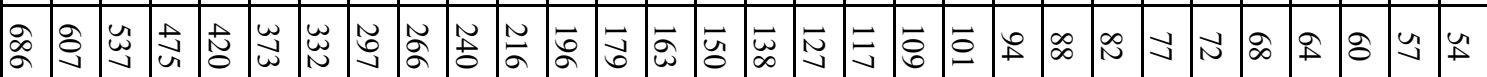

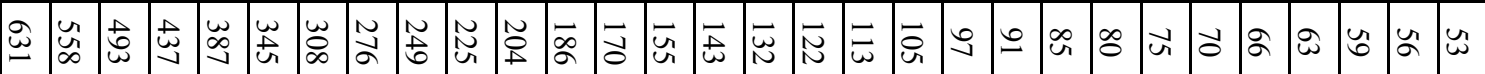

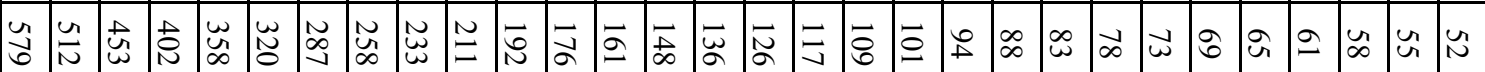

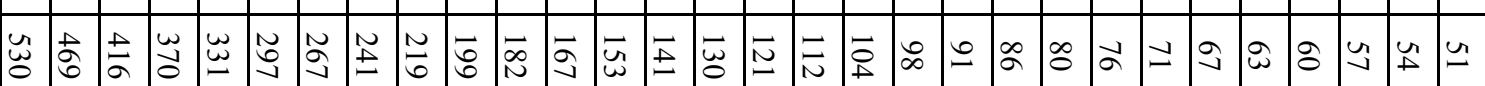


N N N N N N N N N n n $n$ N n $n$ N

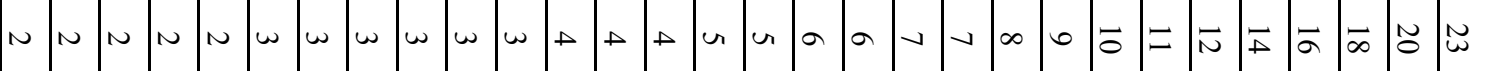

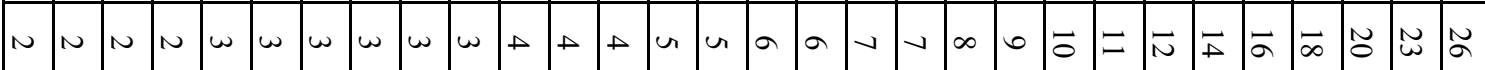

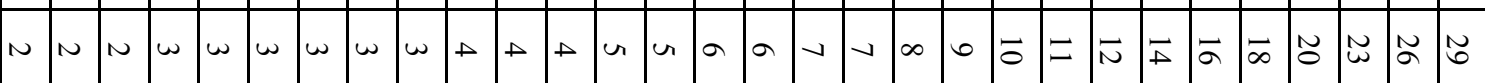

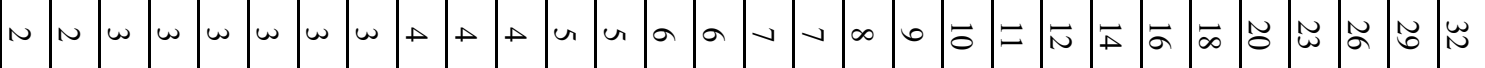

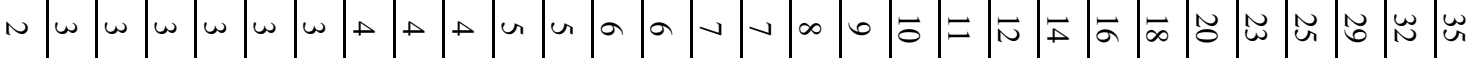

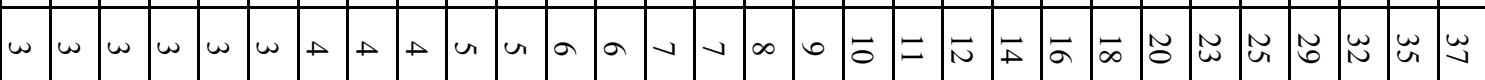

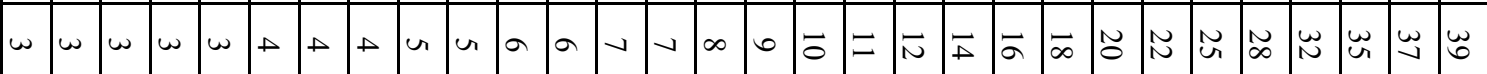

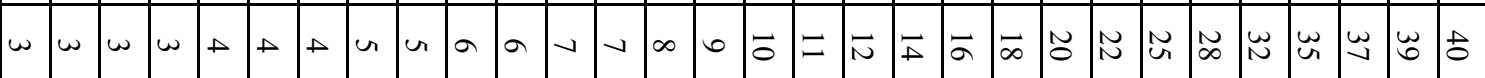

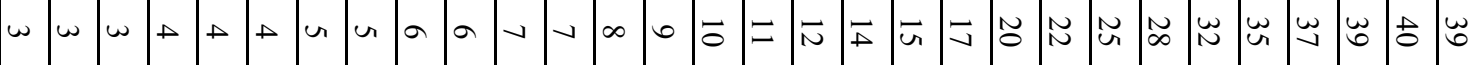

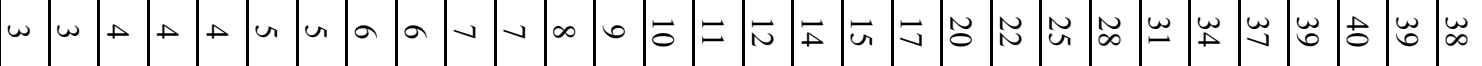

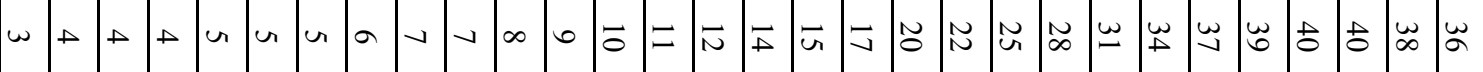

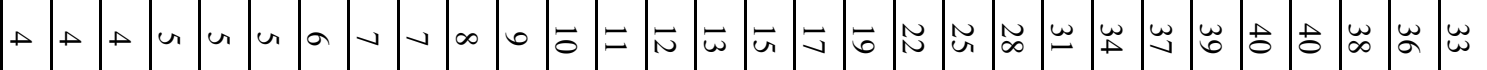

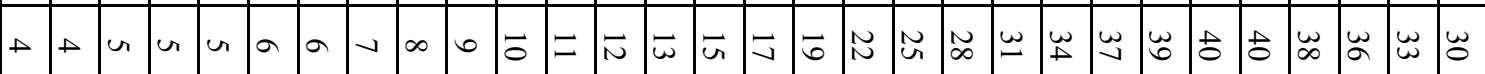
- ur un un a $a$ v

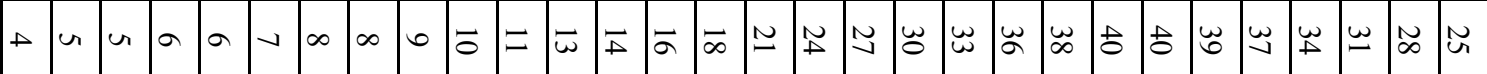
u u

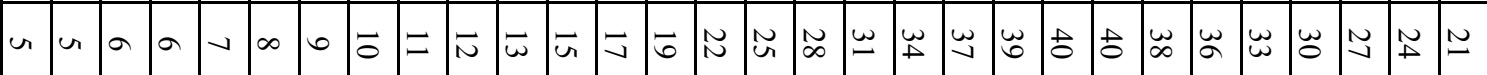

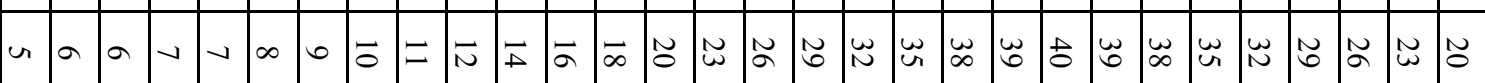

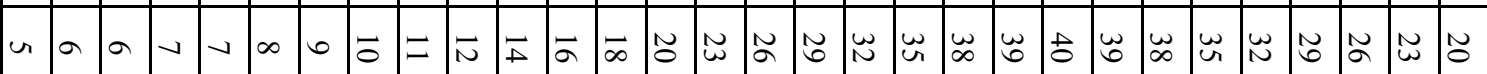

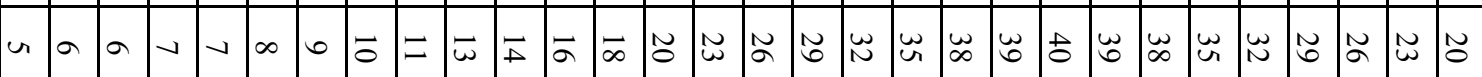
u

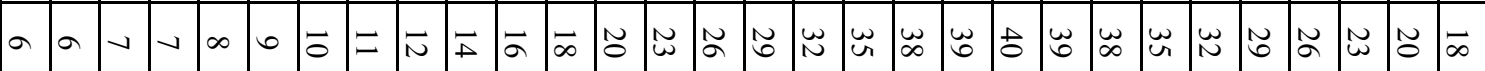

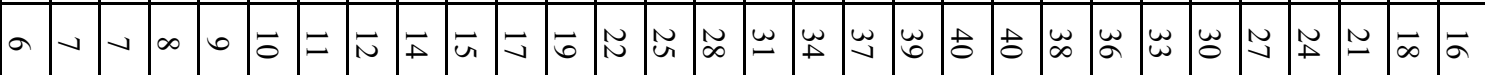

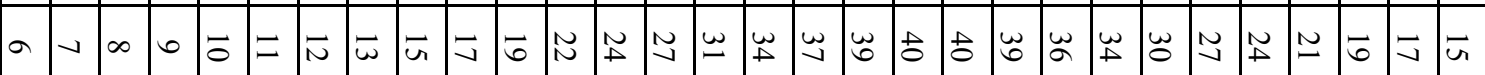

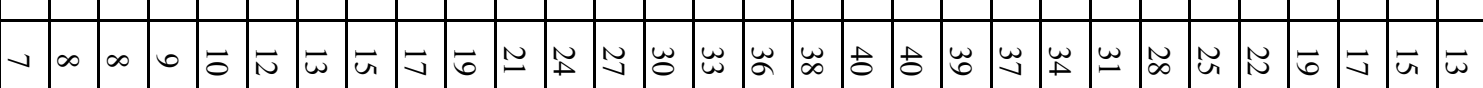

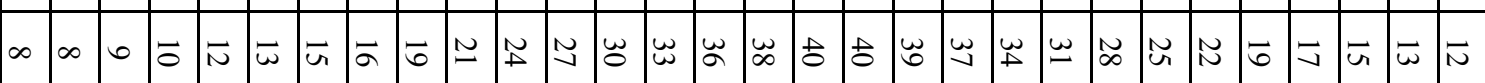

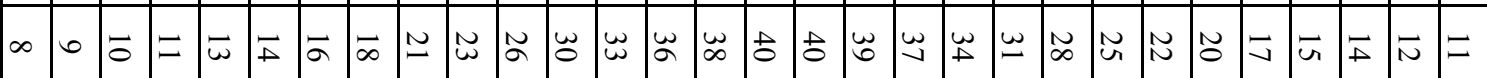

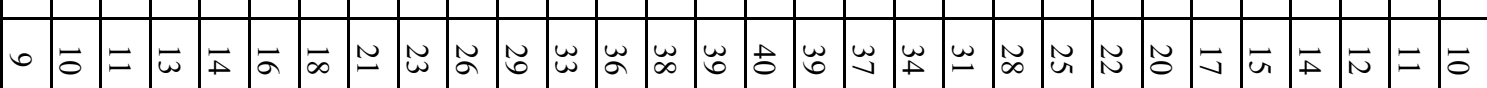




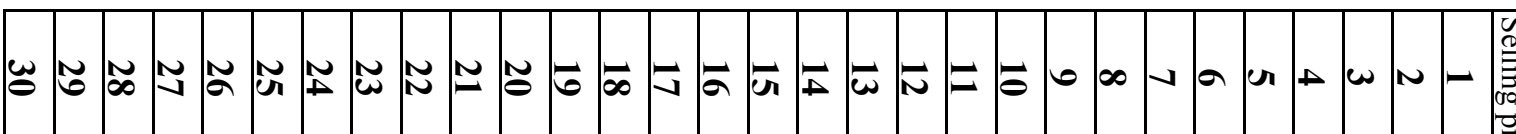

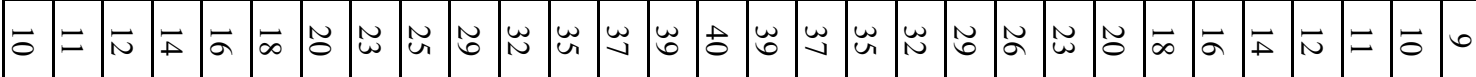

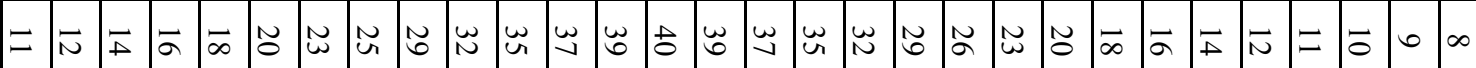

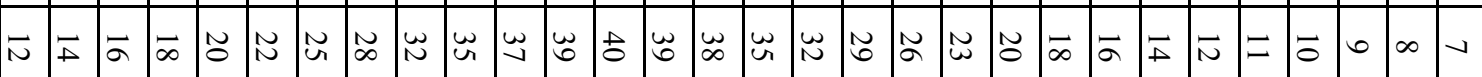

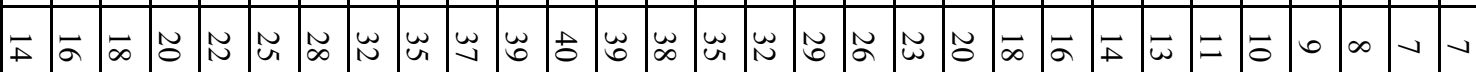

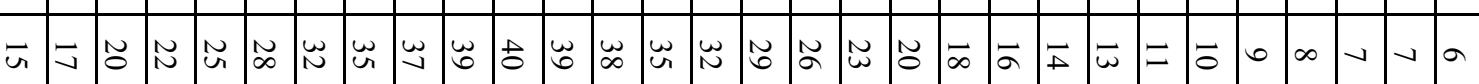

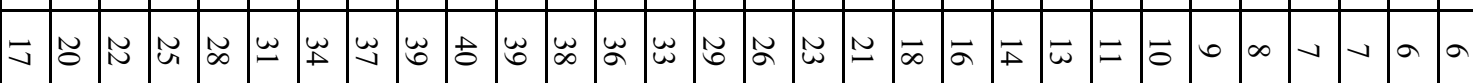

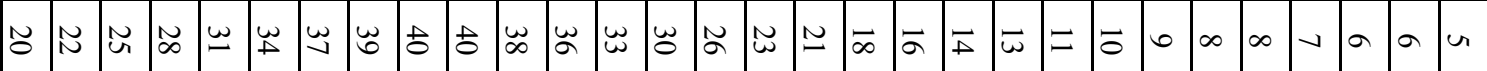

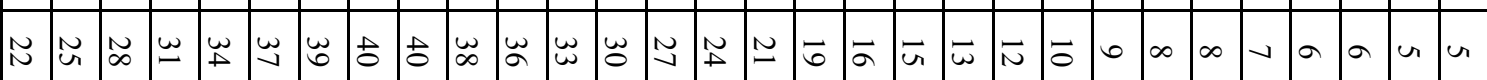

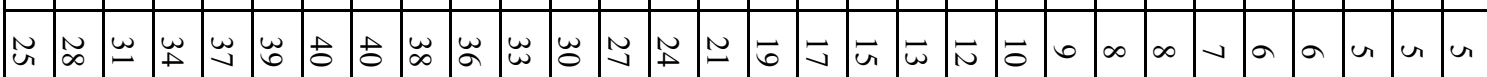
N

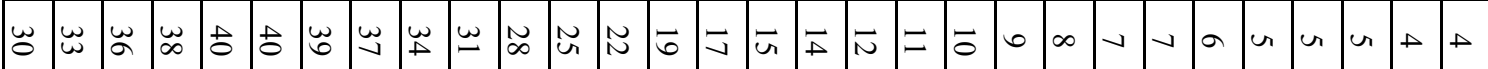

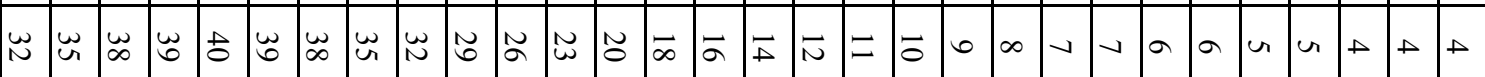

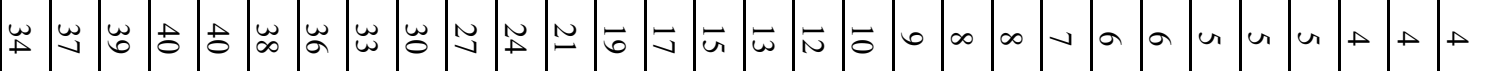

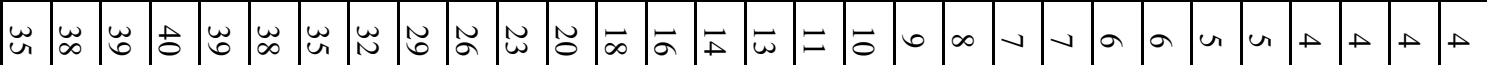

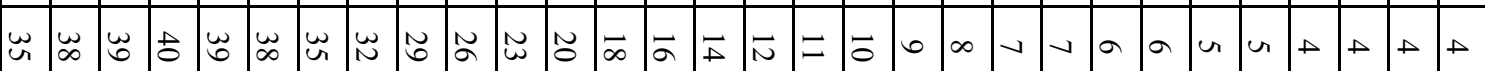

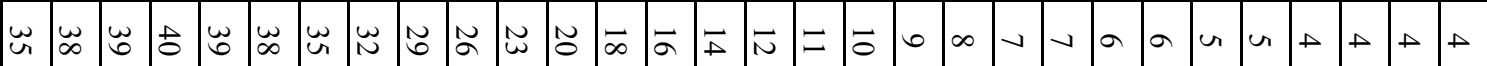

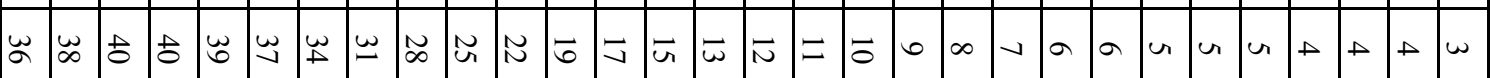

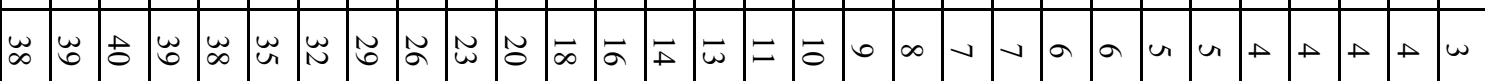

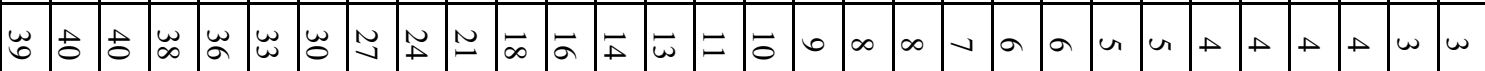

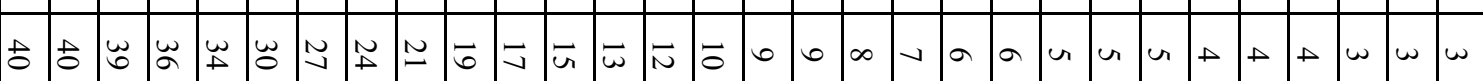

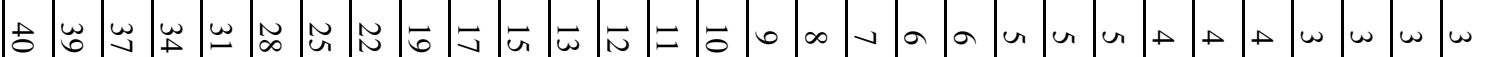

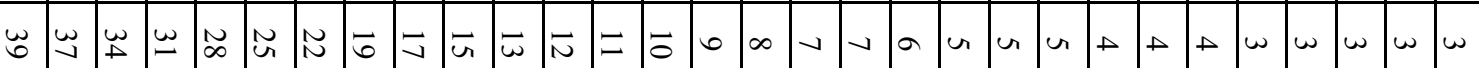

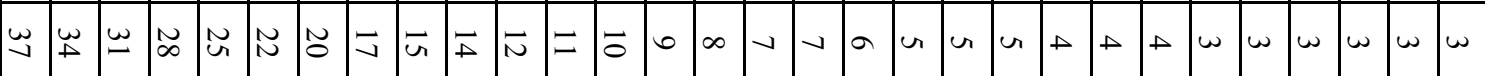

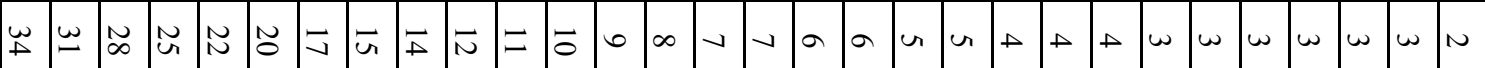
N N U

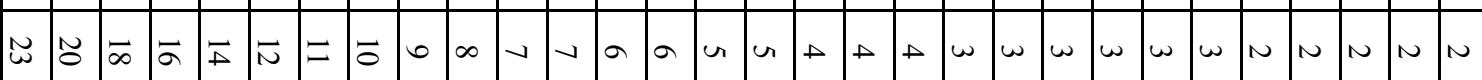

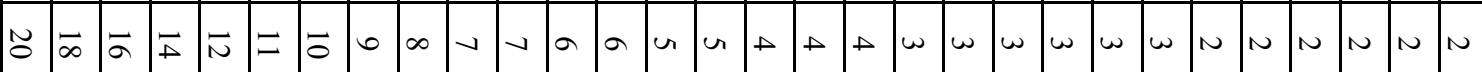

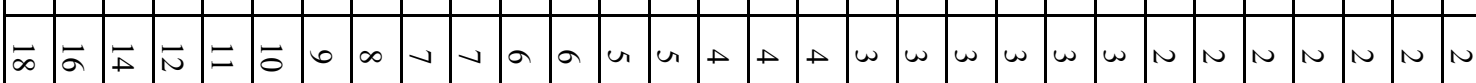




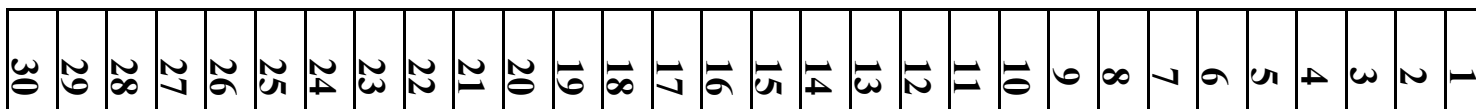

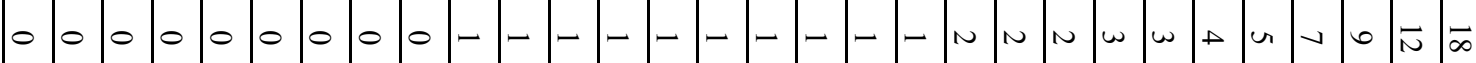

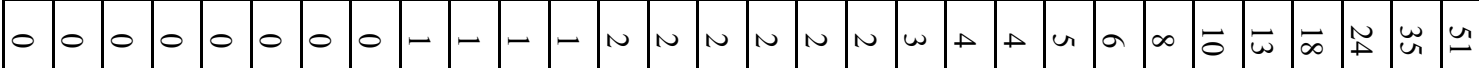

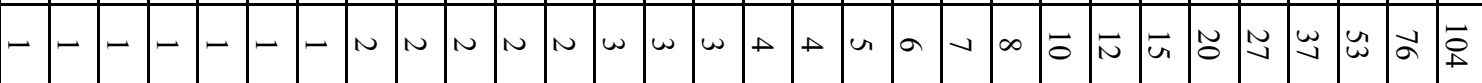

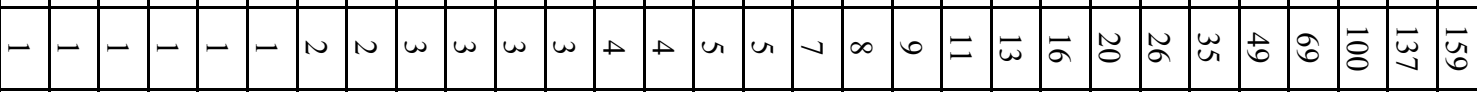
n n n N N N w w w w n n n N n w w $\omega$ w

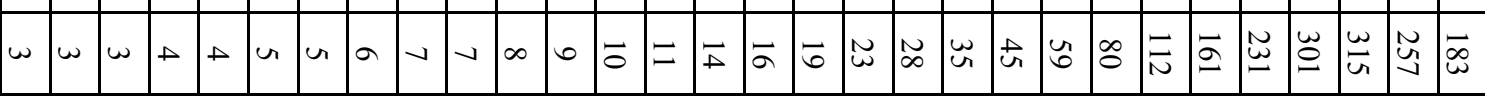

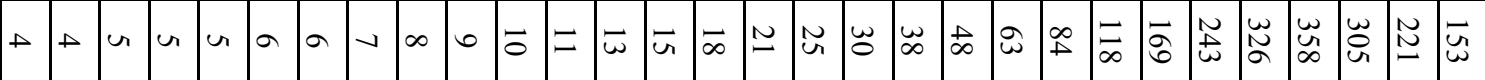

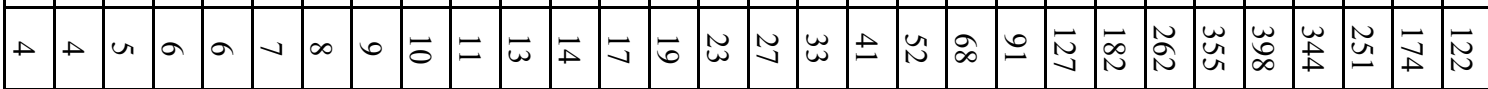

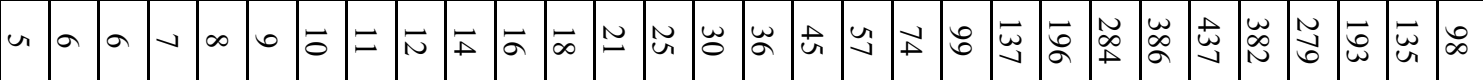

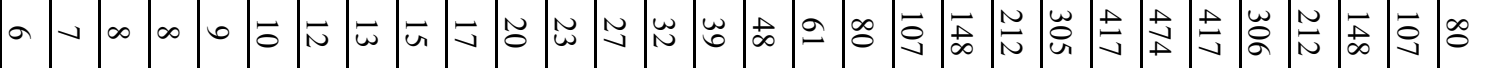

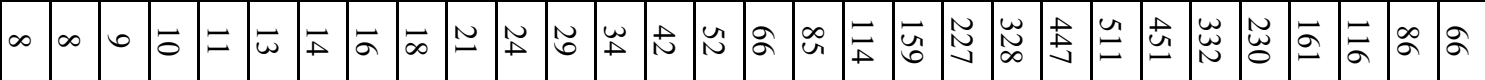

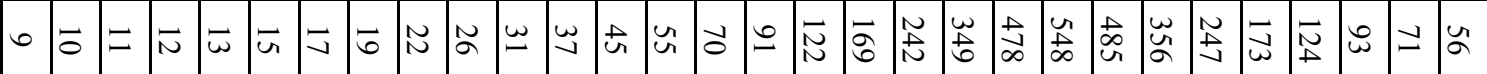

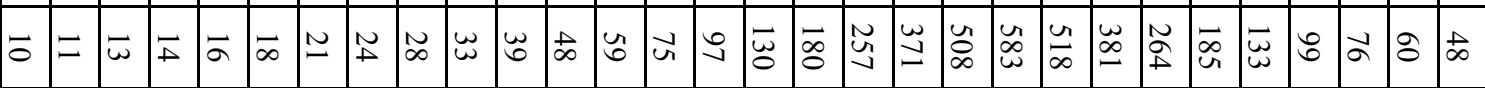

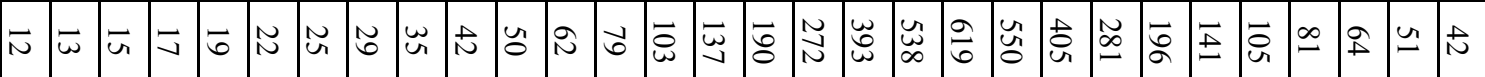

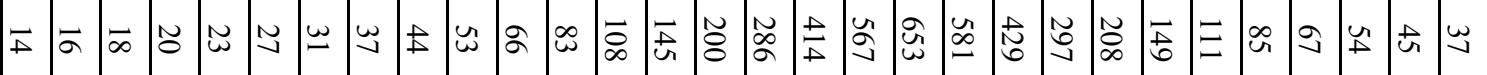

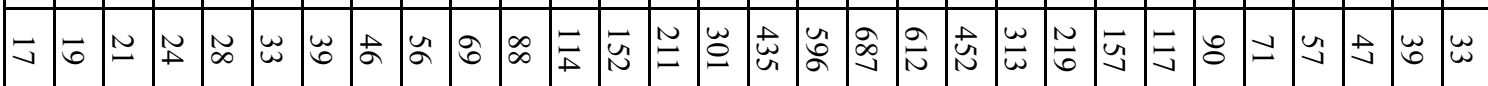

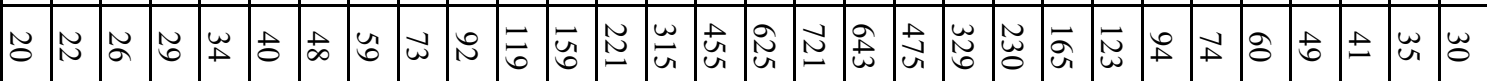

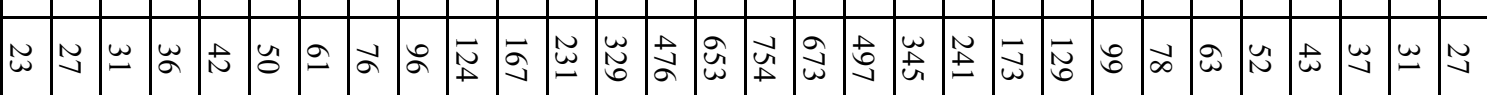

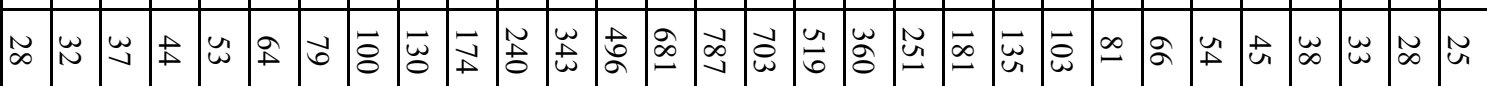

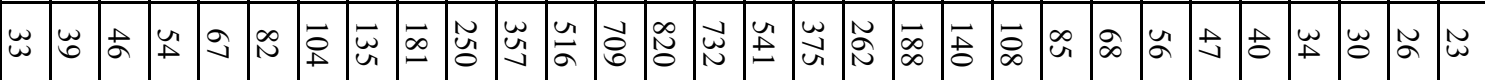

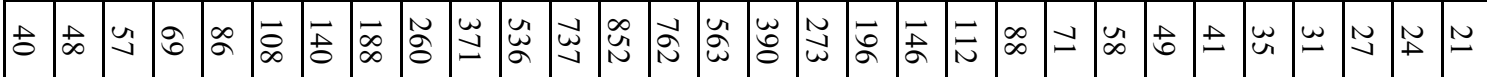

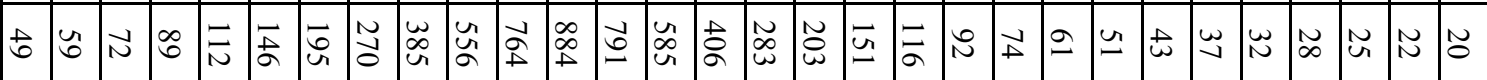

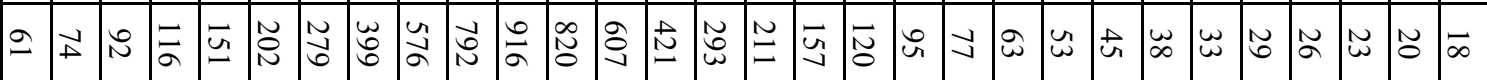

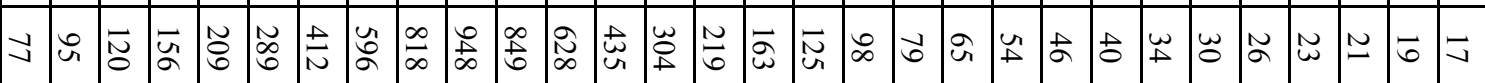

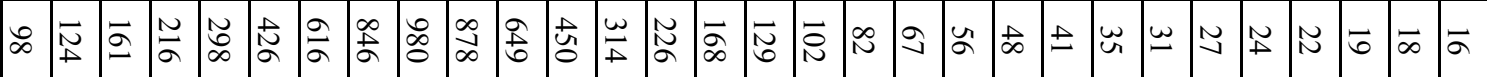

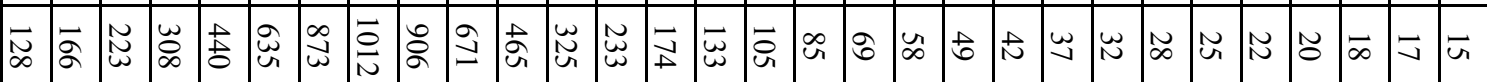

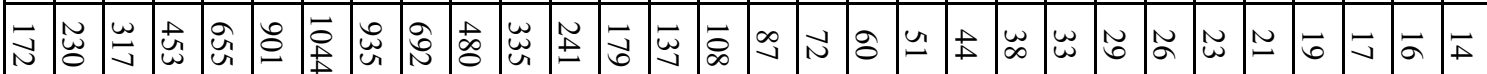

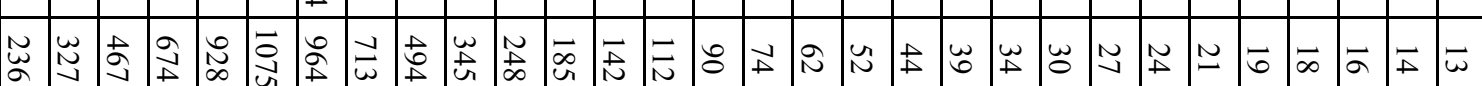




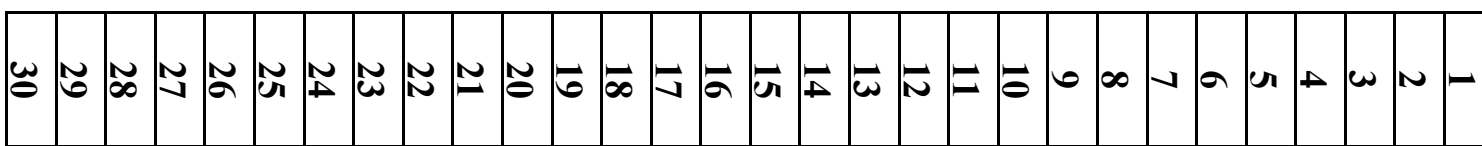

- - - - - - - - - - - - - n n n n

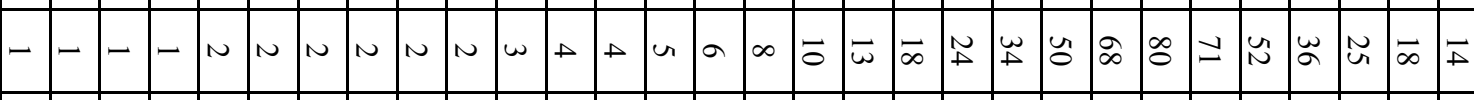
n n n N n

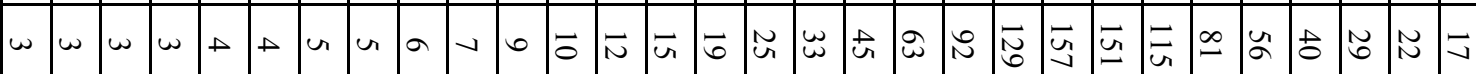

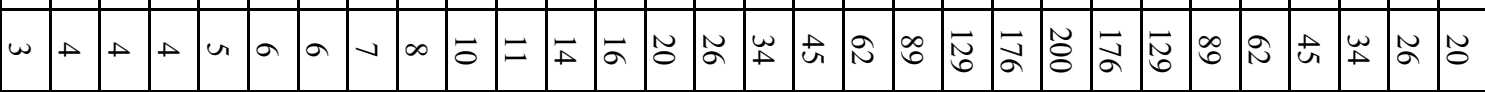

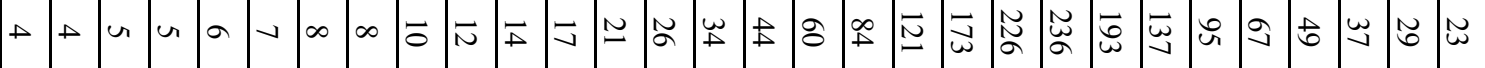

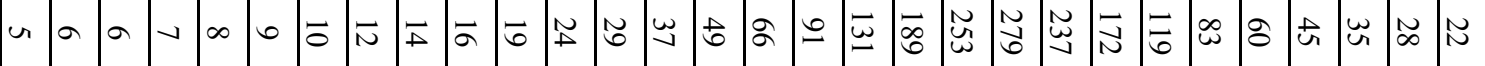

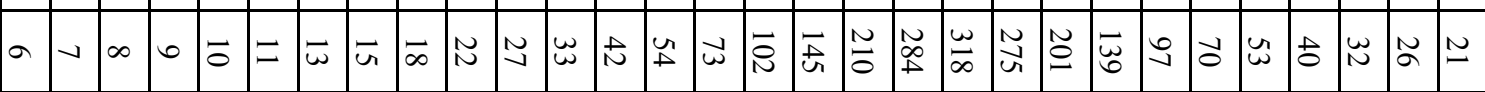

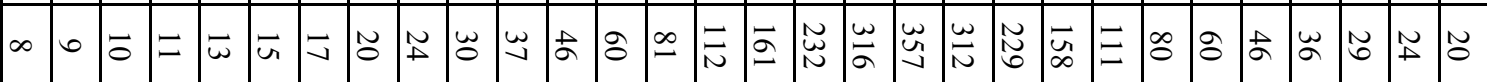

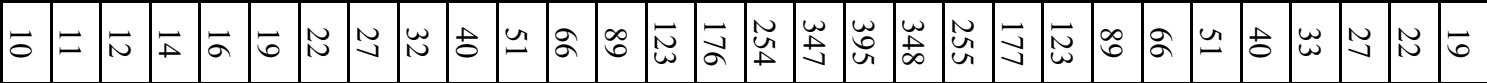

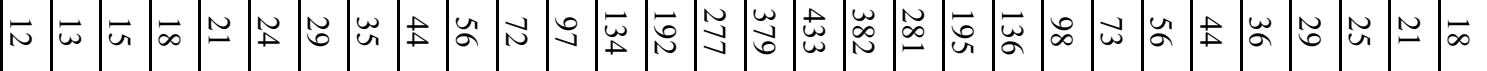

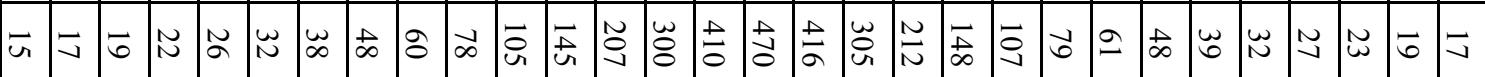

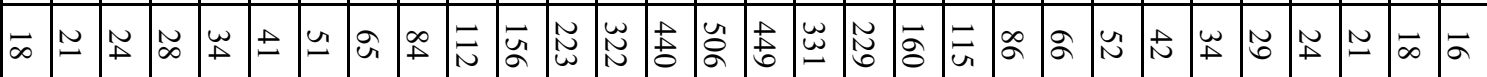

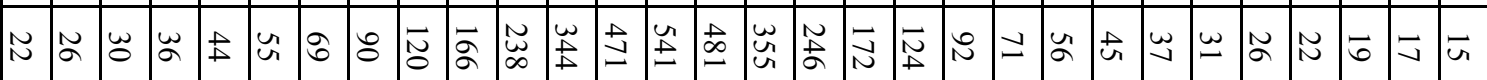

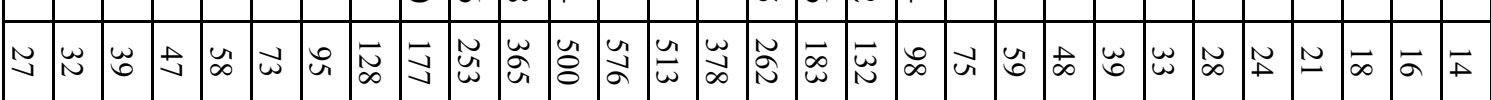

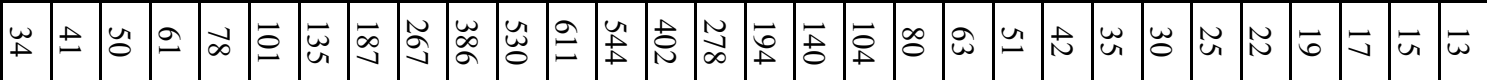

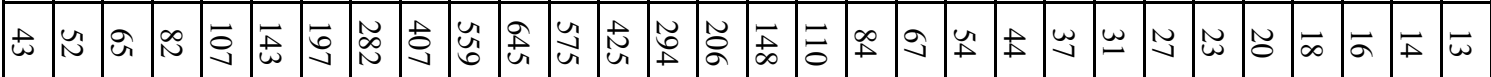

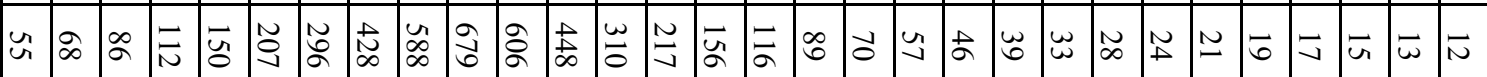

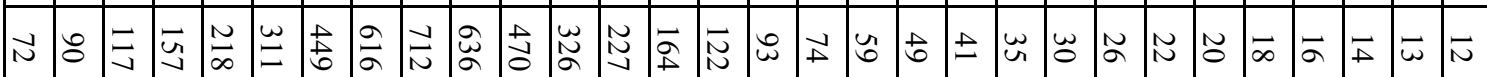

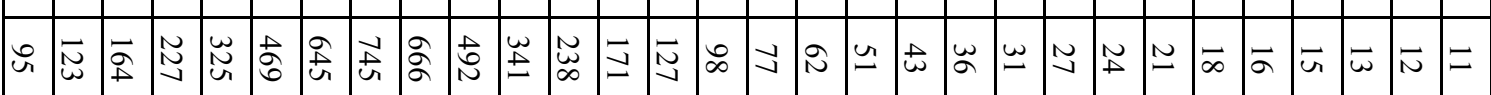

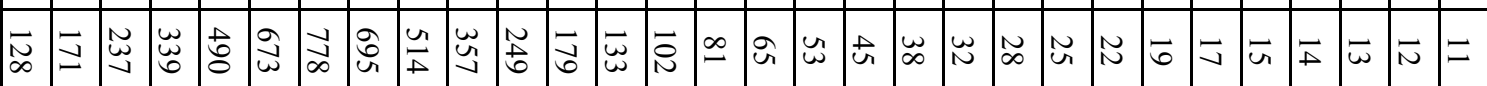

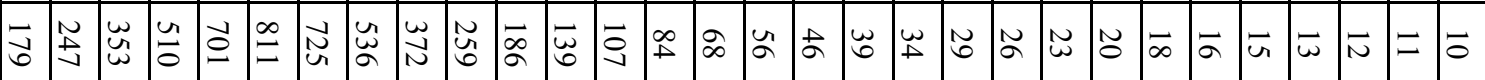

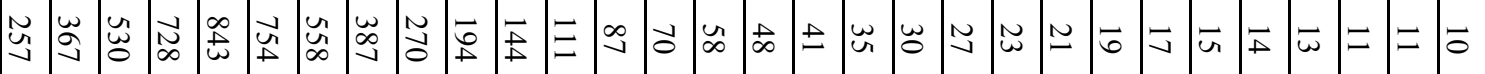

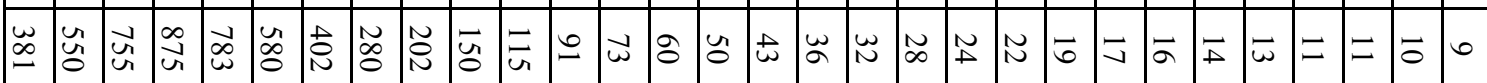

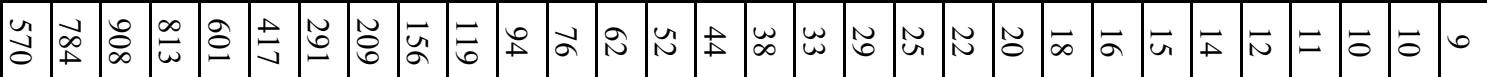

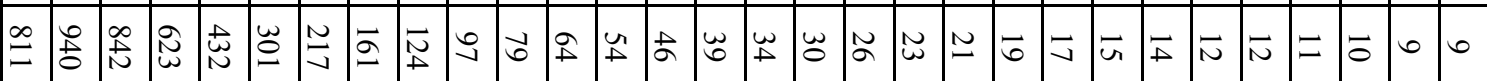

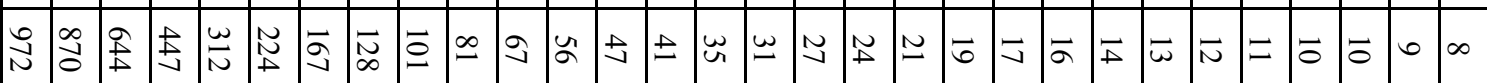

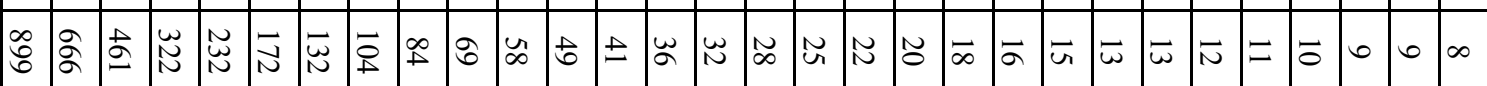

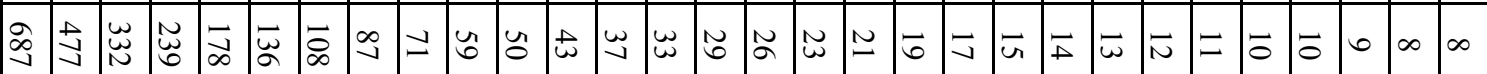

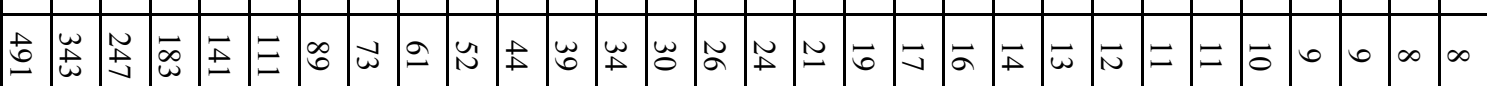




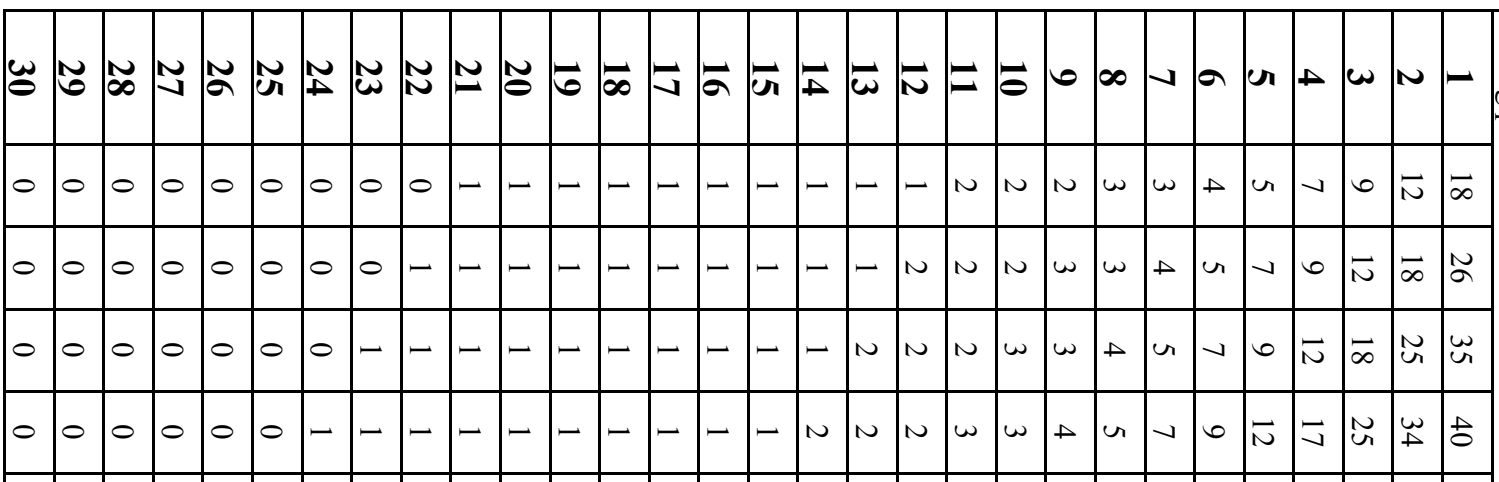

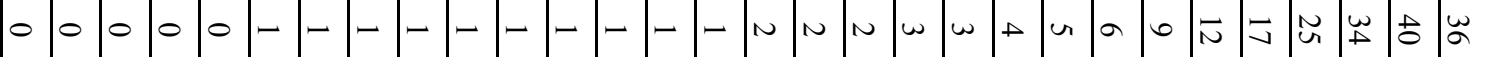

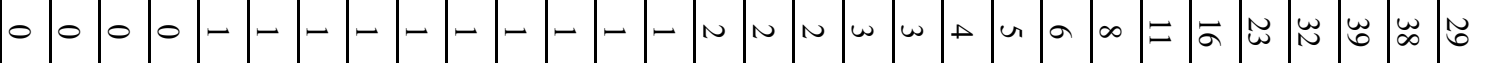

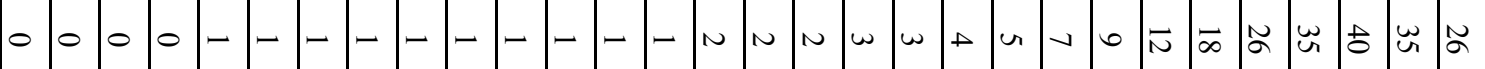

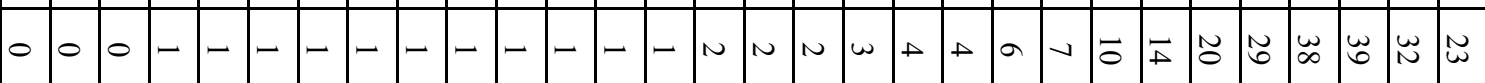

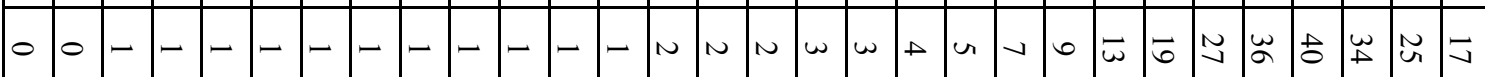

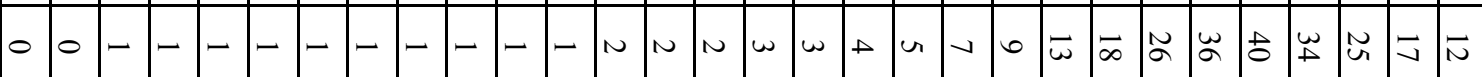

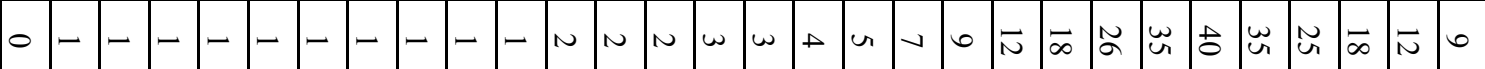

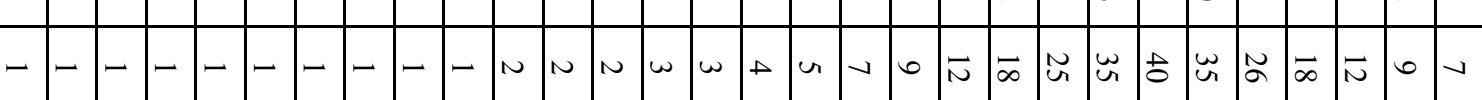

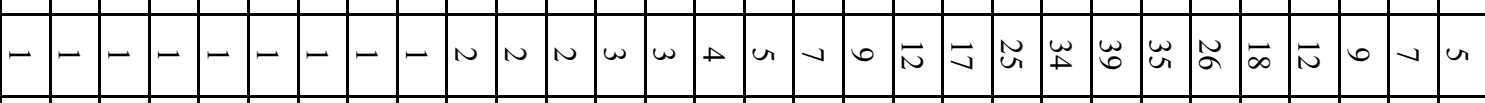

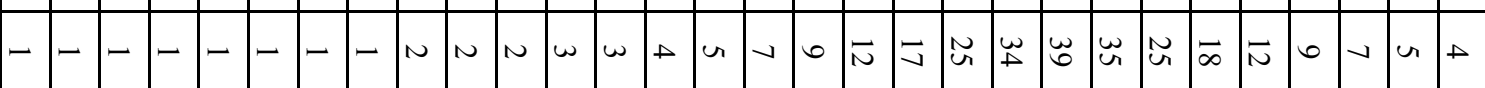

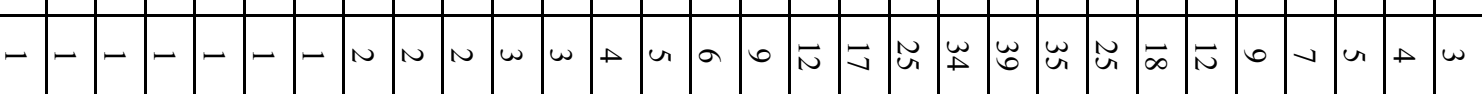

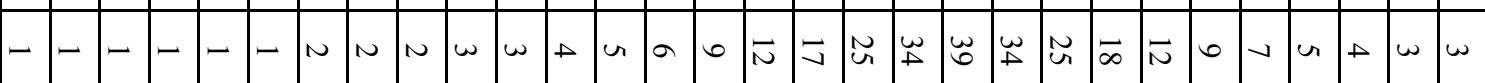

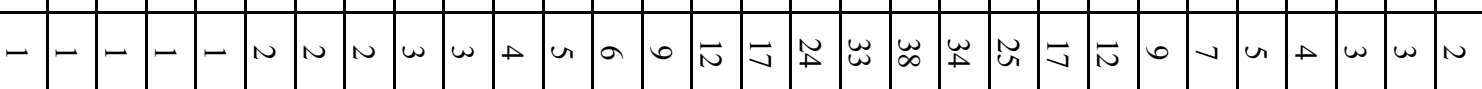

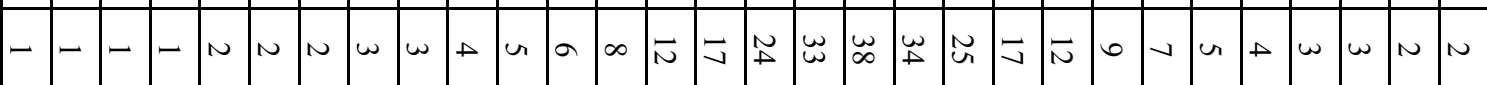

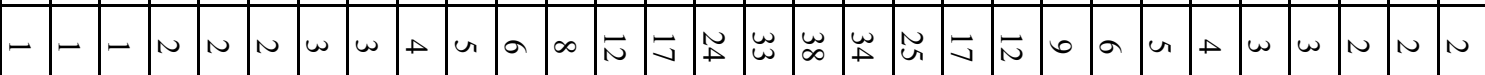

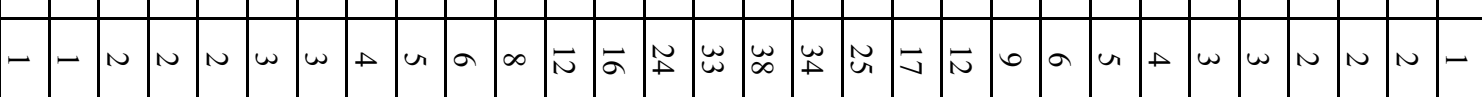

-

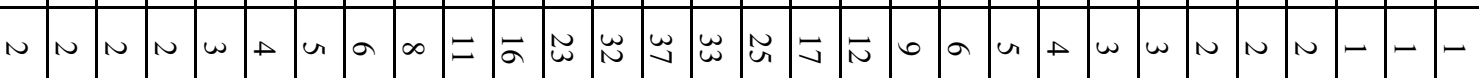

n n $n$ n

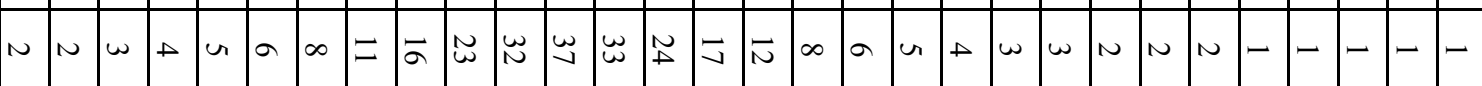

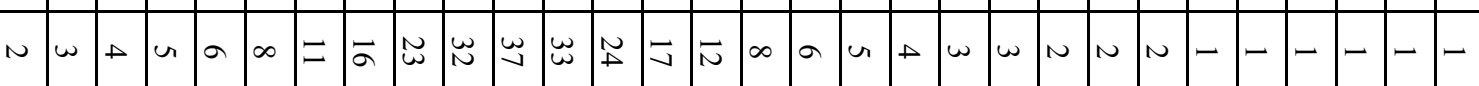

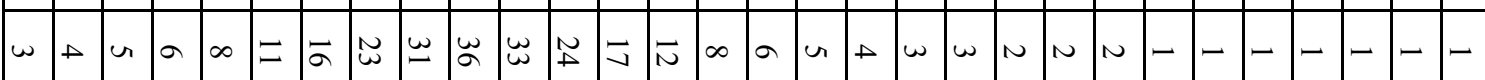

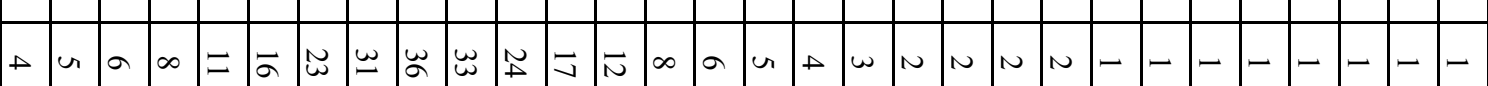

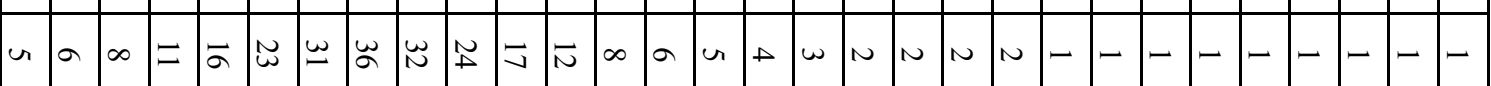

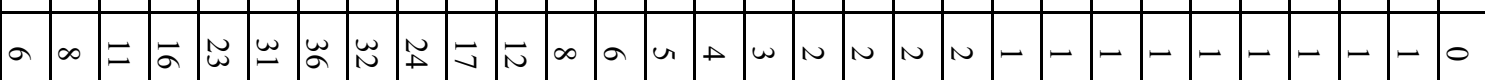

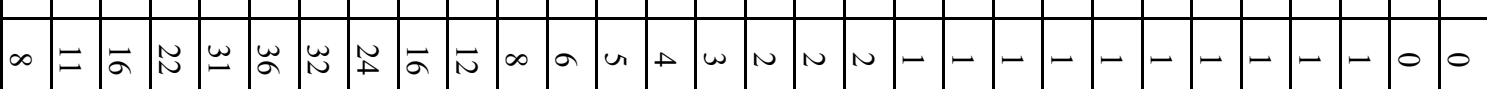

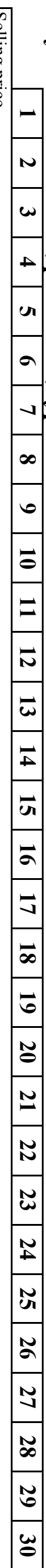




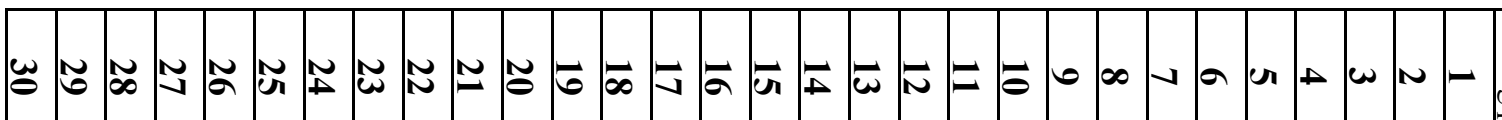

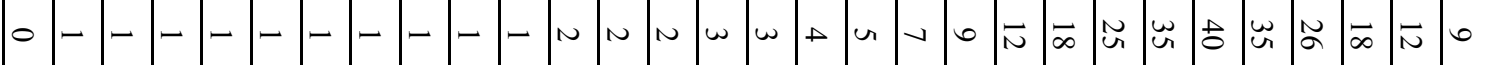

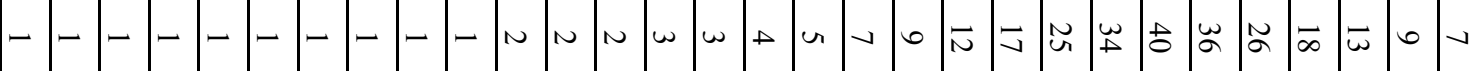

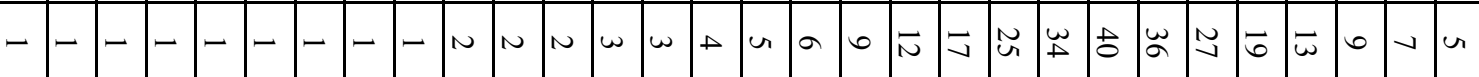

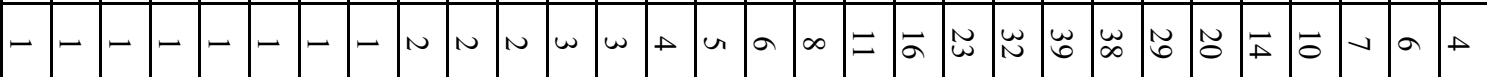

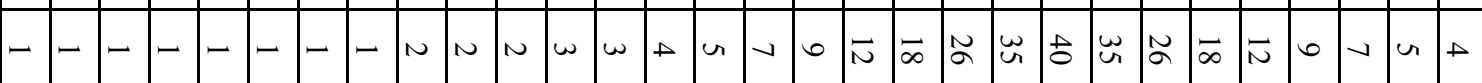

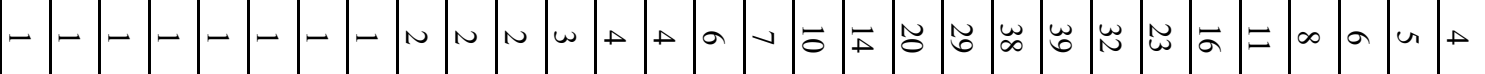

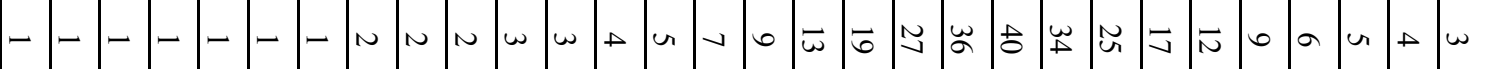

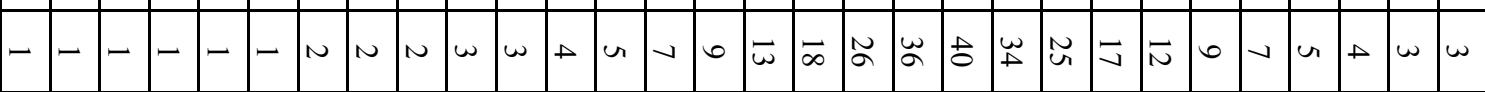

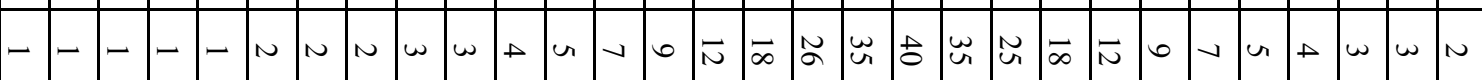

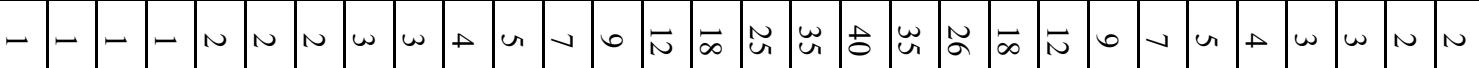

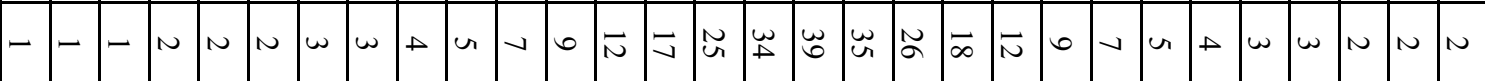

- $-d n$ N n

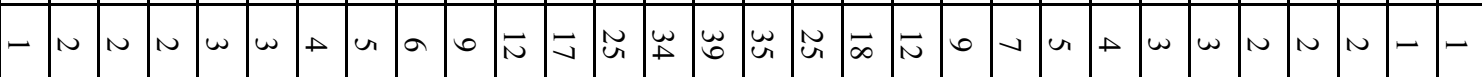

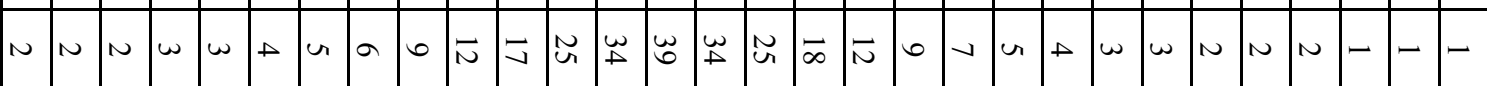

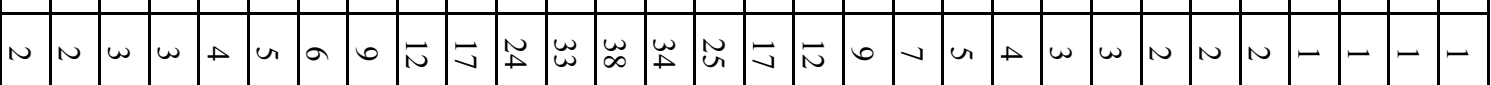

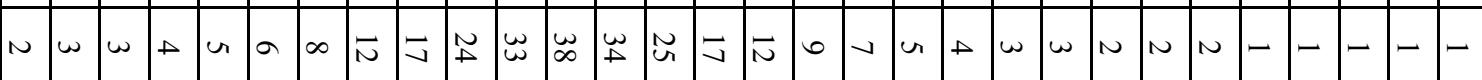

w w $+a$ u

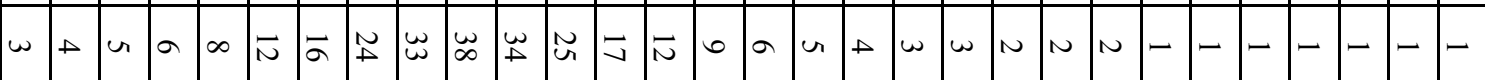

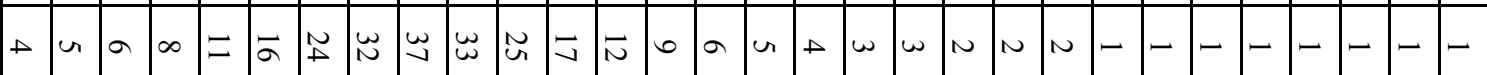

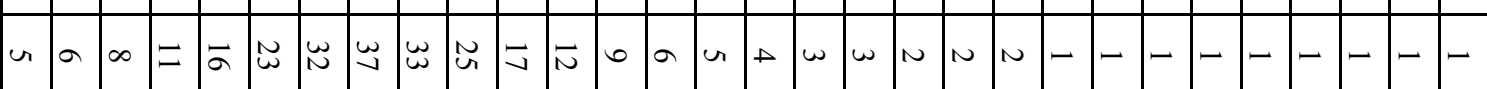

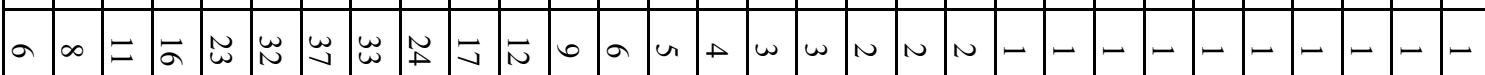

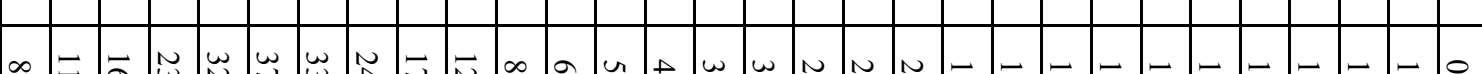

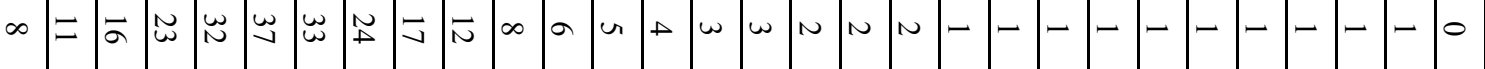

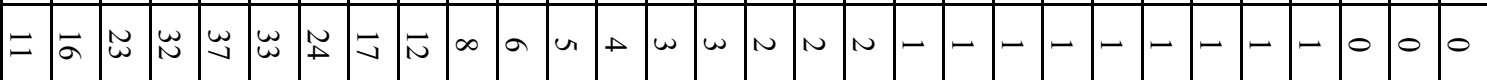

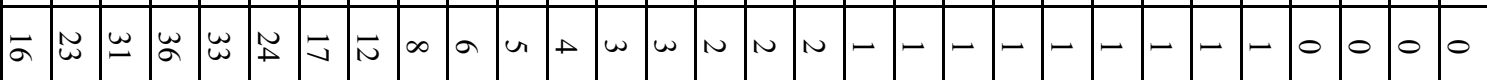

N

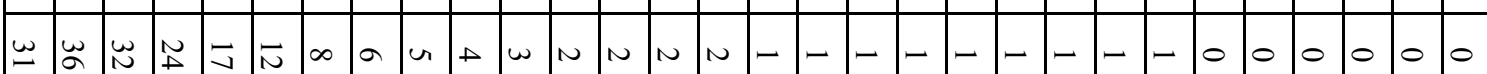

w m

吊

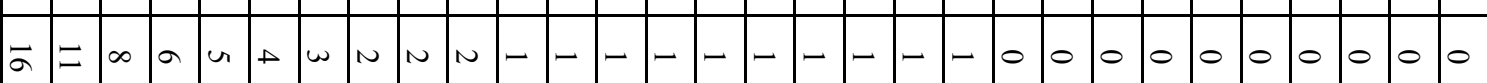




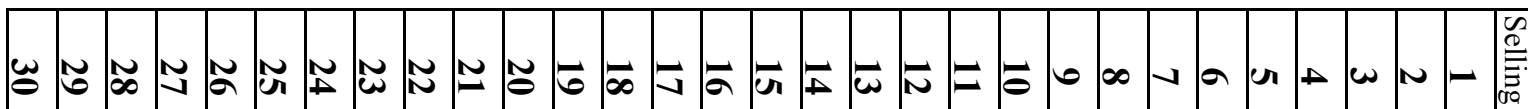

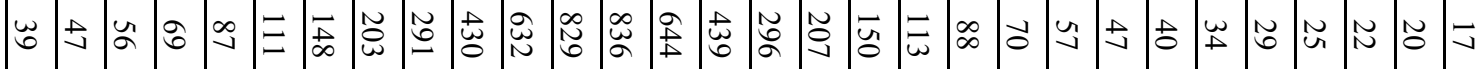

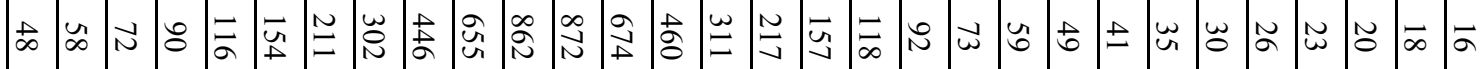

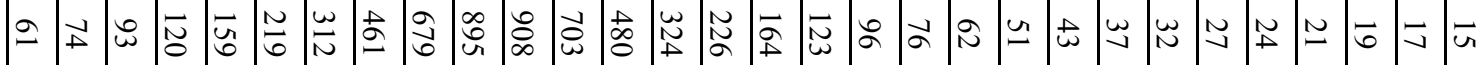

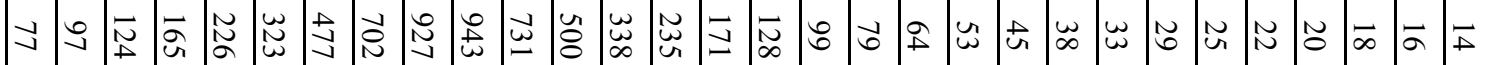

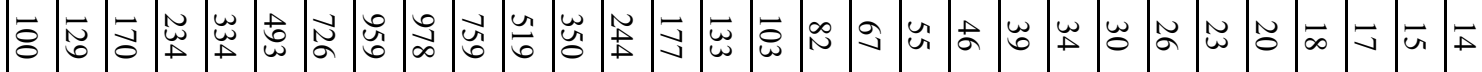

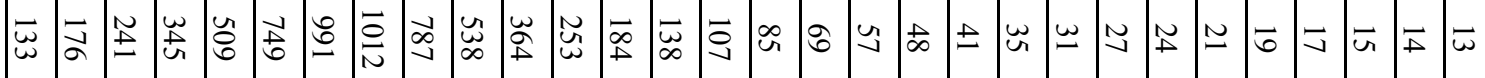

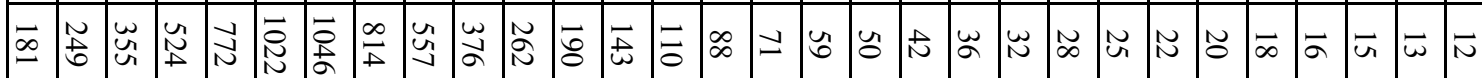

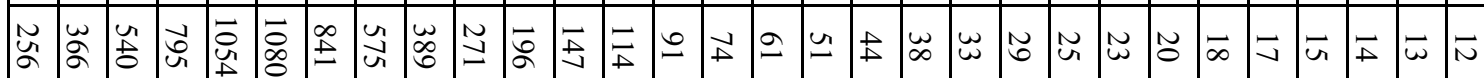

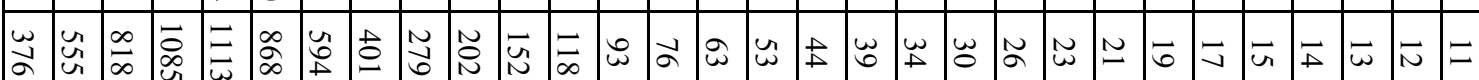




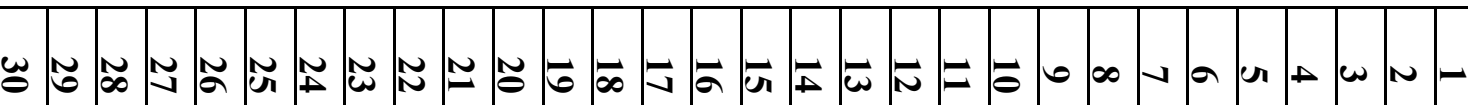

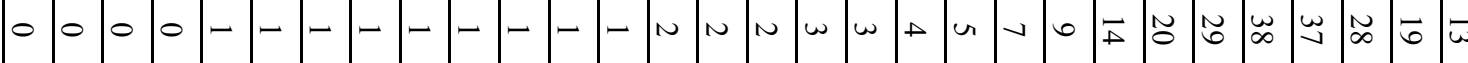

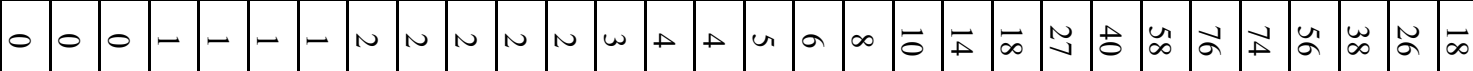

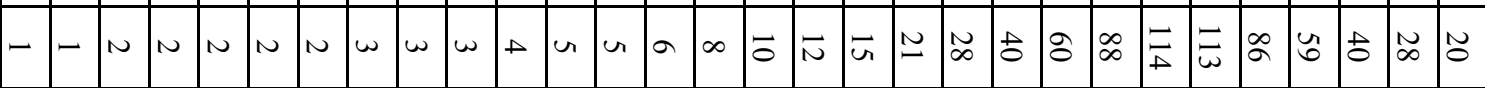
-

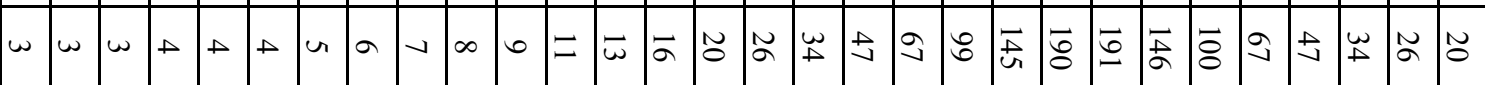

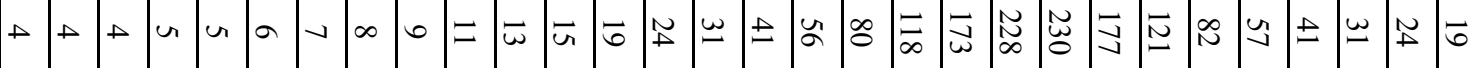

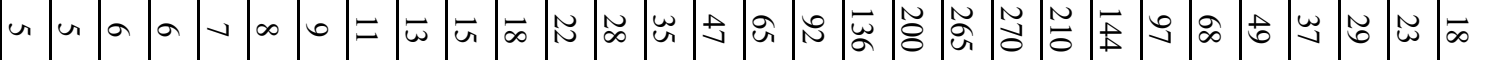

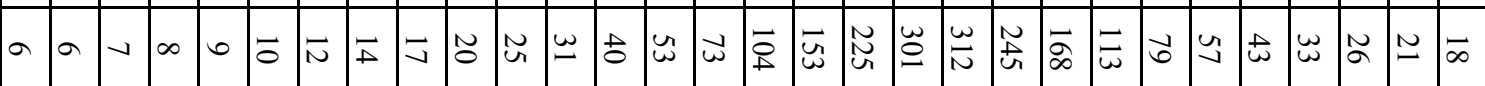

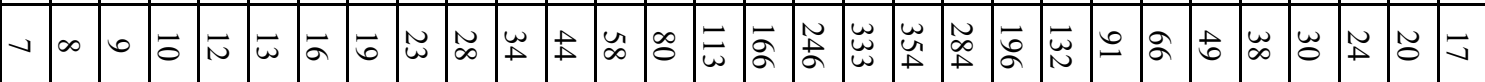

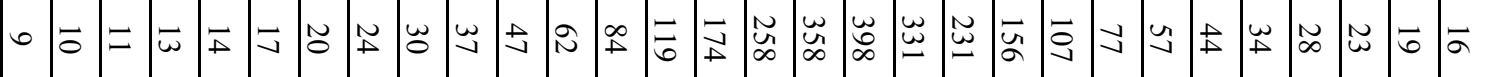

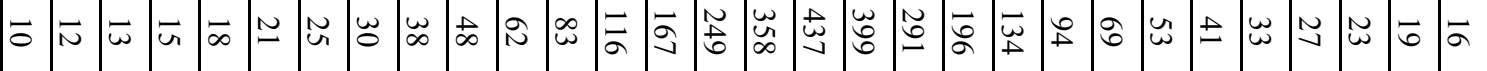

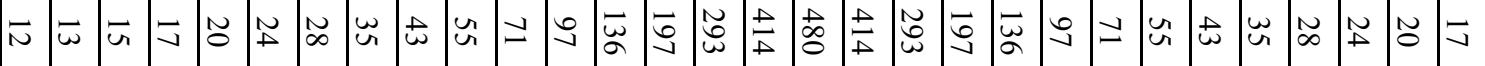

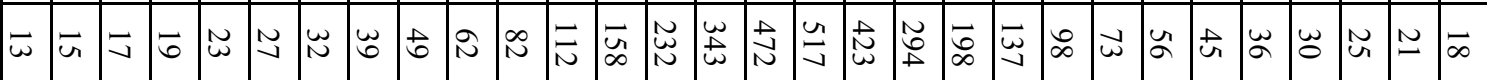

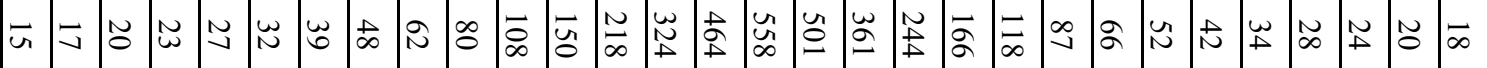

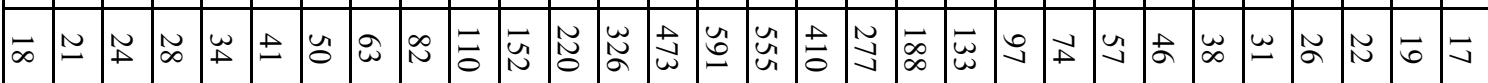

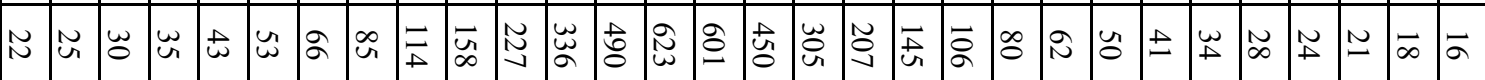

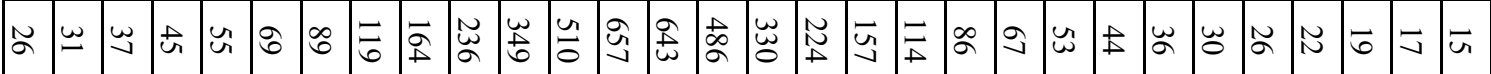

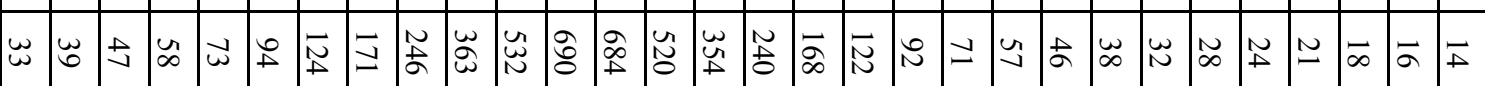

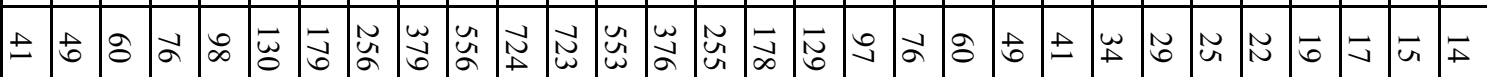

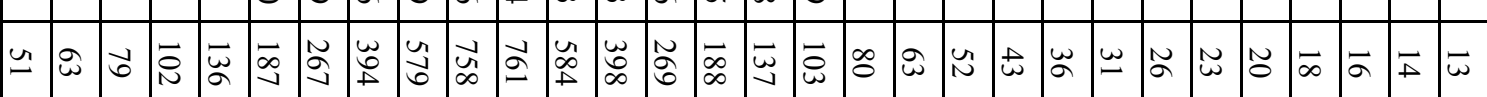

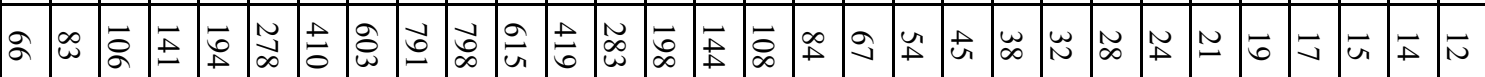

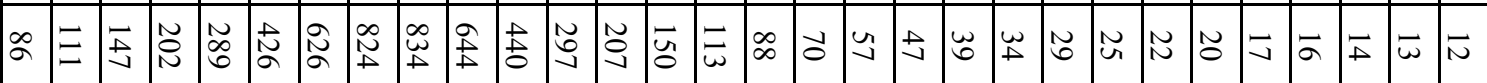

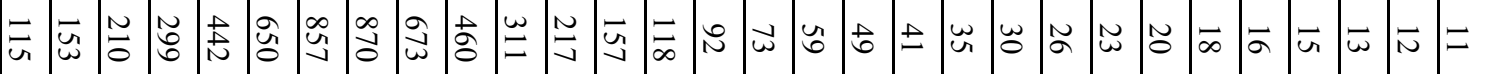

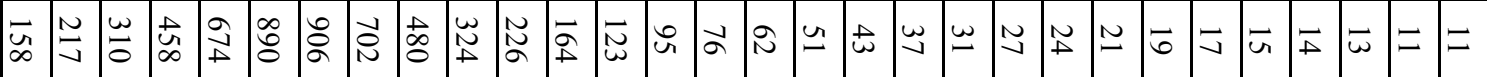

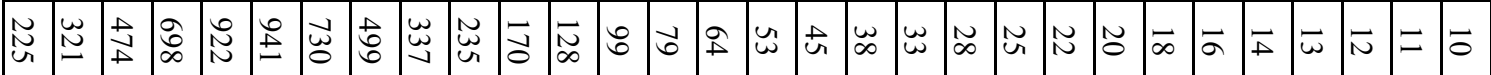

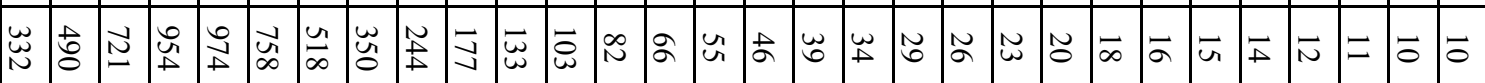

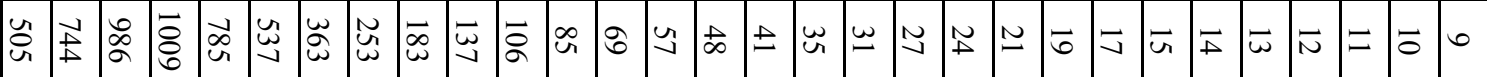

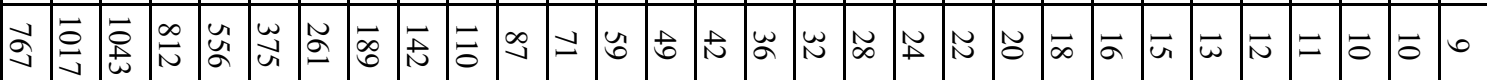

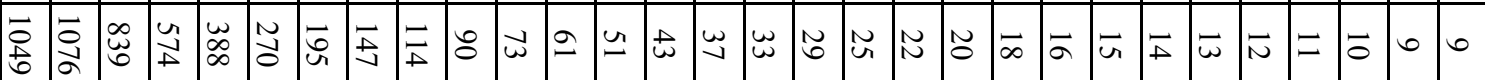

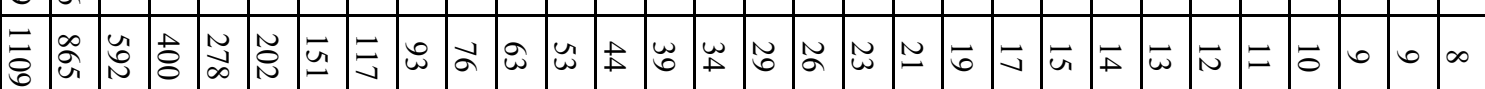




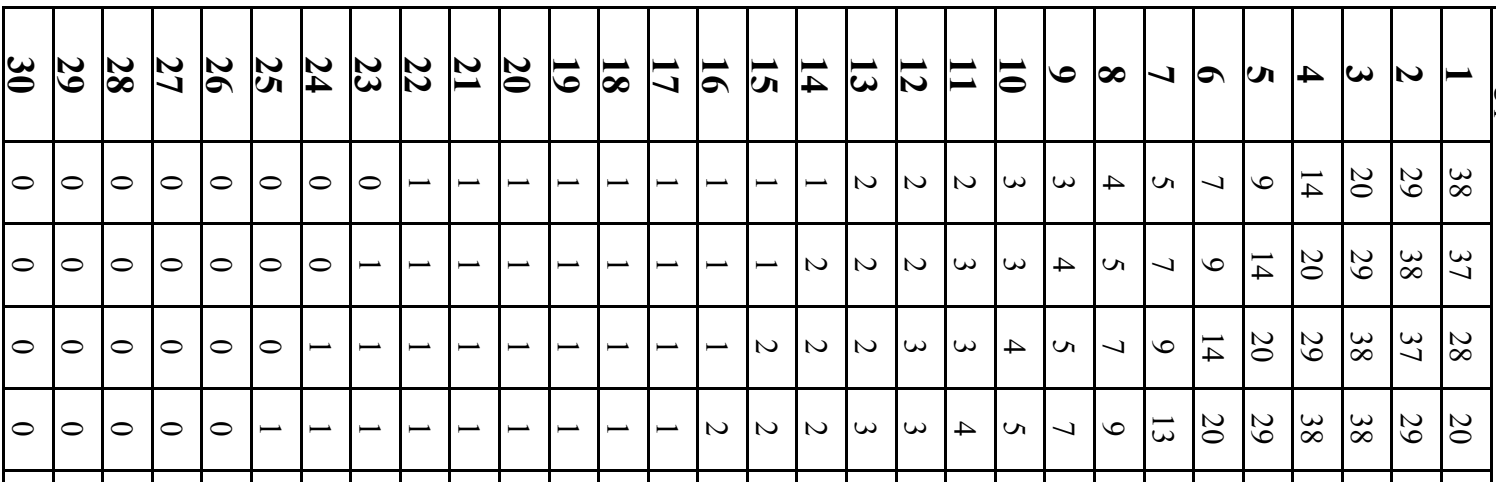

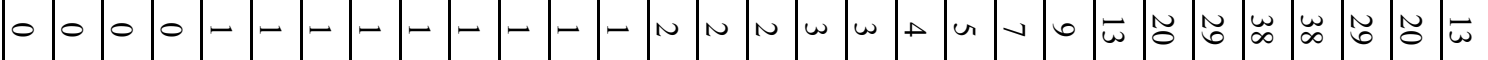

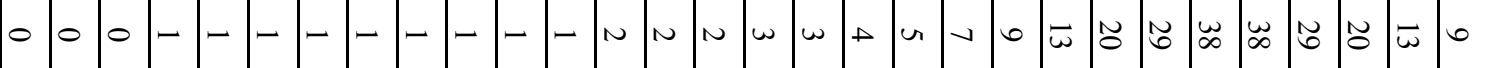

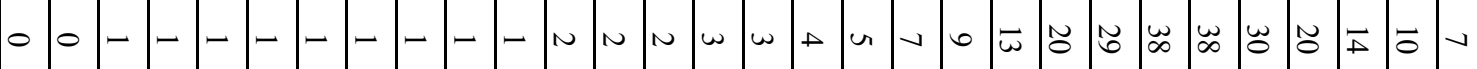

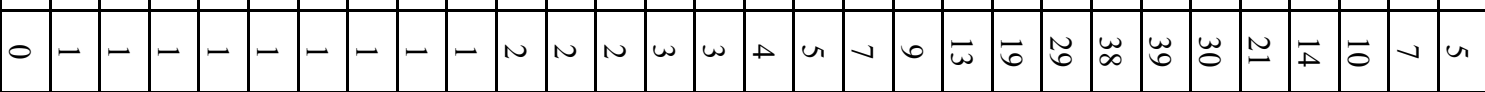

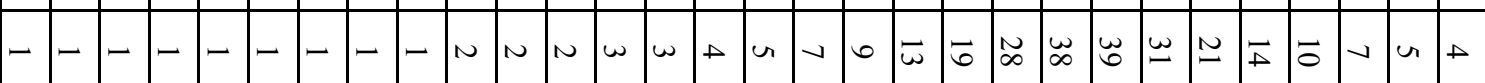

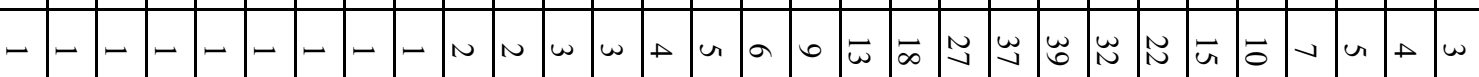

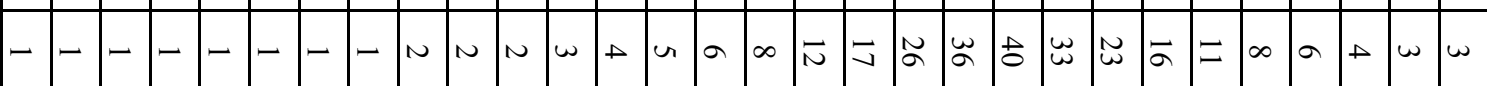

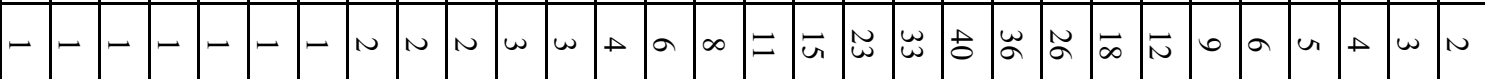

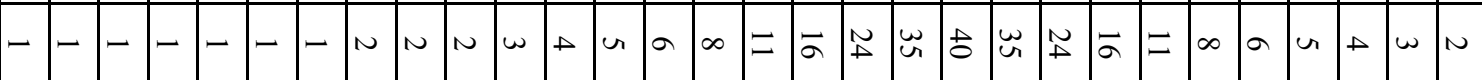

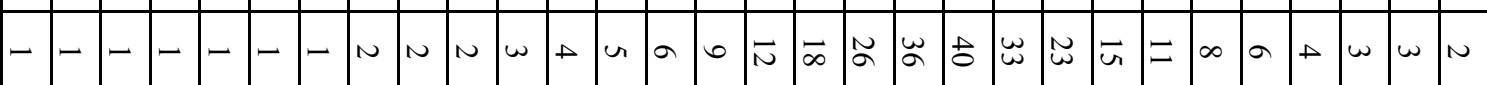

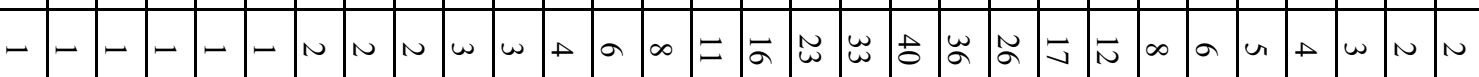

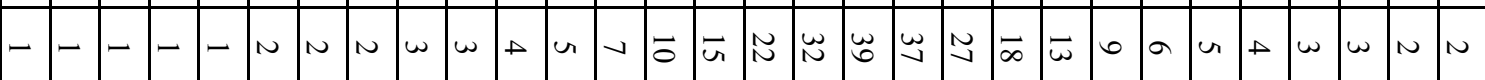

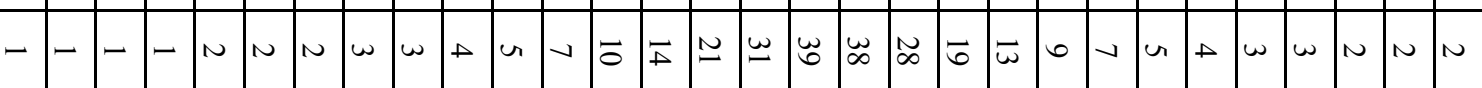

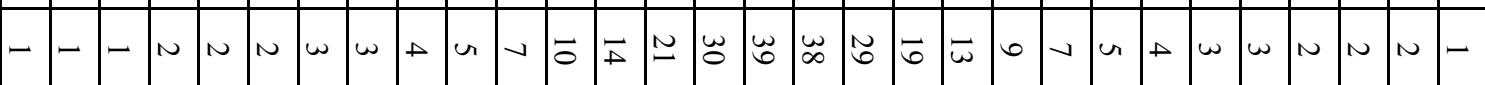

-

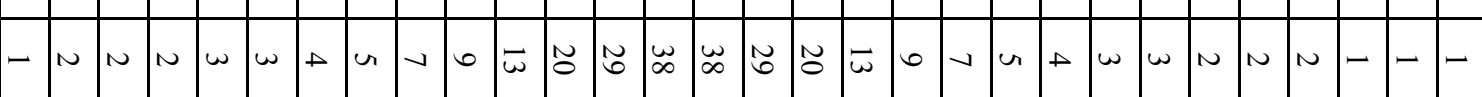

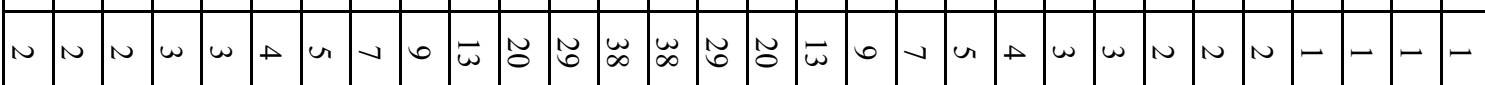

n $N$ N

n

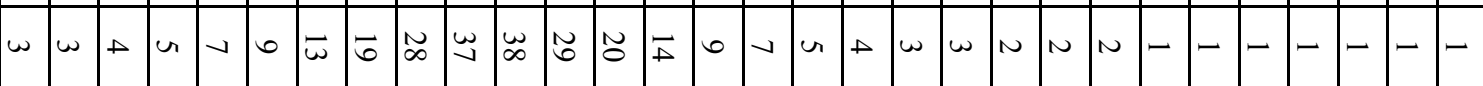

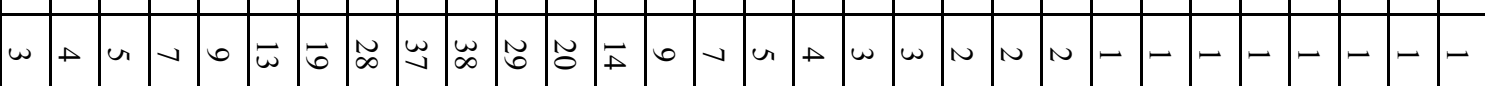

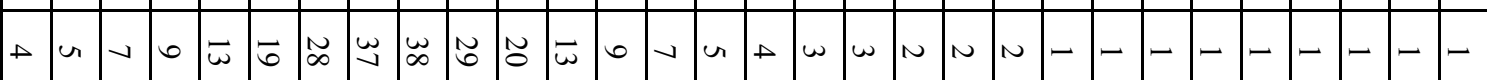

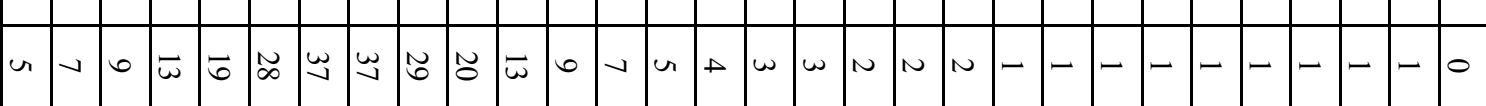

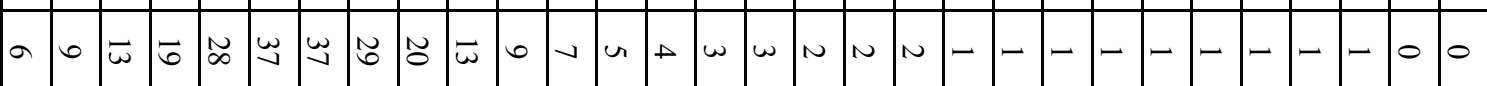

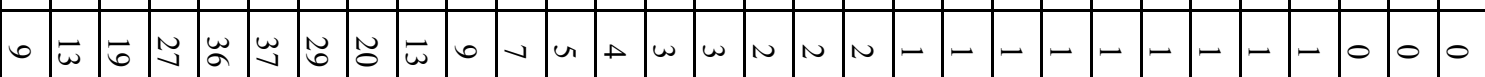

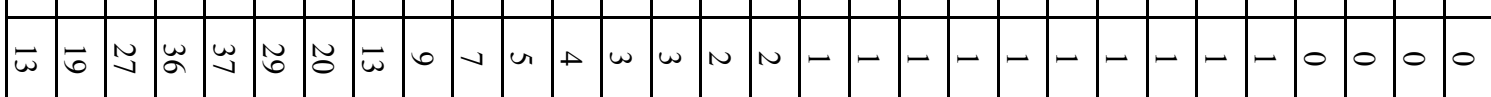

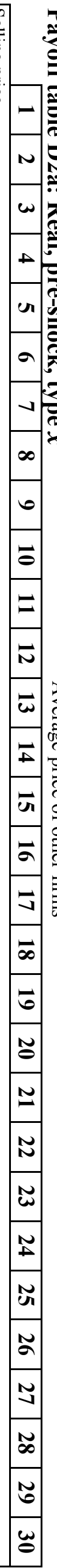




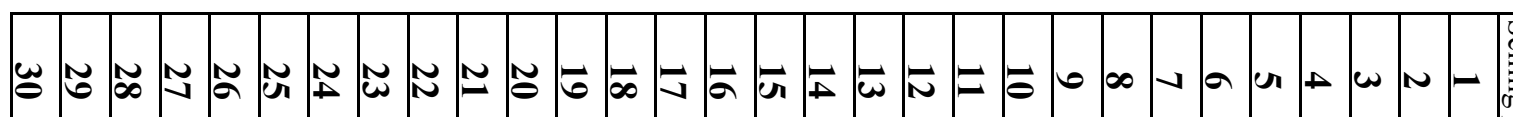

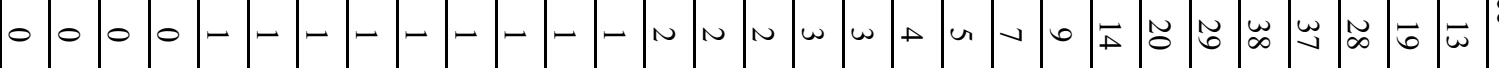

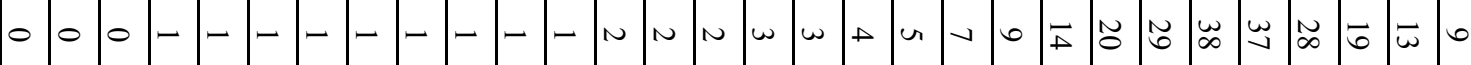

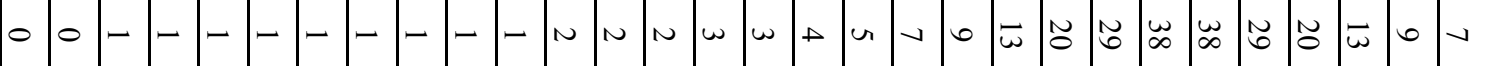

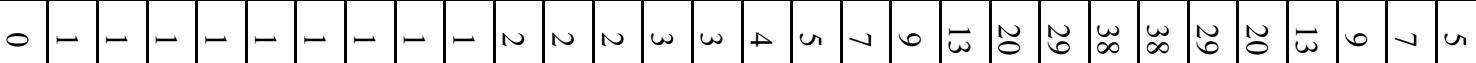

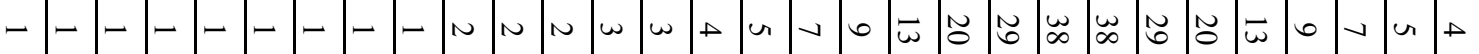

- - - - - - - - - - n n n n w

- - - - - - - - n n n

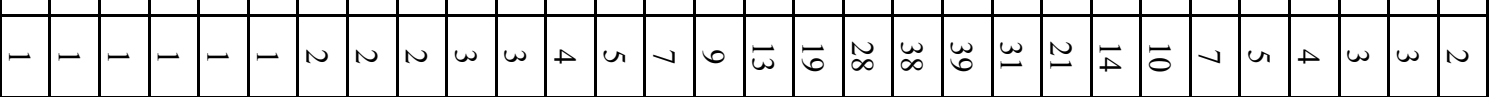

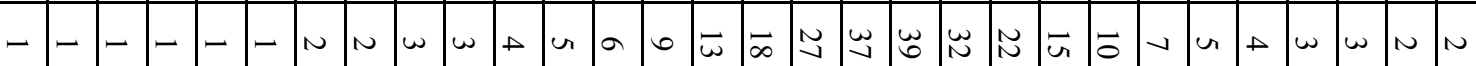

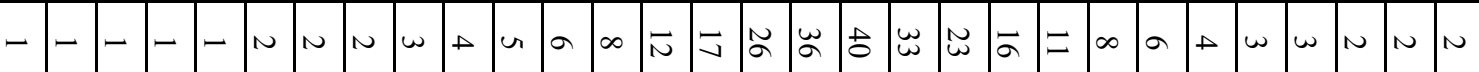

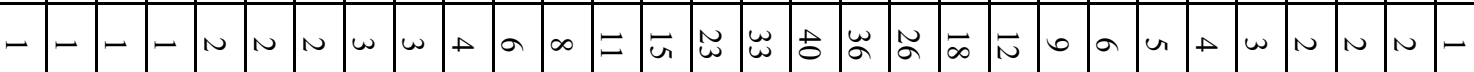

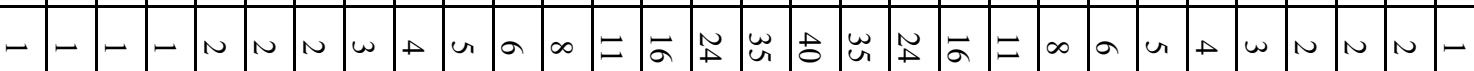

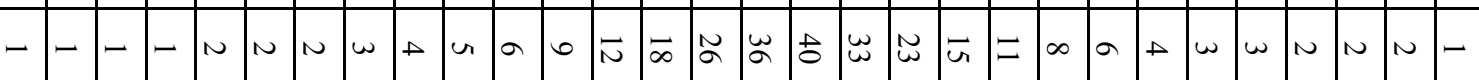

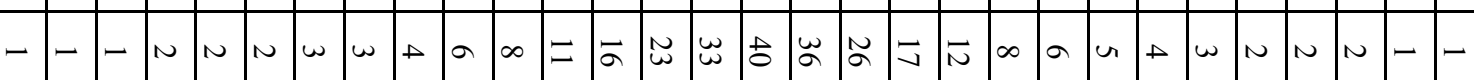

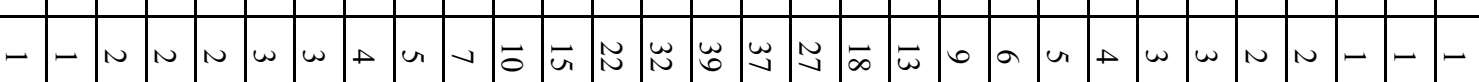

- n n n n

n n n n

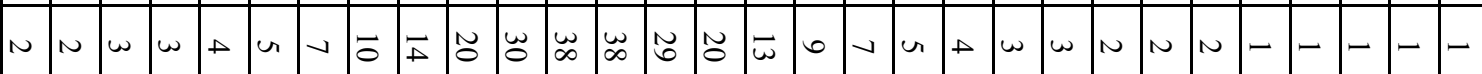

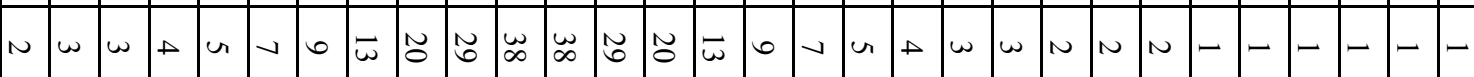

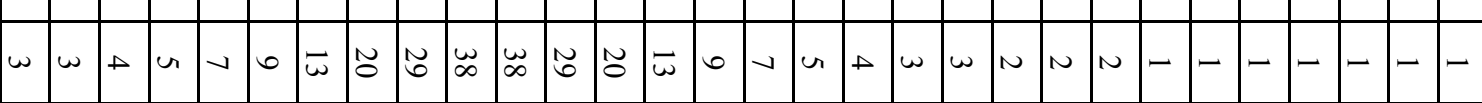

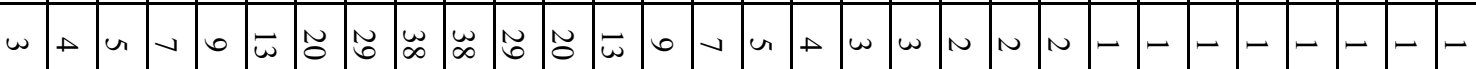

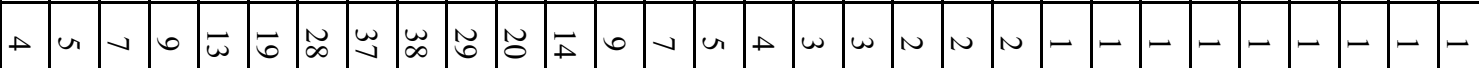

u

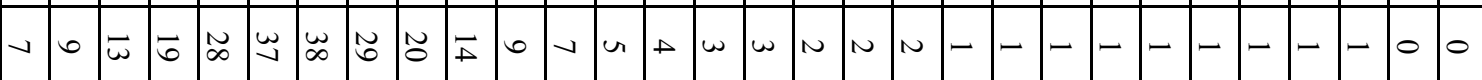

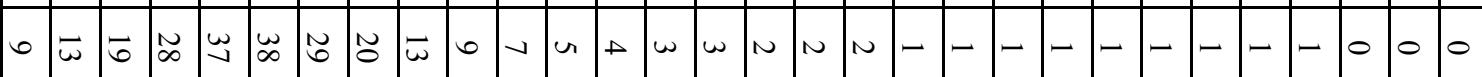

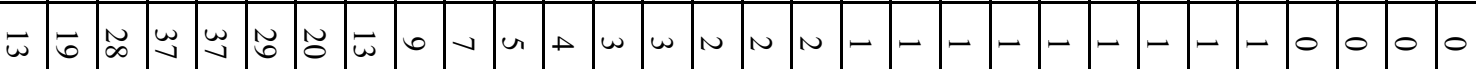

T

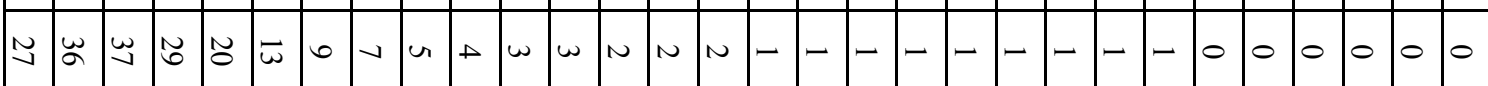

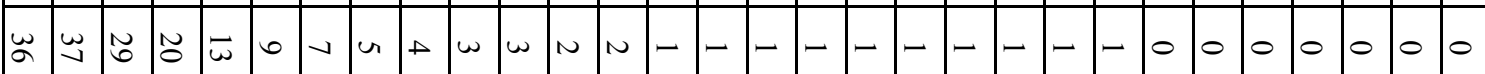

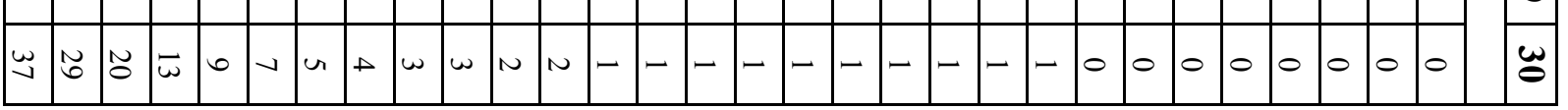




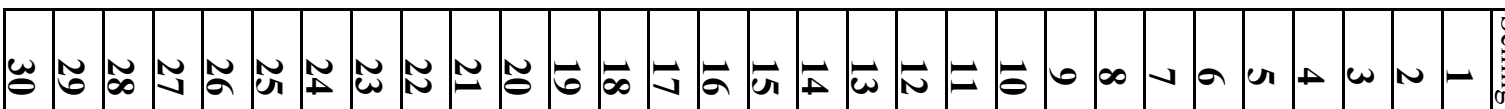

- - - - - - n n n n n n N n

n n n n $n$ N

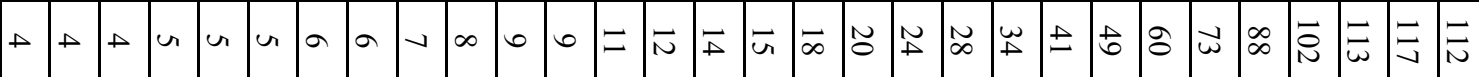

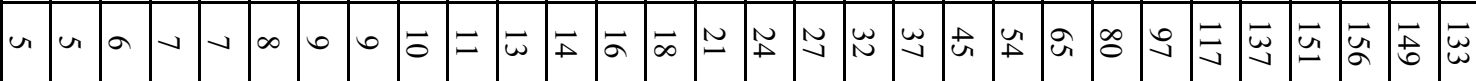

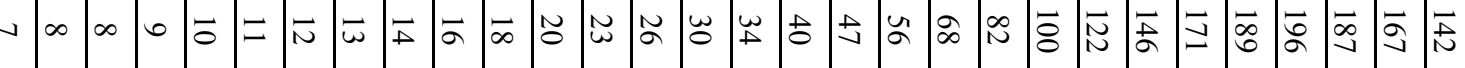

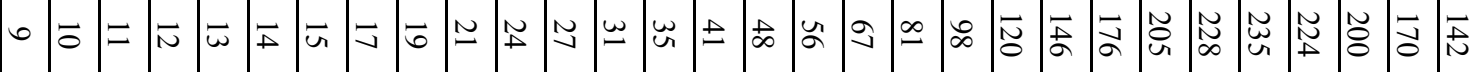

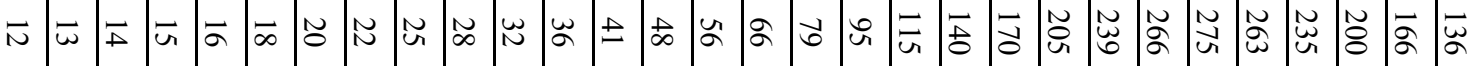

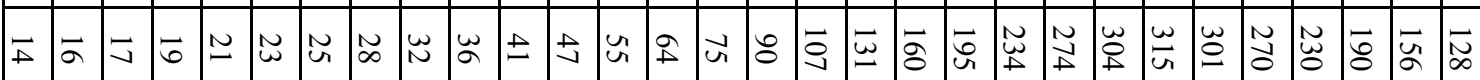

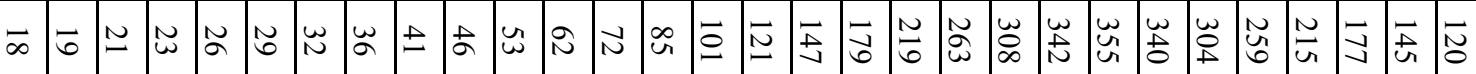

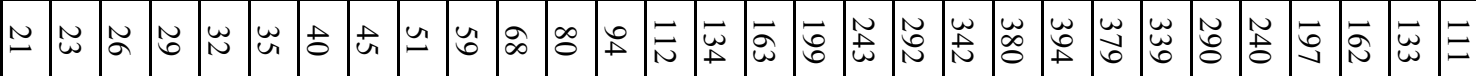

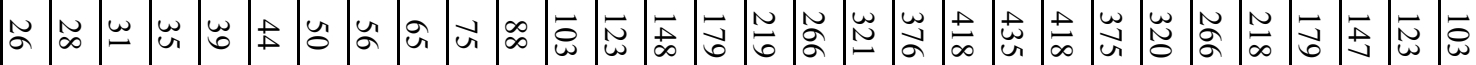

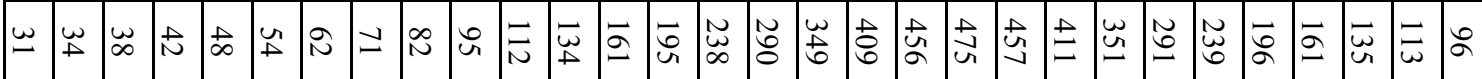

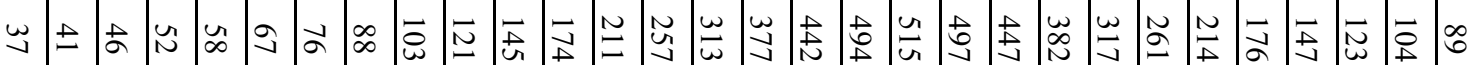

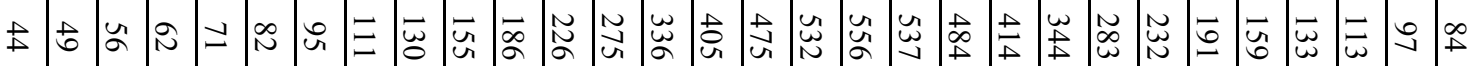

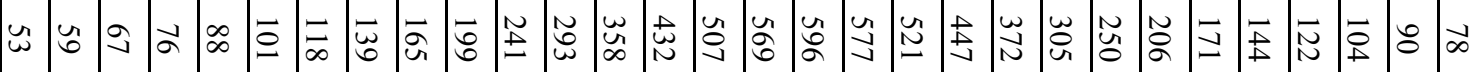

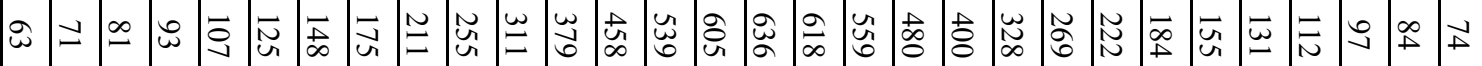

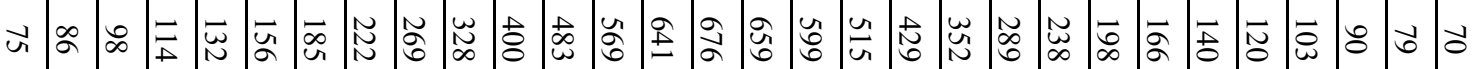

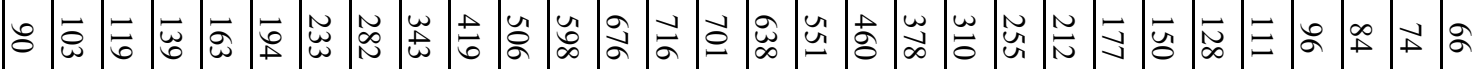

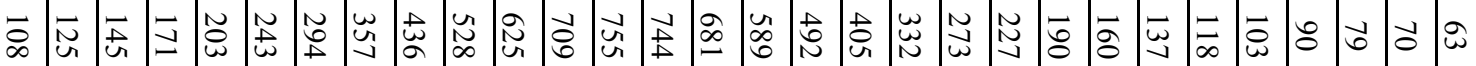

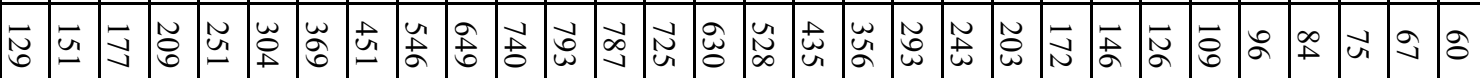

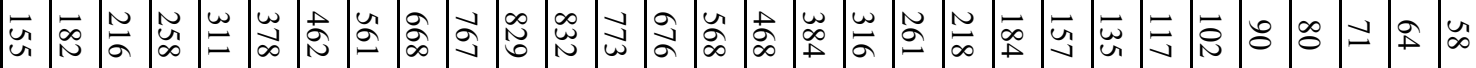

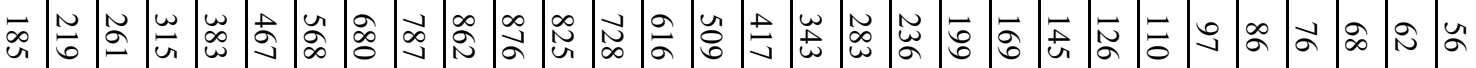

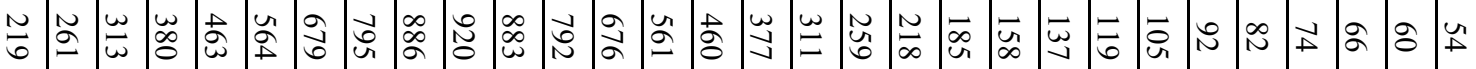

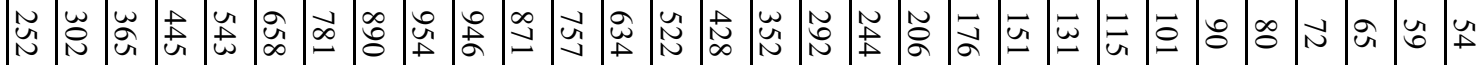
孞岕

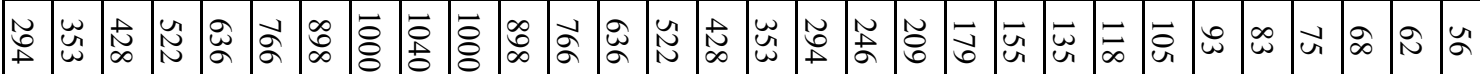

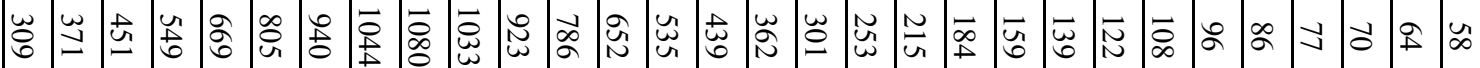

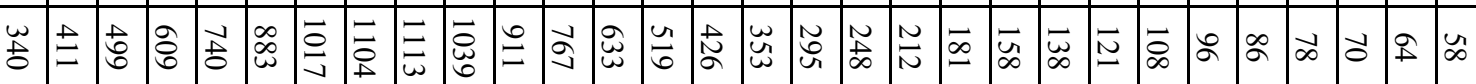

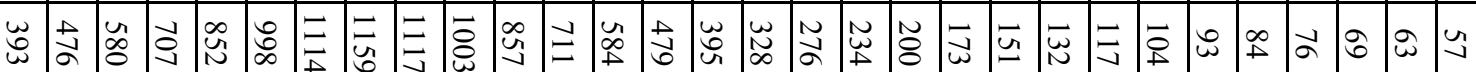

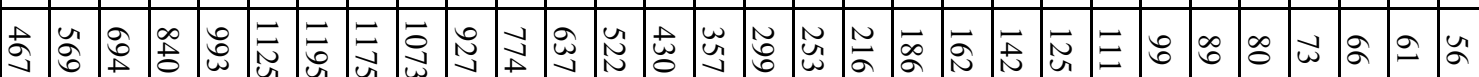




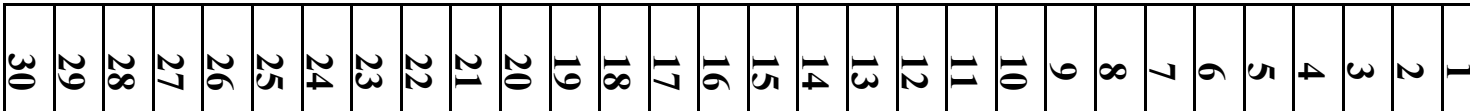

n n n $\omega$ w

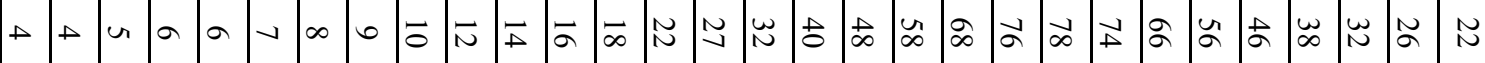

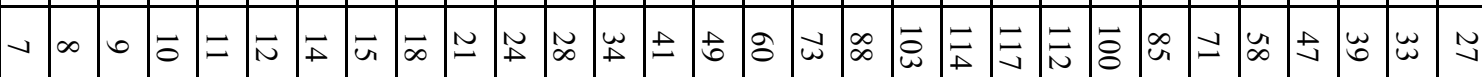

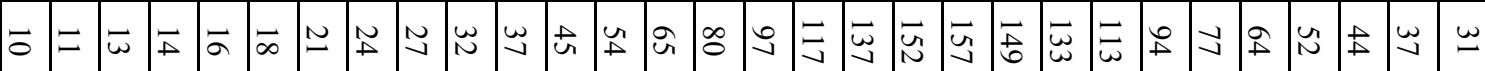

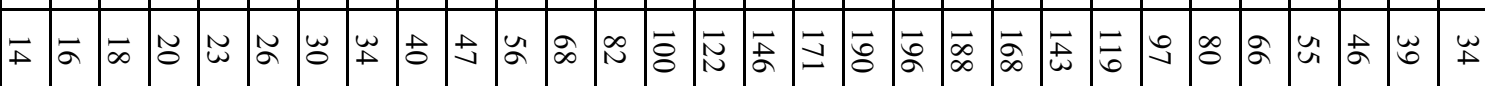

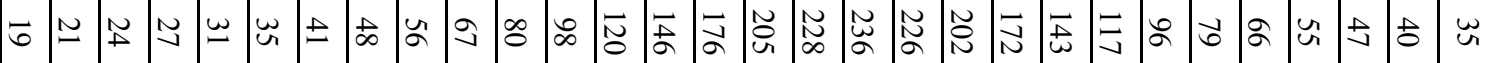

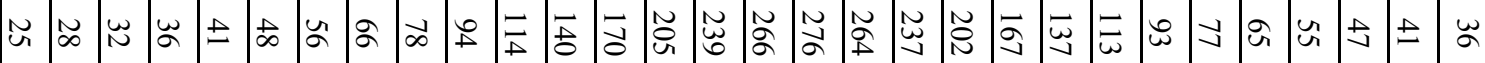

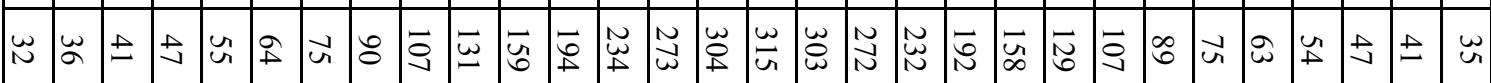

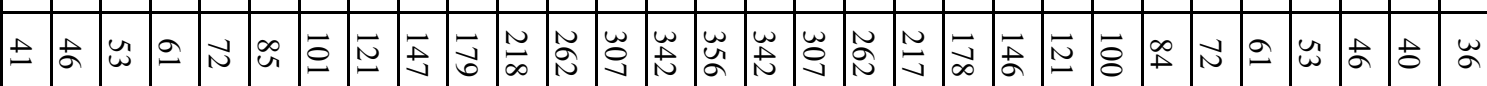

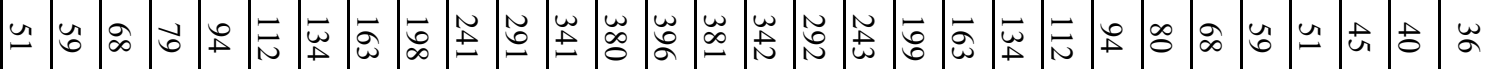

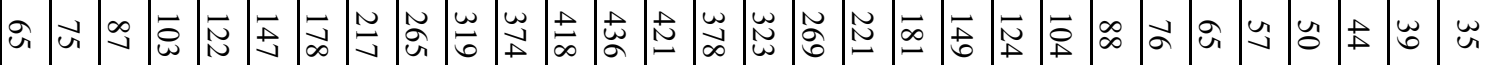

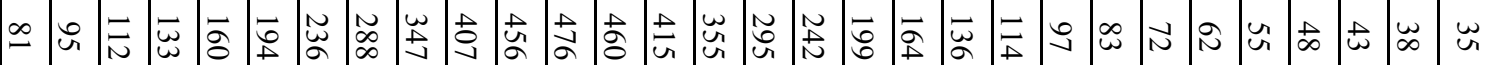

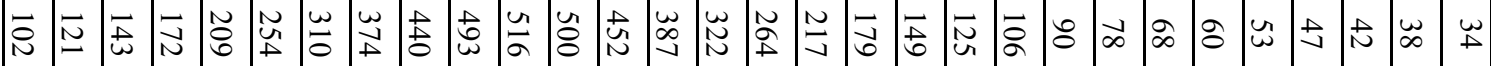

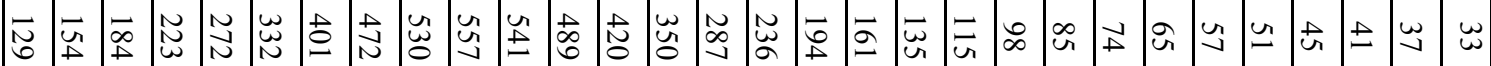

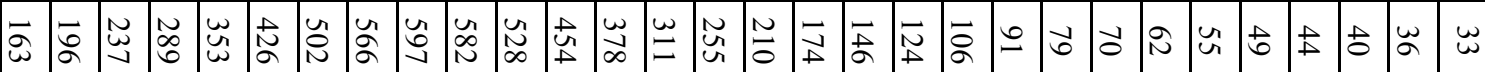

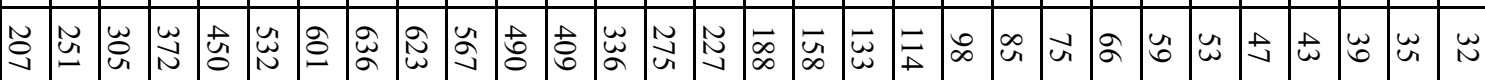

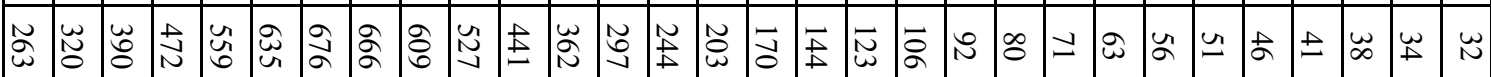

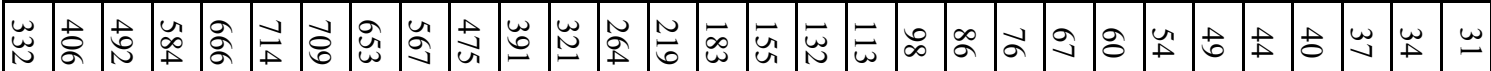

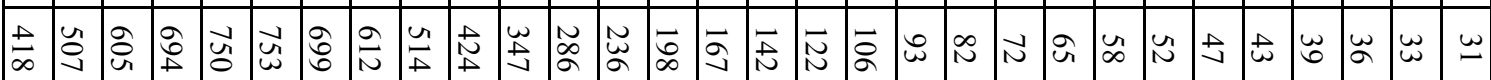

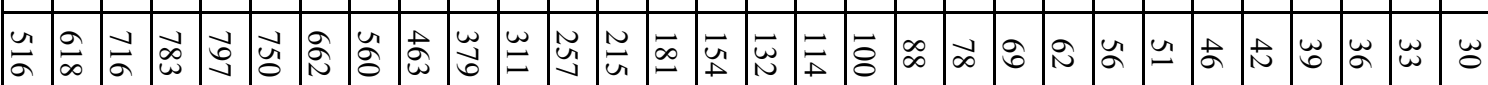
余永

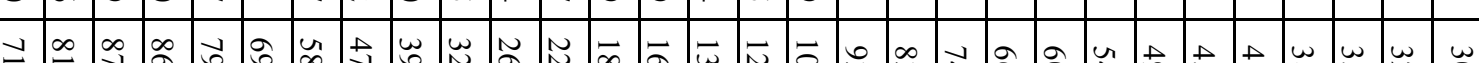

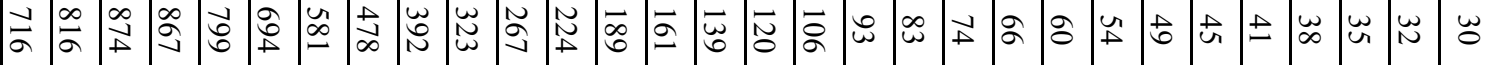

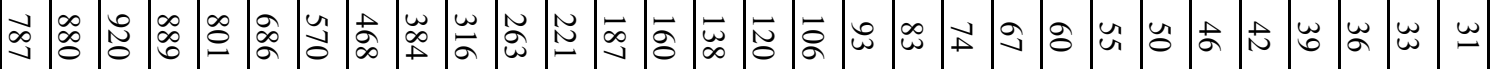

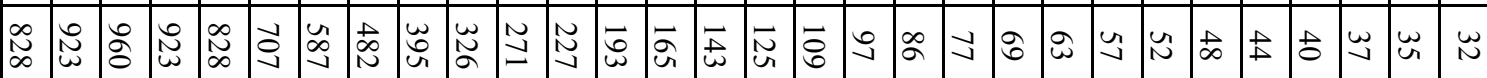

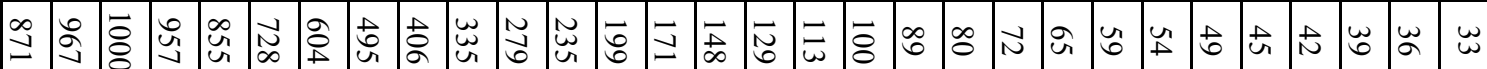

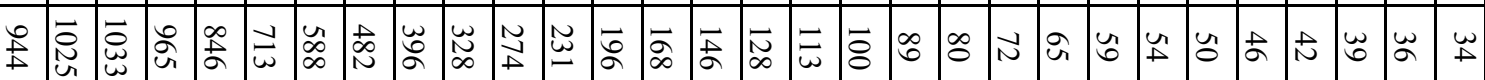

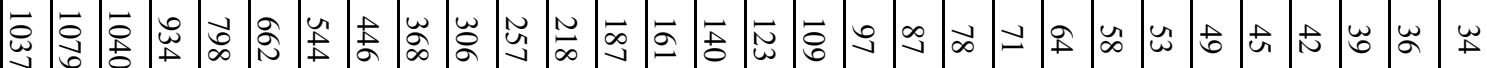

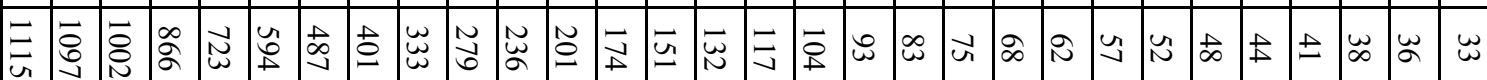

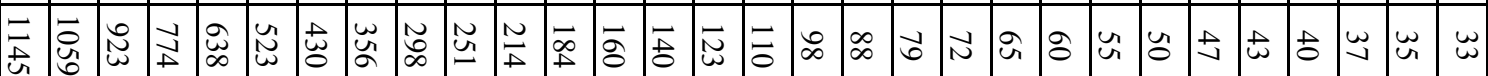

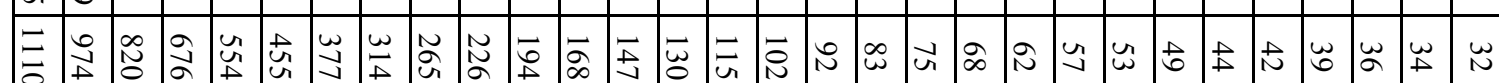




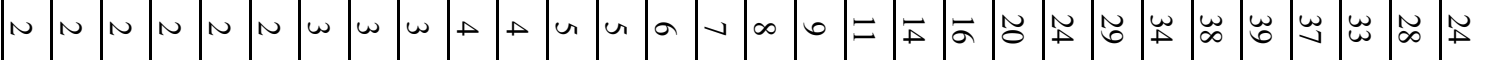
n n n n N n w w w w w

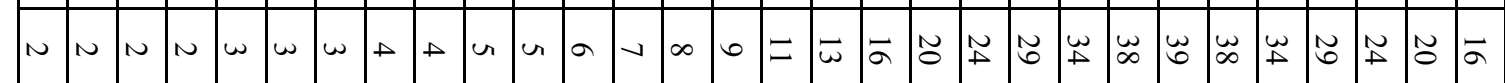
$N$ N $N$ N

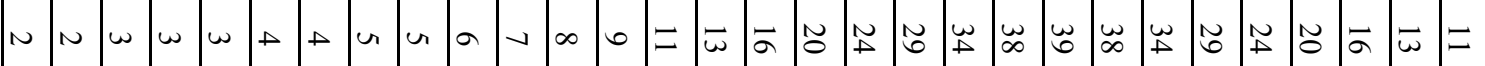
N

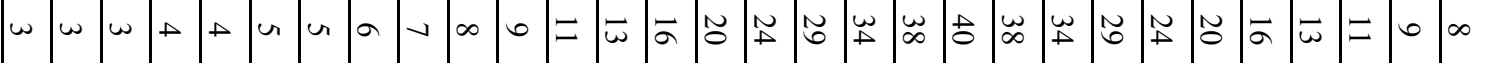

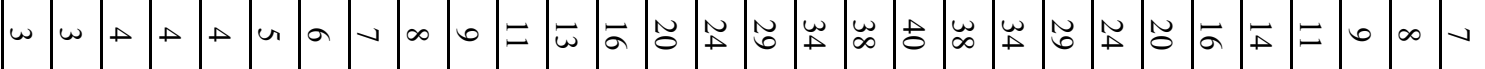

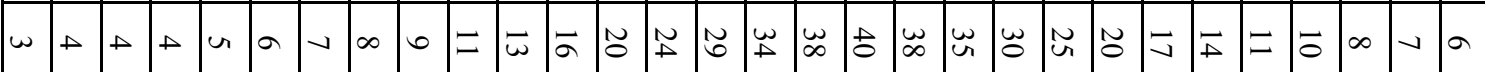

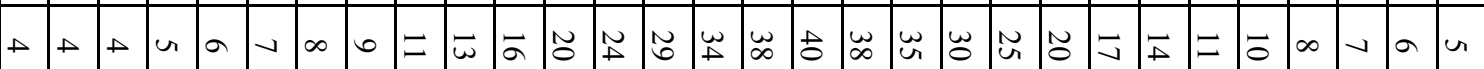

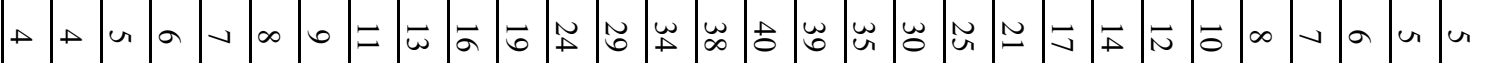

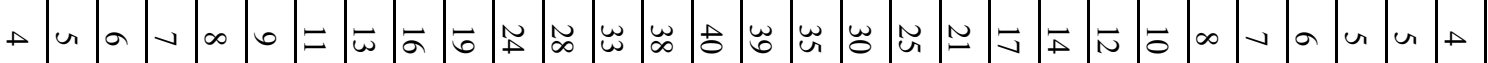

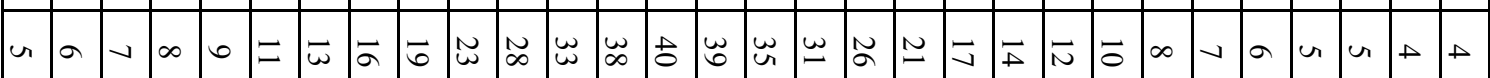

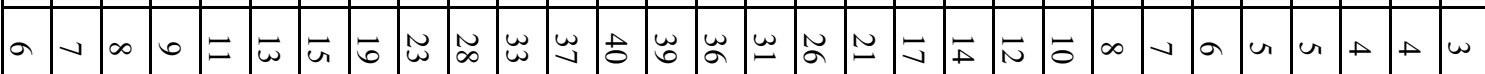

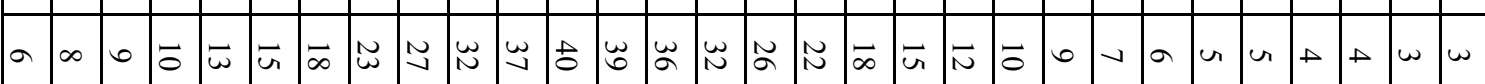

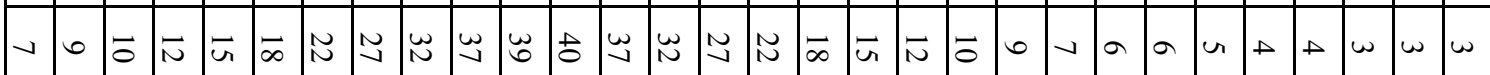

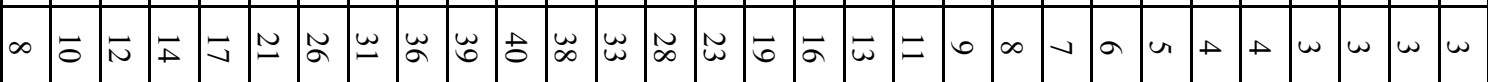

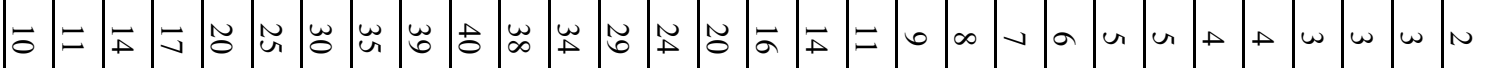

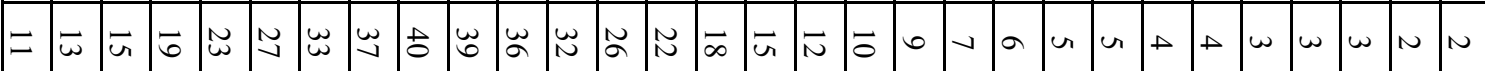

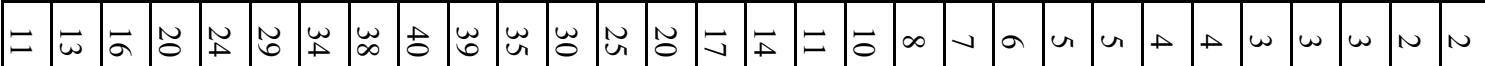

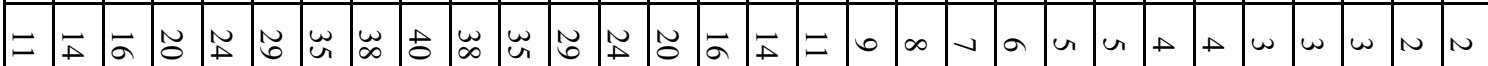

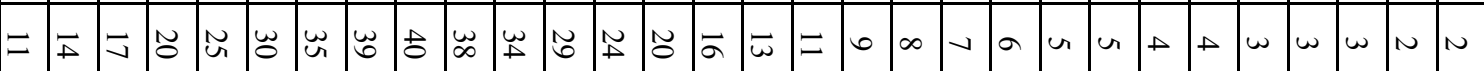

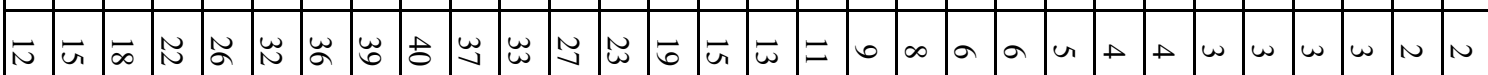

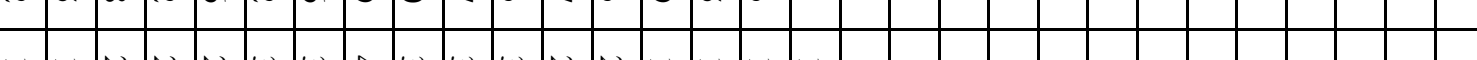

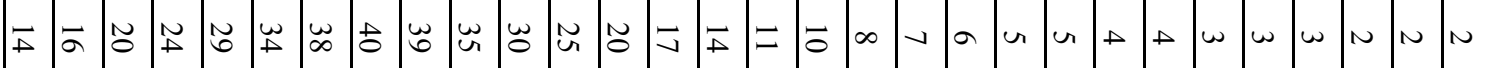

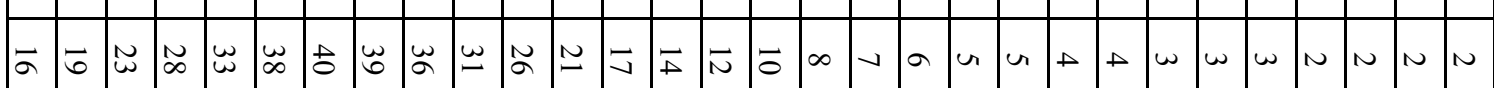




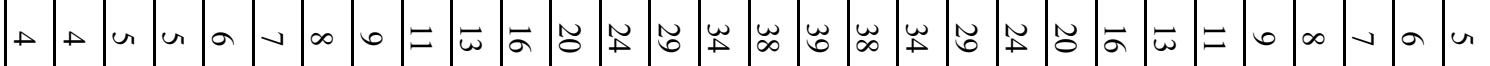

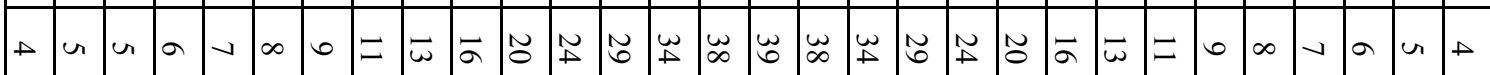

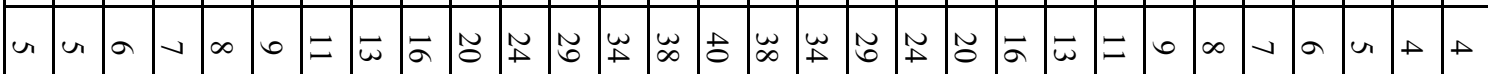

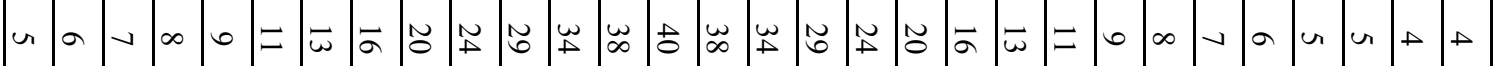

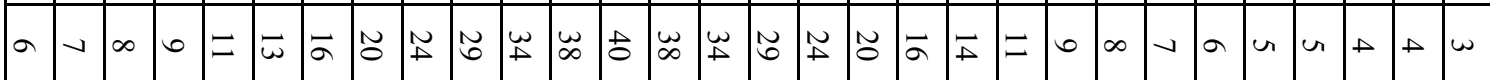

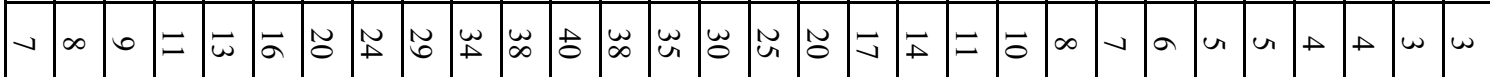

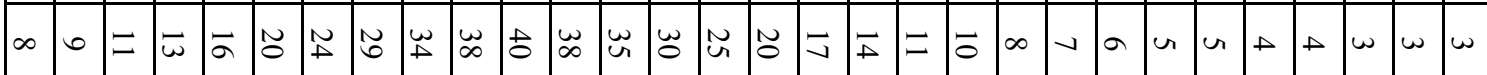

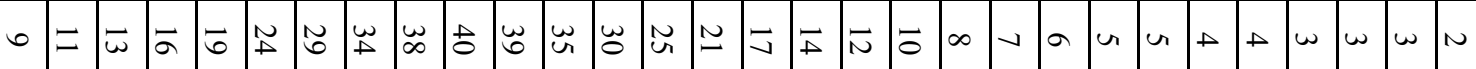

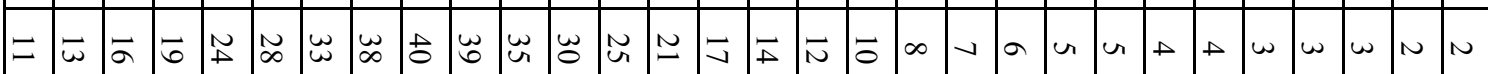

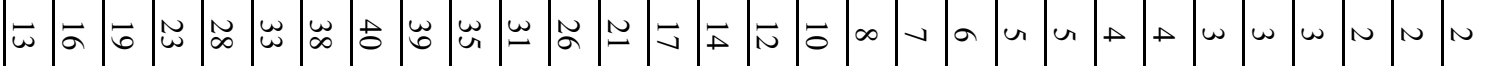

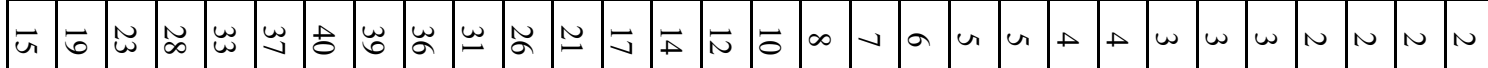
D N

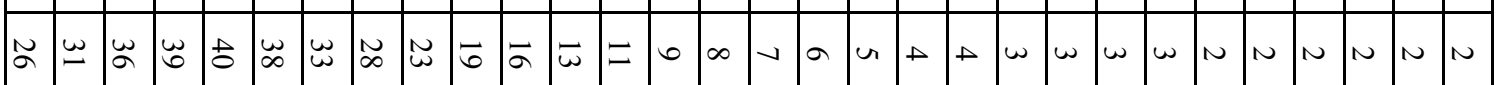

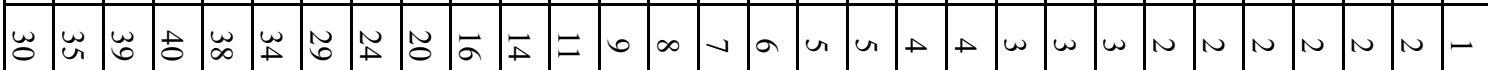

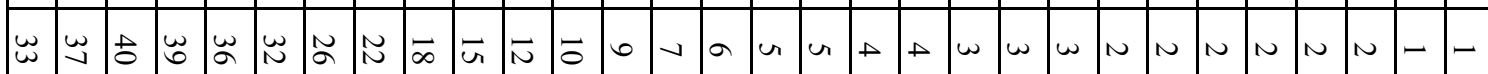

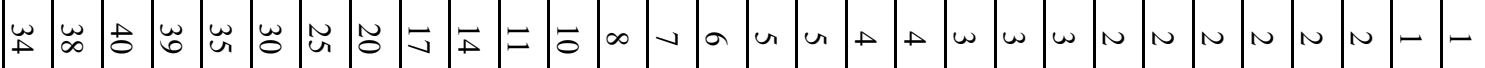

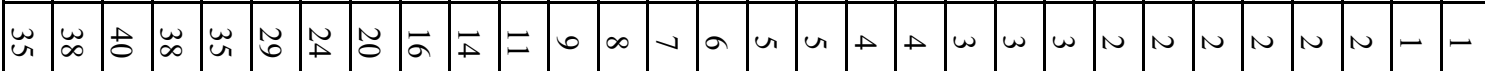

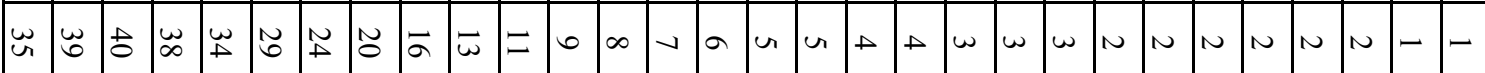

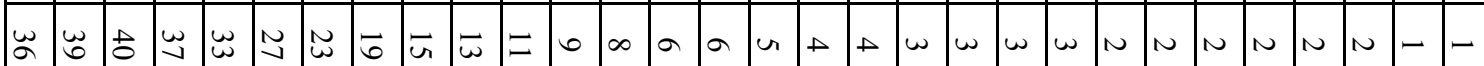

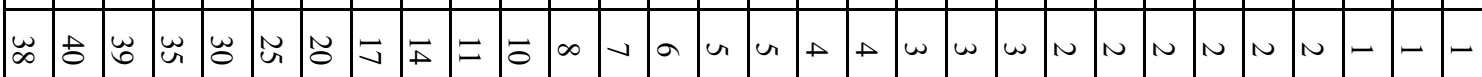

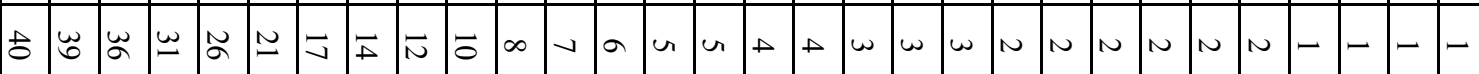

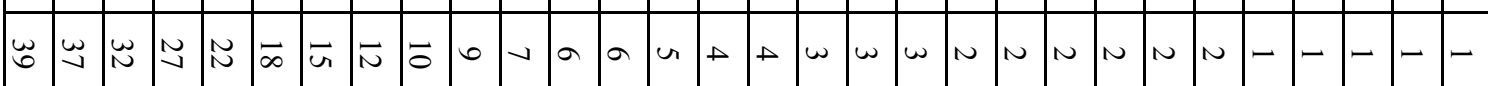

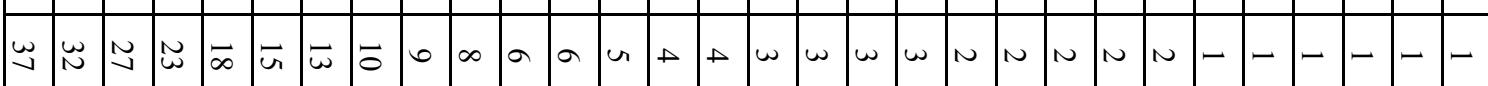




\section{Appendix E: Additional pre-shock tables in treatments with computerized opponents (RC} and NC)

\begin{tabular}{|c|c|}
\hline \multicolumn{2}{|c|}{ Pre-shock, Type $x$} \\
\hline Your price decision & $\begin{array}{l}\text { Average price of the other } \\
\text { three (computerized) firms }\end{array}$ \\
\hline 1 & 20 \\
\hline 2 & 20 \\
\hline 3 & 20 \\
\hline 4 & 20 \\
\hline 5 & 21 \\
\hline 6 & 21 \\
\hline 7 & 21 \\
\hline 8 & 21 \\
\hline 9 & 21 \\
\hline 10 & 21 \\
\hline 11 & 21 \\
\hline 12 & 21 \\
\hline 13 & 21 \\
\hline 14 & 21 \\
\hline 15 & 22 \\
\hline 16 & 22 \\
\hline 17 & 22 \\
\hline 18 & 22 \\
\hline 19 & 23 \\
\hline 20 & 23 \\
\hline 21 & 24 \\
\hline 22 & 24 \\
\hline 23 & 24 \\
\hline 24 & 25 \\
\hline 25 & 25 \\
\hline 26 & 25 \\
\hline 27 & 25 \\
\hline 28 & 25 \\
\hline 29 & 25 \\
\hline 30 & 25 \\
\hline
\end{tabular}

\begin{tabular}{|c|c|}
\hline \multicolumn{2}{|c|}{ Pre-shock, Type $y$} \\
\hline Your price decision & $\begin{array}{l}\text { Average price of the other } \\
\text { three (computerized) firms }\end{array}$ \\
\hline 1 & 6 \\
\hline 2 & 6 \\
\hline 3 & 6 \\
\hline 4 & 6 \\
\hline 5 & 6 \\
\hline 6 & 7 \\
\hline 7 & 7 \\
\hline 8 & 7 \\
\hline 9 & 7 \\
\hline 10 & 7 \\
\hline 11 & 7 \\
\hline 12 & 8 \\
\hline 13 & 9 \\
\hline 14 & 10 \\
\hline 15 & 11 \\
\hline 16 & 11 \\
\hline 17 & 12 \\
\hline 18 & 12 \\
\hline 19 & 13 \\
\hline 20 & 14 \\
\hline 21 & 15 \\
\hline 22 & 15 \\
\hline 23 & 15 \\
\hline 24 & 15 \\
\hline 25 & 15 \\
\hline 26 & 15 \\
\hline 27 & 15 \\
\hline 28 & 15 \\
\hline 29 & 15 \\
\hline 30 & 15 \\
\hline
\end{tabular}


Appendix E: Additional post-shock tables in treatments with computerized opponents (RC and NC)

\begin{tabular}{|c|c|}
\hline \multicolumn{2}{|c|}{ Post-shock, Type $x$} \\
\hline Your price decision & $\begin{array}{l}\text { Average price of the other } \\
\text { three (computerized) firms }\end{array}$ \\
\hline 1 & 7 \\
\hline 2 & 7 \\
\hline 3 & 7 \\
\hline 4 & 7 \\
\hline 5 & 7 \\
\hline 6 & 7 \\
\hline 7 & 7 \\
\hline 8 & 8 \\
\hline 9 & 9 \\
\hline 10 & 10 \\
\hline 11 & 11 \\
\hline 12 & 12 \\
\hline 13 & 13 \\
\hline 14 & 14 \\
\hline 15 & 15 \\
\hline 16 & 16 \\
\hline 17 & 17 \\
\hline 18 & 18 \\
\hline 19 & 19 \\
\hline 20 & 20 \\
\hline 21 & 21 \\
\hline 22 & 22 \\
\hline 23 & 23 \\
\hline 24 & 24 \\
\hline 25 & 25 \\
\hline 26 & 26 \\
\hline 27 & 27 \\
\hline 28 & 28 \\
\hline 29 & 28 \\
\hline 30 & 28 \\
\hline
\end{tabular}

\begin{tabular}{|c|c|}
\hline \multicolumn{2}{|c|}{ Post-shock, Type $y$} \\
\hline Your price decision & $\begin{array}{l}\text { Average price of the other } \\
\text { three (computerized) firms }\end{array}$ \\
\hline 1 & 3 \\
\hline 2 & 3 \\
\hline 3 & 3 \\
\hline 4 & 3 \\
\hline 5 & 4 \\
\hline 6 & 4 \\
\hline 7 & 5 \\
\hline 8 & 5 \\
\hline 9 & 5 \\
\hline 10 & 5 \\
\hline 11 & 5 \\
\hline 12 & 5 \\
\hline 13 & 5 \\
\hline 14 & 6 \\
\hline 15 & 7 \\
\hline 16 & 8 \\
\hline 17 & 9 \\
\hline 18 & 10 \\
\hline 19 & 11 \\
\hline 20 & 12 \\
\hline 21 & 13 \\
\hline 22 & 14 \\
\hline 23 & 15 \\
\hline 24 & 16 \\
\hline 25 & 17 \\
\hline 26 & 18 \\
\hline 27 & 19 \\
\hline 28 & 20 \\
\hline 29 & 21 \\
\hline 30 & 22 \\
\hline
\end{tabular}


Table 1: Treatment conditions

\begin{tabular}{|c|c|c|}
\hline & Payoffs in Real Terms & Payoffs in Nominal Terms \\
\hline \multirow[t]{2}{*}{$\begin{array}{c}\text { Computerized } \\
\text { Opponents }\end{array}$} & $\begin{array}{l}\text { Real treatment with computerized } \\
\text { opponents (RC): } 22 \text { groups with } 1 \\
\text { human and } n-1 \text { computerized } \\
\text { players in each group }\end{array}$ & $\begin{array}{l}\text { Nominal treatment with } \\
\text { computerized opponents (NC): } 24 \\
\text { groups with } 1 \text { human and } n-1 \\
\text { computerized players in each group }\end{array}$ \\
\hline & $\begin{array}{l}\text { Measures nominal inertia caused } \\
\text { by individual optimization errors } \\
\text { that are not due to money illusion }\end{array}$ & $\begin{array}{l}\text { Comparison with RC measures } \\
\text { nominal inertia caused by } \\
\text { individual-level money illusion }\end{array}$ \\
\hline \multirow[t]{2}{*}{$\begin{array}{c}\text { Human } \\
\text { Opponents }\end{array}$} & $\begin{array}{c}\text { Real treatment with human } \\
\text { opponents (RH): } \\
10 \text { groups with } n \text { human players in } \\
\text { each group }\end{array}$ & $\begin{array}{l}\text { Nominal treatment with human } \\
\text { opponents }(\mathbf{N H}) \text { : } \\
11 \text { groups with } n \text { human players in } \\
\text { each group }\end{array}$ \\
\hline & $\begin{array}{l}\text { Comparison with RC measures } \\
\text { nominal inertia caused by the } \\
\text { difficulties of coordinating } \\
\text { expectations and actions }\end{array}$ & $\begin{array}{l}\text { Comparison with RH measures the } \\
\text { total (direct and indirect) effects of } \\
\text { money illusion in a strategic setting }\end{array}$ \\
\hline
\end{tabular}


Table 2: Experimental parameters (negative money shock)

\begin{tabular}{|c|c|c|}
\hline \multirow{8}{*}{$\begin{array}{l}\frac{n}{0} \\
\frac{0}{0} \\
0 \\
\overline{2}\end{array}$} & Representation of payoffs in the nominal frame & $\bar{P}_{-i} \pi_{i}$ \\
\hline & Representation of payoffs in the real frame & $\pi_{i}$ \\
\hline & Group size & $n=4$ \\
\hline & Information feedback in period $t$ & $\bar{P}_{-i}, \pi_{i}$ \\
\hline & Real equilibrium payoff & 40 \\
\hline & Choice variable & $P_{i} \in\{1,2, \ldots, 30\}$ \\
\hline & $\begin{array}{l}\text { Length of pre- and post-shock phase in treatment with } \\
\text { computerized opponents }\end{array}$ & $T=10$ \\
\hline & $\begin{array}{l}\text { Length of pre- and post-shock phase in treatment with } \\
\text { human opponents }\end{array}$ & $T=20$ \\
\hline \multirow{6}{*}{ 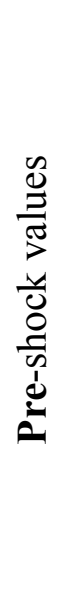 } & Money supply $M_{0}$ & 42 \\
\hline & $\begin{array}{l}\text { Average equilibrium price } \bar{P}^{*} \text { and average equilibrium } \\
\text { expectation for the whole group }\end{array}$ & 18 \\
\hline & Equilibrium price for type $x$ & 9 \\
\hline & Equilibrium expectation $\bar{P}_{-i}^{e}$ for type $x$ & 21 \\
\hline & Equilibrium price for type $y$ & 27 \\
\hline & Equilibrium expectation $\bar{P}_{-i}^{e}$ for type $y$ & 15 \\
\hline \multirow{6}{*}{ 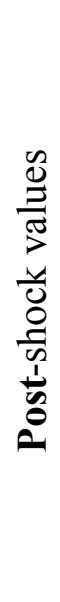 } & Money supply $M_{1}$ & 14 \\
\hline & $\begin{array}{l}\text { Average equilibrium price } \bar{P}^{*} \text { and average equilibrium } \\
\text { expectation for the whole group }\end{array}$ & 6 \\
\hline & Equilibrium price for type $x$ & 3 \\
\hline & Equilibrium expectation $\bar{P}_{-i}^{e}$ for type $x$ & 7 \\
\hline & Equilibrium price for type $y$ & 9 \\
\hline & Equilibrium expectation $\bar{P}_{-i}^{e}$ for type $y$ & 5 \\
\hline
\end{tabular}


Table 3: Evolution of prices and efficiency losses over time

\begin{tabular}{|c|c|c|c|c|c|c|c|c|}
\hline \multirow[b]{3}{*}{ period } & \multicolumn{4}{|c|}{ Average price } & \multicolumn{4}{|c|}{ Average efficiency loss (percent) } \\
\hline & \multicolumn{2}{|c|}{ Computerized opponents } & \multicolumn{2}{|c|}{ Human opponents } & \multicolumn{2}{|c|}{ Computerized opponents } & \multicolumn{2}{|c|}{ Human opponents } \\
\hline & $\begin{array}{l}\text { Real } \\
\text { (RC) }\end{array}$ & $\begin{array}{c}\text { Nominal } \\
\text { (NC) }\end{array}$ & $\begin{array}{l}\text { Real } \\
(\mathrm{RH})\end{array}$ & $\begin{array}{c}\text { Nominal } \\
(\mathrm{NH})\end{array}$ & $\begin{array}{l}\text { Real } \\
(\mathrm{RC})\end{array}$ & $\begin{array}{c}\text { Nominal } \\
\text { (NC) }\end{array}$ & $\begin{array}{l}\text { Real } \\
(\mathrm{RH})\end{array}$ & $\begin{array}{c}\text { Nominal } \\
(\mathrm{NH})\end{array}$ \\
\hline-20 & & & 17.6 & 18.5 & & & 14.4 & 19.0 \\
\hline-19 & & & 18.2 & 19.3 & & & 21.5 & 14.6 \\
\hline-18 & & & 17.8 & 19.1 & & & 14.1 & 10.2 \\
\hline-17 & & & 17.7 & 19.4 & & & 9.5 & 11.7 \\
\hline-16 & & & 17.9 & 19.2 & & & 8.8 & 6.8 \\
\hline-15 & & & 18.3 & 19.1 & & & 10.8 & 13.2 \\
\hline-14 & & & 17.6 & 18.2 & & & 8.0 & 9.9 \\
\hline-13 & & & 17.9 & 18.6 & & & 8.2 & 4.2 \\
\hline-12 & & & 17.9 & 18.7 & & & 6.3 & 3.1 \\
\hline-11 & & & 17.6 & 18.3 & & & 5.5 & 7.5 \\
\hline-10 & 17.9 & 15.2 & 17.8 & 18.4 & 1.0 & 16.4 & 9.4 & 3.4 \\
\hline-9 & 18.1 & 17.0 & 17.5 & 18.2 & 0.5 & 12.6 & 3.6 & 1.6 \\
\hline-8 & 17.8 & 17.2 & 17.6 & 19.0 & 1.6 & 9.0 & 3.3 & 6.0 \\
\hline-7 & 18.0 & 18.0 & 17.7 & 18.3 & 0.5 & 3.0 & 2.4 & 1.8 \\
\hline-6 & 17.6 & 17.2 & 17.6 & 18.2 & 2.4 & 10.4 & 10.9 & 1.3 \\
\hline-5 & 18.0 & 17.7 & 18.1 & 18.3 & 0.3 & 5.4 & 7.0 & 2.7 \\
\hline-4 & 18.0 & 18.1 & 18.1 & 18.4 & 0.0 & 3.5 & 7.3 & 2.5 \\
\hline-3 & 17.8 & 16.1 & 17.6 & 18.6 & 1.3 & 12.6 & 3.7 & 2.8 \\
\hline-2 & 18.4 & 18.3 & 17.9 & 18.2 & 2.3 & 1.9 & 2.2 & 0.7 \\
\hline-1 & 18.0 & 17.0 & 18.0 & 18.2 & 0.0 & 5.3 & 0.9 & 0.9 \\
\hline 1 & 6.0 & 8.0 & 9.1 & 13.1 & 0.0 & 10.4 & 51.8 & 65.1 \\
\hline 2 & 7.0 & 7.4 & 7.7 & 12.9 & 3.6 & 8.2 & 20.0 & 47.5 \\
\hline 3 & 6.0 & 6.8 & 7.4 & 11.4 & 0.0 & 4.4 & 15.0 & 34.8 \\
\hline 4 & 6.0 & 6.4 & 6.9 & 10.4 & 0.6 & 6.5 & 9.1 & 27.4 \\
\hline 5 & 6.0 & 6.9 & 7.0 & 9.9 & 0.0 & 8.0 & 14.8 & 17.4 \\
\hline 6 & 6.0 & 6.8 & 6.6 & 10.2 & 0.0 & 15.6 & 7.7 & 15.9 \\
\hline 7 & 6.0 & 7.5 & 6.3 & 9.7 & 0.0 & 9.3 & 4.5 & 16.4 \\
\hline 8 & 6.0 & 6.8 & 6.4 & 9.1 & 0.0 & 15.5 & 4.6 & 10.7 \\
\hline 9 & 6.0 & 6.5 & 6.3 & 8.7 & 0.0 & 4.3 & 3.8 & 9.5 \\
\hline 10 & 5.9 & 6.5 & 6.8 & 8.6 & 1.6 & 3.8 & 11.0 & 13.8 \\
\hline 11 & & & 6.1 & 8.1 & & & 4.6 & 8.2 \\
\hline 12 & & & 6.2 & 7.6 & & & 3.3 & 6.4 \\
\hline 13 & & & 6.2 & 7.2 & & & 2.1 & 6.2 \\
\hline 14 & & & 6.2 & 6.9 & & & 2.8 & 4.6 \\
\hline 15 & & & 6.1 & 6.7 & & & 2.6 & 2.6 \\
\hline 16 & & & 6.1 & 7.3 & & & 2.1 & 9.6 \\
\hline 17 & & & 6.0 & 6.8 & & & 0.9 & 5.2 \\
\hline 18 & & & 6.1 & 7.2 & & & 1.8 & 14.2 \\
\hline 19 & & & 6.1 & 7.5 & & & 1.4 & 12.5 \\
\hline 20 & & & 6.2 & 7.0 & & & 3.0 & 2.4 \\
\hline
\end{tabular}


Table 4: Deviation from post-shock equilibrium in treatments with human opponents

$$
\bar{P}_{i t}-\bar{P}^{*}={ }_{t=1}^{19} \alpha_{t} d_{t}+{ }_{t=1}^{20} \beta_{t}\left(1-d_{t}\right)+u
$$

where $\bar{P}_{i t}$ denotes the average price of group i in period $\mathrm{t}$ and $d_{t}=1$ if the price observation in period $t$ comes from the RH.

\begin{tabular}{|c|c|c|}
\hline & $\begin{array}{c}\text { Real treatment } \\
\text { with human opponents } \\
(\mathrm{RH})\end{array}$ & $\begin{array}{c}\text { Nominal treatment } \\
\text { with human opponents } \\
(\mathrm{NH})\end{array}$ \\
\hline $\begin{array}{c}\text { Post-shock } \\
\text { period }\end{array}$ & Coefficient $\alpha_{t}$ & Coefficient $\beta_{t}$ \\
\hline 1 & $3.10 * * *$ & $7.14 * * *$ \\
\hline 2 & $1.68 * *$ & $6.86^{* * *}$ \\
\hline 3 & 1.43 & $5.43 * * *$ \\
\hline 4 & 0.90 & $4.41 * * *$ \\
\hline 5 & 1.00 & $3.86^{* * *}$ \\
\hline 6 & 0.55 & $4.18^{* * *}$ \\
\hline 7 & 0.25 & $3.77 * * *$ \\
\hline 8 & 0.35 & $3.05^{* * *}$ \\
\hline 9 & 0.25 & $2.70^{* * *}$ \\
\hline 10 & 0.83 & $2.59 * * *$ \\
\hline 11 & 0.13 & $2.05 * * *$ \\
\hline 12 & 0.23 & $1.61 * *$ \\
\hline 13 & 0.18 & 1.18 \\
\hline 14 & 0.18 & 0.89 \\
\hline 15 & 0.10 & 0.70 \\
\hline 16 & 0.13 & 1.25 \\
\hline 17 & 0.03 & 0.80 \\
\hline 18 & 0.13 & 1.20 \\
\hline 19 & 0.05 & 1.45 \\
\hline 20 & - & 0.95 \\
\hline
\end{tabular}

$* * *=$ significant at the 1 percent level, $* *=$ significant at the 5 percent level. 
Table 5: Evolution of prices over time in treatments with positive shock

\begin{tabular}{|c|c|c|}
\cline { 2 - 3 } \multicolumn{1}{c|}{} & \multicolumn{2}{c|}{ Average price } \\
\hline Period & $\begin{array}{c}\text { Real } \\
(\mathrm{RH})\end{array}$ & $\begin{array}{c}\text { Nominal } \\
\text { (NH) }\end{array}$ \\
\hline-15 & 13.0 & 14.9 \\
\hline-14 & 13.0 & 14.7 \\
\hline-13 & 12.7 & 14.6 \\
\hline-12 & 12.7 & 14.3 \\
\hline-11 & 12.7 & 14.3 \\
\hline-10 & 12.5 & 14.1 \\
\hline-9 & 12.5 & 13.6 \\
\hline-8 & 12.5 & 13.4 \\
\hline-7 & 12.4 & 13.7 \\
\hline-6 & 12.5 & 13.8 \\
\hline-5 & 12.5 & 13.8 \\
\hline-4 & 12.5 & 13.9 \\
\hline-3 & 12.5 & 13.6 \\
\hline-2 & 12.6 & 13.1 \\
\hline-1 & 12.5 & 13.1 \\
\hline 1 & 22.5 & 20.5 \\
\hline 2 & 24.3 & 22.8 \\
\hline 3 & 24.8 & 24.1 \\
\hline 4 & 24.9 & 24.8 \\
\hline 5 & 25.0 & 25.0 \\
\hline 6 & 25.0 & 25.1 \\
\hline 7 & 25.0 & 25.2 \\
\hline 8 & 25.0 & 25.1 \\
\hline 9 & 25.0 & 25.0 \\
\hline 10 & 25.0 & 25.2 \\
\hline 11 & 25.0 & 25.2 \\
\hline 12 & 25.0 & 25.0 \\
\hline 13 & 25.0 & 25.0 \\
\hline 14 & 24.3 & 24.5 \\
\hline 15 & 24.6 & 24.9 \\
\hline
\end{tabular}




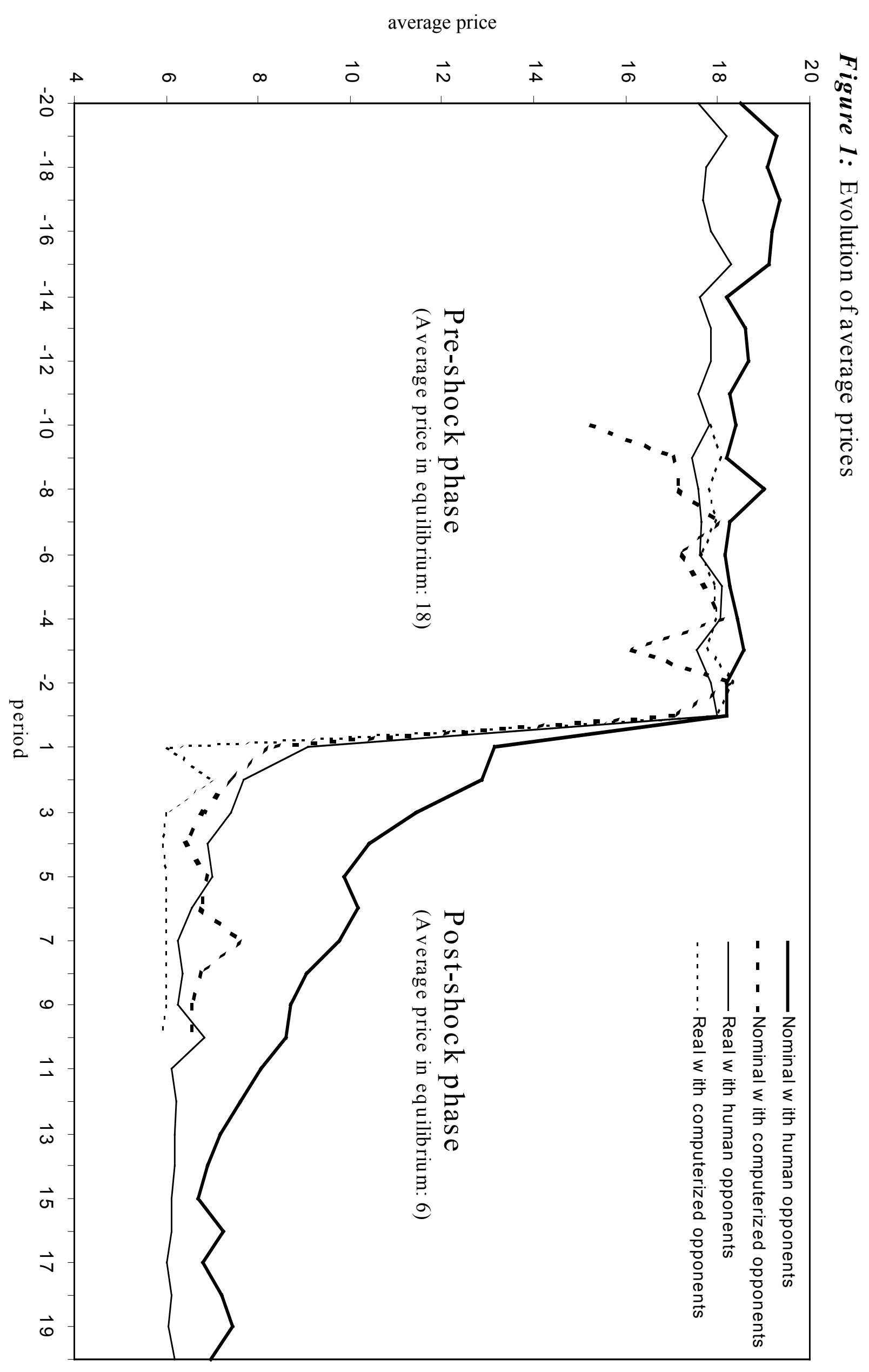

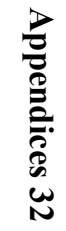


Figure 2: Evolution of average expectations

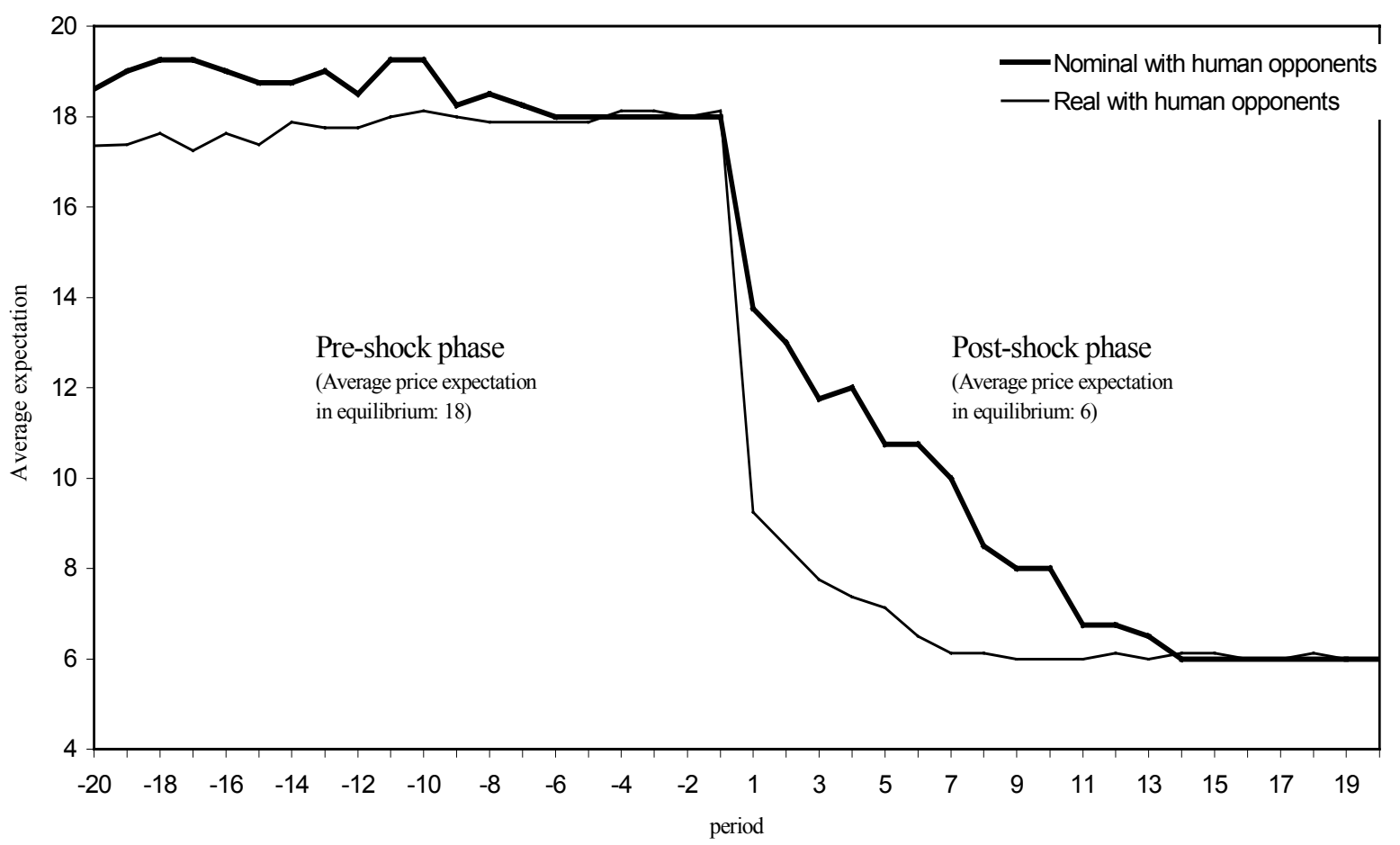

Figure 3: Differences in deviations from equilibrium across the negative and the positive shock

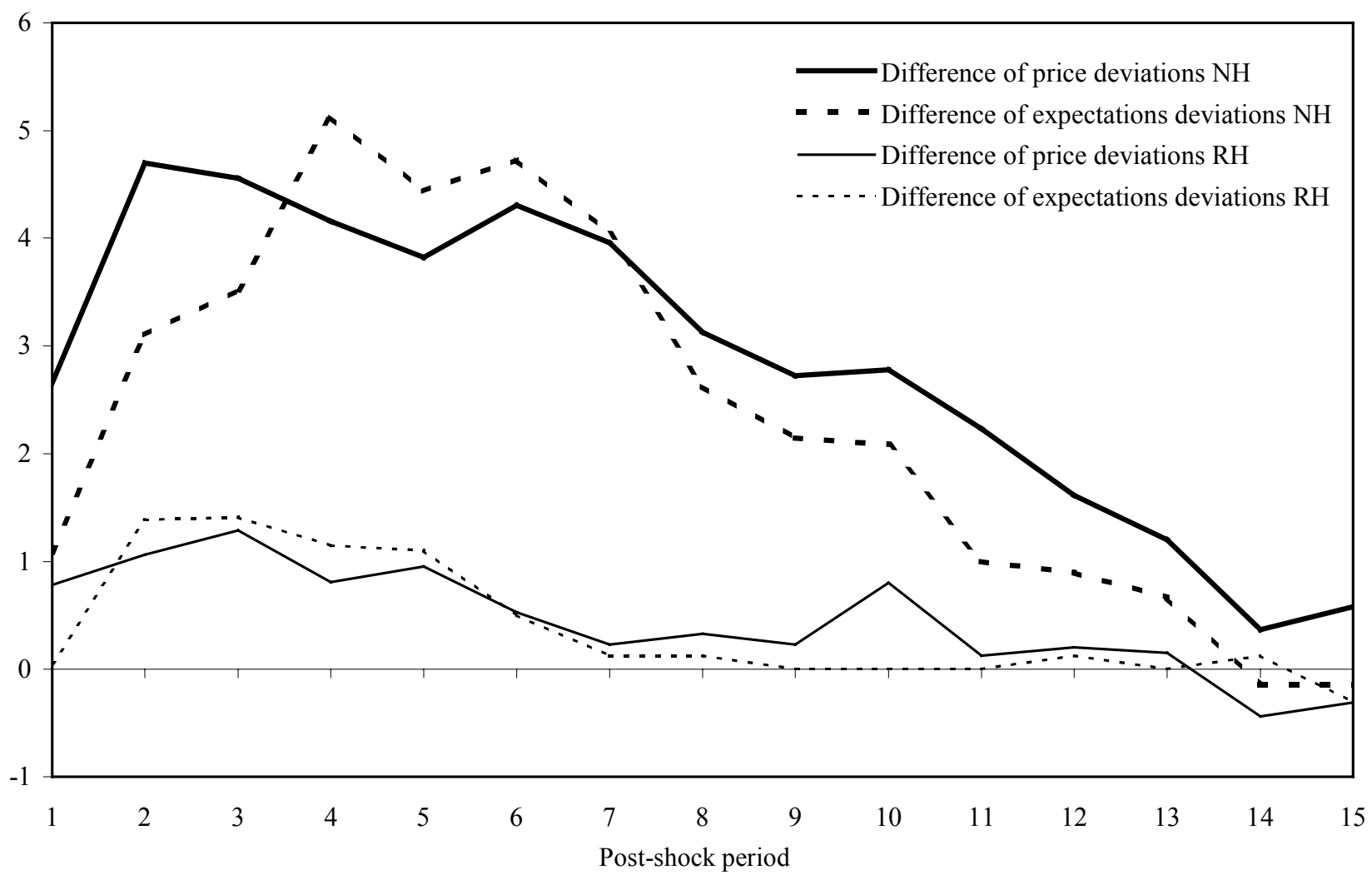




\section{IZA Discussion Papers}

No. Author(s)

71

72

L. Goerke

J. Fersterer

R. Winter-Ebmer

73

G. S. Epstein

S. Nitzan

74 M. Kräkel

75

B. Henry

M. Karanassou

D. J. Snower

76

G. Brunello

M. Giannini

77

C. M. Schmidt

78

J. Hansen

R. Wahlberg

79

J. S. Earle

Z. Sakova

80 J. C. van Ours

J. Veenman

81

T. J. Hatton

S. Wheatley Price

82 K. A. Konrad

83

R. Euwals

84

C. M. Schmidt

85 S. Pudney

M. A. Shields

86

J.P. Haisken-DeNew

C. M. Schmidt

87
Title

Area

Date

The Wedge

3

$11 / 99$

Are Austrian Returns to Education Falling Over

Time?

The Endogenous Determination of Minimum Wage 3

Strategic Mismatches in Competing Teams

5

Adjustment Dynamics and the Natural Rate: An 1

Account of UK Unemployment

Selective Schools

5

Knowing What Works: The Case for Rigorous

Program Evaluation

Endogenous Schooling and the Distribution of the Gender Wage Gap

Entrepreneurship from Scratch: Lessons on the Entry Decision into Self-Employment from Transition Economies

The Netherlands: Old Emigrants - Young Immigrant Country

Migration, Migrants and Policy in the United Kingdom

Privacy, time consistent optimal labor income taxation and education policy

Female Labour Supply, Flexibility of Working Hours, 1 and Job Mobility in the Netherlands

The Heterogeneity and Cyclical Sensitivity of 1 Unemployment: An Exploration of German Labor Market Flows

Gender and Racial Discrimination in Pay and 5/6 Promotion for NHS Nurses

Money for Nothing and Your Chips for Free?

5 The Anatomy of the PC Wage Differential

Educational Mismatch and Wages in Germany
5

$11 / 99$

$11 / 99$

$12 / 99$

$12 / 99$

$12 / 99$

$12 / 99$

$12 / 99$

$12 / 99$

$12 / 99$

$12 / 99$

$12 / 99$

$12 / 99$

12/99

$12 / 99$

$12 / 99$

$12 / 99$ 
P. Cahuc

A. Zylberberg

97

A. Barrett

98

J.P. Haisken-DeNew

C. M. Schmidt

L. Husted

H. S. Nielsen

M. Rosholm

N. Smith
G. Brunello
C. Graziano
B. Parigi

Migration in Spain: Historical Background and 1 Current Trends

Aliyah to Israel: Immigration under Conditions of 1 Adversity

Tenures that Shook the World: Worker Turnover in $\quad 4$ Russia, Poland and Britain

Identification and Estimation of Causal Effects of 6 Multiple Treatments Under the Conditional Independence Assumption

The Rate of Return to Private Schooling

An Evaluation of Public-Sector-Sponsored

\section{Germany}

An Evaluation of Public Employment Programmes 6 in the East German State of Sachsen-Anhalt

Job Protection, Minimum Wage and Unemployment 3

Irish Migration: Characteristics, Causes and 1

Industry Wage Differentials Revisited: A

Longitudinal Comparison of Germany and USA

Residential Location and Youth Unemployment: 1

The Economic Geography of School-to-Work-

Transitions

Immigrant Assimilation and Welfare Participation: 1/3

Do Immigrants Assimilate Into or Out-of Welfare?

Employment and Wage Assimilation of Male First 3 Generation Immigrants in Denmark

Labor Supply and Matching Rates for Welfare

Characteristics

Estimation in a Duration Model for Evaluating

Matching Model with Uncertainty -

An Extension of Mortensen and Pissarides (1994)

Ownership or Performance: What Determines 1 
1979 - 1990: An analysis of the (West-)German multivariate failure times and unobserved heterogeneity

107 J. C. van Ours G. Ridder

J. Boone

J. C. van Ours

G. J. van den Berg

B. van der Klaauw

110 D. DeVoretz

C. Werner

111 V. Sorm

K. Terrell

L. Bellmann

T. Schank

113 R. Euwals

114 G. Brunello

A. Medio

115 A. Cigno

F. C. Rosati

116 C. Belzil

117 S. Bender

A. Haas

C. Klose

118 M. A. Shields

M. E. Ward

119 A. Lindbeck

D. J. Snower

120 P. T. Pereira

P. S. Martins

121 J. C. van Ours

122 D. Munich

J. Svejnar

K. Terrell

123 J. Hunt
Fast Track or Failure: A Study of the Completion

Rates of Graduate Students in Economics

Modeling Financial Incentives to Get Unemployed Back to Work

Combining Micro and Macro Unemployment

Duration Data

A Theory of Social Forces and Immigrant Second

Language Acquisition

Sectoral Restructuring and Labor Mobility:

A Comparative Look at the Czech Republic

Innovations, Wages and Demand for

Heterogeneous Labour: New Evidence from a

Matched Employer-Employee Data-Set

Do Mandatory Pensions Decrease Household

Savings? Evidence for the Netherlands

An Explanation of International Differences in

Education and Workplace Training

Why do Indian Children Work, and is it Bad for

Them?

Unemployment Insurance and Subsequent Job

Duration: Job Matching vs. Unobserved

Heterogeneity

IAB Employment Subsample 1975-1995.

Opportunities for Analysis Provided by the

Anonymised Subsample

Improving Nurse Retention in the British National

Health Service: The Impact of Job Satisfaction on

Intentions to Quit

The Division of Labor and the Market for

Organizations

Does Education Reduce Wage Inequality?

Quantile Regressions Evidence from Fifteen

European Countries

Do Active Labor Market Policies Help Unemployed Workers to Find and Keep Regular Jobs?

Returns to Human Capital under the Communist

Wage Grid and During the Transition to a Market

Economy

Why Do People Still Live in East Germany?
3

5

$2 / 00$

5

$2 / 00$

5

$2 / 00$

$1 / 00$

$1 / 00$

$1 / 00$

$2 / 00$

$2 / 00$

$2 / 00$

$2 / 00$

$2 / 00$

$2 / 00$

$2 / 00$

$2 / 00$

7

/00

$3 / 00$

$4 / 6$

4

$3 / 00$ 
Rational Poverty or Poor Rationality? The Take-up

125 F. Büchel

J. R. Frick

of Social Assistance Benefits

The Income Portfolio of Immigrants in Germany - $\quad 1 / 3$

$3 / 00$

Effects of Ethnic Origin and Assimilation. Or:

Who Gains from Income Re-Distribution?

126 J. Fersterer

R. Winter-Ebmer

Smoking, Discount Rates, and Returns to

Education

127 M. Karanassou

D. J. Snower

Characteristics of Unemployment Dynamics: The

Chain Reaction Approach

128 O. Ashenfelter

Do Unemployment Insurance Recipients Actively

Seek Work? Evidence From Randomized Trials in

D. Ashmore

O. Deschênes

129 B. R. Chiswick

M. E. Hurst

130 G. Brunello

S. Comi

C. Lucifora

Four U.S. States

The Employment, Unemployment and

Unemployment Compensation Benefits of

$1 / 3 \quad 3 / 00$

Immigrants

The Returns to Education in Italy: A New Look at $5 \quad 3 / 00$

the Evidence

Are Immigrants Favorably Self-Selected? An $\quad 1 \quad 3 / 00$

Economic Analysis

Hours and Wages in the Depression: British $7 \quad 3 / 00$

Engineering, 1926-1938

Paid and Unpaid Overtime Working in Germany and $1 \quad 3 / 00$

133 D. N. F. Bell

R. A. Hart

O. Hübler

W. Schwerdt

134 A. D. Kugler

G. Saint-Paul

135 A. Barrett

P. J. O'Connell

the UK

Hiring and Firing Costs, Adverse Selection and

3

$3 / 00$

Long-term Unemployment

Is There a Wage Premium for Returning Irish

1

$3 / 00$

Migrants?

136 M. Bräuninger

M. Pannenberg

Unemployment and Productivity Growth: An

3

$3 / 00$

Empirical Analysis within the Augmented Solow

Model

137 J.-St. Pischke

Continuous Training in Germany

$3 / 00$

138 J. Zweimüller

R. Winter-Ebmer

Firm-specific Training: Consequences for Job

Mobility

139 R. A. Hart

Y. Ma

Wages, Hours and Human Capital over the

Life Cycle

5

$3 / 00$

Education and Earnings Growth: Evidence from 11

European Countries

The Effects of Public Sector Sponsored Training on

Individual Employment Performance in East

$4 / 00$ 

both Worlds?

$\begin{array}{cl}145 & \text { M.-S. Yun } \\ 146 & \begin{array}{l}\text { T. K. Bauer } \\ \text { J.P. Haisken-DeNew }\end{array} \\ 147 & \begin{array}{l}\text { M. Belot } \\ \text { J. C. van Ours }\end{array}\end{array}$

Decomposition Analysis for a Binary Choice Model

Does the Recent Success of Some OECD

Microeconometric Evaluation of the Active Labour 6 Market Policy in Switzerland

The Duration of Immigrants' Unemployment Spells: $\quad 1 / 3 \quad 5 / 00$

155 J. Hansen

156 C. Dustmann Evidence from Sweden

Language Proficiency and Labour Market Per- 1

M. Jäntti

O. Raaum

E. Österbacka

Finland, Norway and Sweden Compared to the United States 
A Comparison of the Human Capital and Signaling Models: The Case of the Self-Employed and the Increase in the Schooling Premium in the 1980's

161 V. Gimpelson

D. Treisman

G. Monusova

162 C. Dustmann M. E. RochinaBarrachina

R. A. Hart Y. Ma

164 M. A. Shields

S. Wheatley Price

165

P. J. Pedersen

166 Z. MacDonald M. A. Shields
A. Barrett
J. FitzGerald
B. Nolan

168 G. S. Epstein

A. L. Hillman

169 R. Winkelmann

170 T. K. Bauer

K. F. Zimmermann

171 C. Dustmann

F. Windmeijer

172 D. Card

173 D. S. Hamermesh
Public Employment and Redistributive Politics:

Evidence from Russia's Regions

4

$6 / 00$

Selection Correction in Panel Data Models: An Application to Labour Supply and Wages

Why do Firms Pay an Overtime Premium?

Racial Harassment, Job Satisfaction and Intentions

to Quit: Evidence from the British Nursing Profession

Immigration in a High Unemployment Economy: 1 The Recent Danish Experience

The Impact of Alcohol Consumption on Occupa- 5 tional Attainment in England

Earnings Inequality, Returns to Education and 5 Immigration into Ireland

$6 / 00$

Social Harmony at the Boundaries of the Welfare $3 \quad 6 / 00$

State: Immigrants and Social Transfers

$7 / 00$

New Zealand and Australia

Immigration Policy in Integrated National Economies $\quad 1$

$7 / 00$

Wages and the Demand for Health - A Life Cycle 5 Analysis

$7 / 00$

Reforming the Financial Incentives of the Welfare 3 System

$7 / 00$

Timing, Togetherness and Time Windfalls

5

$7 / 00$

Does Money Illusion Matter? An Experimental 7 Approach 